\title{
A multidomain P450 epoxidase and a terpene cyclase from ascochlorin biosynthetic pathway in Fusarium sp.
}

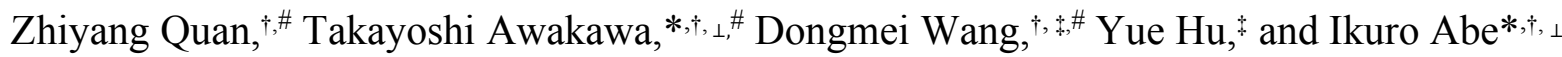

${ }^{\dagger}$ Graduate School of Pharmaceutical Sciences, The University of Tokyo, Bunkyo-ku, Tokyo 113-0033, Japan

${ }^{\perp}$ Collaborative Research Institute for Innovative Microbiology, The University of Tokyo, Yayoi 1-1-1, Bunkyo-ku, Tokyo 113-8657, Japan

${ }^{\sharp}$ School of Pharmaceutical Sciences, Sun Yat-sen University, No. 135, Xingang Xi Road, Guangzhou, 510275, P. R. China

\section{Table of Contents}

Supplementary Material and Methods 


\section{Supplementary Materials and Methods}

\section{General}

Solvents and chemicals were purchased from Wako Chemicals Ltd. (Tokyo, Japan) or Kanto Chemical Co., Inc. (Tokyo, Japan), unless noted otherwise. Oligonucleotide primers were purchased from Eurofins Genetics (Tokyo, Japan), and Sigma Aldrich Japan Genosys (Table S1). PCR was performed using a TaKaRa PCR Thermal Cycler Dice Gradient (TaKaRa), with KOD FX Neo (TOYOBO) or iProof DNA polymerase (BIORAD). Ligations of DNA fragments were performed using an in-Fusion HD cloning kit (Clontech). Sequence analyses were performed by Eurofins Genetics (Tokyo). Total mRNA isolation of Fusarium sp. NBRC100844 was performed utilizing ISOGEN Reagent (NIPPON GENE CO., LTD.). Reverse transcription of mRNA was performed utilizing a SuperScript ${ }^{\mathrm{TM}}$ III First-Strand Synthesis System (Thermo Fisher Scientific Inc.). Silica gel column chromatography was performed using Silica Gel $60 \mathrm{~N}$ (spherical, neutral, 40-50 $\mu \mathrm{m}$ ) (Kanto Chemical Co., Inc.). Analytical and preparative HPLC were performed on a Shimadzu Prominence system, using a an ODS-80T $\mathrm{T}_{\mathrm{m}}$ column (4.6 i.d. x $150 \mathrm{~mm}$, Tosoh Co. Ltd.) and an ODS-80T ${ }_{\mathrm{M}}$ column (7.8 i.d. x $300 \mathrm{~mm}$, Tosoh Co. Ltd.). Samples for LC-MS analysis were injected into an Shimadzu Prominence system HPLCMicroTOF mass spectrometer (Bruker Daltonics), using electrospray ionization with a COSMOSIL 2.5C $\mathrm{C}_{18}$-MSII column (2.0 i.d. x $75 \mathrm{~mm}$; Nacalai Tesque, Inc.). NMR spectra were obtained at $500 \mathrm{MHz}(\mathrm{H})$ and $125 \mathrm{MHz}$ $(\mathrm{C})$ with a JEOL ECX-500 or ECZ-500 spectrometer, and chemical shifts were recorded with reference to solvent signals ('H NMR: $\mathrm{CDCl}_{3} 7.26$ ppm; $\mathrm{C} \mathrm{NMR}^{\mathrm{C}} \mathrm{CDCl}_{3} 77.0 \mathrm{ppm}$ ). Optical rotation of each metabolite was measured utilizing DIP-1000 digital polarimeter (JASCO). The ascochlorin producing strain, Fusarium sp. NBRC100844 was purchased from NITE. Draft genome sequencing and assembling of Fusarium sp. NBRC100844 was ordered from Macrogen Japan (Kyoto, Japan). Gene prediction was performed by AUGUSTUS (http://bioinf.uni-greifswald.de/webaugustus/). The glufosinate solution for the fungal transformation was extracted from Basta (Bayer), as previously described, ${ }^{\prime}$ and used at a $50 \mu \mathrm{L} / \mathrm{mL}$ concentration.

\section{Plasmids construction and fungal transformation}

Aspergillus oryzae NSAR1 (niaD, $s C, \triangle a r g B$, adeA) and fungal transformation vector pTAex3, pUSA, pUNA, and pAdeA are kindly provided by Prof. K. Gomi (Graduate School of Agricultural Sciences, Tohoku University) and Prof. K. Kitamoto (Graduate School of Agricultural Sciences, The University of Tokyo). pPTRI vector was purchased from TAKARA. ${ }^{3}$ pBARI vector was constructed based on pPTRI as previously reported. ${ }^{4}$ Fungal transformation was performed by the protoplast-polyethylene glycol method, as reported previously.

1. Plasmids construction

Primers for fungal expression plasmids construction used in this research were listed in Table S1. The 
procedures of plasmids construction were summarized in Table S2, and all the ligations are performed utilizing a in-Fusion HD cloning kit.

2. Fungal transformation

A. oryzae transformants constructed for this study and their construction procedures are summarized in Table S3.

\section{Constructions of plasmids for in vitro assay and mutagenesis study}

Primers for in vitro assay and mutagenesis study were listed in Table S4. Ligations of pET28a-AscD, pColdIIAscE, and pESC-URA-AscF were summarized in Table S5. Point mutation of AscF was performed using PCR method. The reaction solution of PCR was digested with DpnI (TAKARA) and purified to linear DNA. The linear DNA was introduced to DH5 $\alpha$ (Clontech) to yield plasmid for mutation. The information of mutation plasmid construction was summarized in Table S5.

\section{Preparation of the protein lysate containing AscD from in E. coli}

E. coli RosettaII (DE3) pLysS cells harboring pET28a-AscD were cultured to an $\mathrm{OD}_{\alpha 0}$ of 0.7 in $\mathrm{LB}$ media containing $50 \mu \mathrm{g} \mathrm{ml}^{-1}$ kanamycin and $34 \mu \mathrm{g} \mathrm{ml}-1$ chloramphenicol at $37^{\circ} \mathrm{C}$. Isopropyl $\beta$-D-1thiogalactopyranoside was then added to a final concentration of $0.4 \mathrm{mM}$ to induce gene expression, and the cultures were incubated further for $16 \mathrm{~h}$ at $15^{\circ} \mathrm{C}$. The $200 \mathrm{~mL}$ E. coli cells were harvested by centrifugation at $5,000 \mathrm{~g}$ and resuspended in $4 \mathrm{~mL}$ buffer A [50 mM Tris- $\mathrm{HCl}$ buffer $\mathrm{pH} 7.5$, containing $300 \mathrm{mM} \mathrm{NaCl}, 1 \mathrm{mM}$ EDTA, and $2 \mathrm{mM}$ DTT]. The cells were disrupted by sonication and the lysate was centrifuged at 12,000 $\mathrm{g}$ for $15 \mathrm{~min}$. The soluble protein lysate was concentrated into $0.5 \mathrm{~mL}$, and used for the assay immediately.

\section{Preparation of the protein lysate containing AscE from in E. coli}

E. coli RosettaII (DE3) pLysS cells harboring pColdII-AscE were cultured to an $\mathrm{OD}_{6 ю}$ of 0.5 in ZYM-5052 autoinducing medium(F. W. Studier, Structural Genomics, Methods in Molecular Biology, Vol.1091, pp 17-32, (2013)) containing $50 \mu \mathrm{g} \mathrm{ml}^{-1}$ kanamycin and $100 \mu \mathrm{g} \mathrm{ml} \mathrm{l}^{-1}$ ampicillin at $37^{\circ} \mathrm{C}$. Isopropyl $\beta$-D-1thiogalactopyranoside, aminolevlic acid, and $\mathrm{Fe}\left(\mathrm{SO}_{4}\right)_{2}\left(\mathrm{NH}_{4}\right)_{2} \cdot 6 \mathrm{H}_{2} \mathrm{O}$ was then added to a final concentration of $0.05 \mathrm{mM}, 225 \mu \mathrm{g} / \mathrm{mL}$, and $300 \mu \mathrm{M}$ to induce gene expression and biosynthesis of heme, and the cultures were incubated further for $16 \mathrm{~h}$ at $15^{\circ} \mathrm{C}$. The $50 \mathrm{~mL}$ E. coli cells were harvested by centrifugation at 5,000 $\mathrm{g}$ and resuspended in $5 \mathrm{~mL}$ buffer B [50 mM Tris- $\mathrm{HCl}$ buffer $\mathrm{pH}$ 8.0, containing $200 \mathrm{mM} \mathrm{NaCl}, 20 \%$ (v/v) glycerol, and Complete Ultra Tablets Mini EDTA-free (Roche)]. The cells were disrupted by sonication and the lysate was centrifuged at $12,000 \mathrm{~g}$ for $15 \mathrm{~min}$. The reddish soluble protein lysate was concentrated into $2.0 \mathrm{~mL}$, and used for the assay immediately.

\section{Preparation of microsome fraction containing AscF from yeast}


pESC-URA-AscF was introduced into Saccharomyces cerevisiae INVSC1 (invitrogen) with Frozen-EZ Yeast transformation II (Zymo research). The transformant was inoculated into $10 \mathrm{~mL}$ Synthetic dextrose (SD)-Ura medium, and incubated at $30{ }^{\circ} \mathrm{C}$ for 2 days as Preculture1. Preculture1 was transferred into $500 \mathrm{~mL}$ SD-Ura medium, and incubated at $30{ }^{\circ} \mathrm{C}$ in 1 day as Preculture2. The cells in Preculture 2 was centrifuged, resuspended with Synthetic Glactose (SG)-Ura medium, and transferred into $500 \mathrm{~mL}$ SG-Ura medium, and incubated at 30 ${ }^{\circ} \mathrm{C}$ for 1 day. Cells from $250 \mathrm{~mL}$ culture were harvested, resuspended in $10 \mathrm{~mL}$ of $0.1 \mathrm{M} \mathrm{KPB}(\mathrm{pH} 7.4)$ and disrupted with glass beads. After centrifugation $(10,000 \mathrm{~g})$ to remove the cell debris, ultracentrifugation $(100,000 \mathrm{~g})$ was carried out fort 1 hour to collect the microsome fraction which was suspended in $500 \mu \mathrm{L}$ of 0.1 M KPB (pH 7.4) with 24 mM CHAPS.

\section{Assay of AscD reaction}

For assay of AscD, $200 \mu \mathrm{M}$ FAD, $20 \mathrm{mM}$ NADH, $200 \mu \mathrm{M} 2$ or 5 were incubated with the soluble protein lysate from AscD-expressing culture with total $50 \mu \mathrm{L}$ scale for $30{ }^{\circ} \mathrm{C}$ in $400 \mathrm{~min}$, and the reaction was extracted with $500 \mu \mathrm{L}$ of EtoAc, and the extract was evaporated in vacuo. $50 \mu \mathrm{L}$ of methanol was added into the extract, and $20 \mu \mathrm{L}$ was analyzed with HPLC.

\section{Assay of AscEF reaction}

$\mathrm{CO}$ spectra assay for AscE was performed as the literature. For assay of AscE, $200 \mu \mathrm{M} \mathrm{FAD}+10 \mathrm{mM} \mathrm{NADPH}$, $200 \mu \mathrm{M} 2$ (or 5-farnesyl-6-hydroxymellein) were incubated with the soluble protein lysate from AscEexpressing culture with total $50 \mu \mathrm{L}$ scale for $30^{\circ} \mathrm{C}$ in $12 \mathrm{hr}$, and $25 \mu \mathrm{L}$ of the microsome fraction containing AscF was added into the reaction. After additional $12 \mathrm{hr}$ incubation, enzymes in the assay were precipitated by addition of $50 \mu \mathrm{L}$ methanol and centrifugation. $20 \mu \mathrm{L}$ of the reaction was analyzed with HPLC.

\section{Synthesis and preperation of racemic 4}

1. Preparation of bromohydrin-2

a) Synthesis of bromohydrin-2 from 2

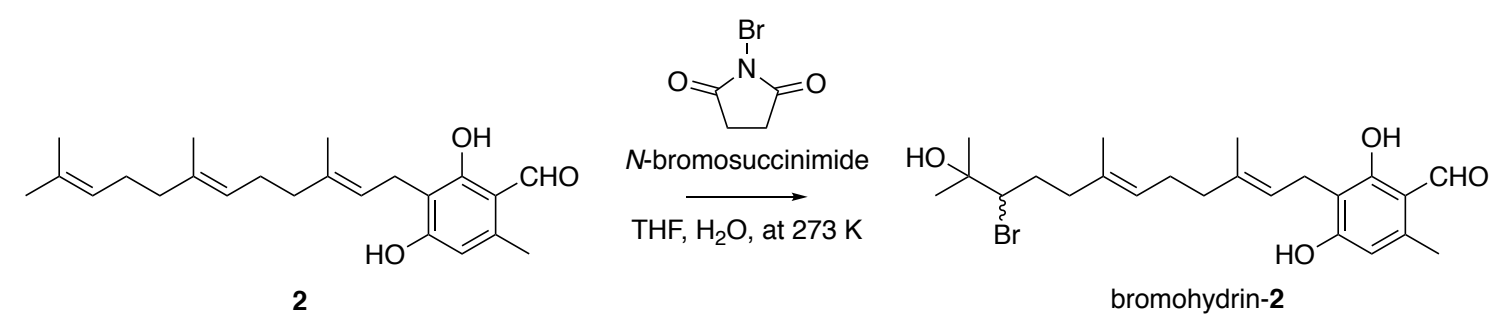

Compound $2(3.5 \mathrm{mg}, 10 \mu \mathrm{mol})$ was dissolved in THF $(372 \mu \mathrm{L})$ and $\mathrm{H}_{2} \mathrm{O}(105 \mu \mathrm{L})$, then the solution was left on ice-water mixture while stiring until the temperature of the whole system fell to $0{ }^{\circ} \mathrm{C}$. Recrystallized $N$-bromosuccinimide (NBS, $0.6 \mathrm{mg}, 3 \mu \mathrm{mol}$ ) was added to solution of $\mathbf{2}$, and stirred for $30 \mathrm{~min}$ at $30^{\circ} \mathrm{C}$. This operation was repeated for 6 times. Then, the reaction mixture was subjected to a 
semi-preparative HPLC at once to isolate bromohydrin-2 as clear oil.

b) Isolation of bromohydrin-2

The mixture was subjected to a reverse-phase preparative HPLC, with a solvent system of milliQ (solvent A) and acetonitrile (solvent B), at a flow rate of $3.5 \mathrm{~mL} / \mathrm{min}$ and a column temperature at 40 ${ }^{\circ} \mathrm{C}$. Isolation was started with solvent $\mathrm{B} /$ solvent $\mathrm{A}(85: 15)$, then a linear gradient from $\mathrm{B} / \mathrm{A}(85: 15)$ to B/A (100:0) within the following $5 \mathrm{~min}, \mathrm{~B} / \mathrm{A}$ (100:0) for an additional 1min. Bromohydrin-2 was yielded as clear oil.

6 trials (compound 2 at a total weight of $21 \mathrm{mg}, 60 \mu \mathrm{mol}$ ) was conducted at the same time in order to accumulate enough bromohydrin-2, the precursor of racemic 4.

2. Synthesis of racemic 4

a) Dehydrochlorination of bromohydrin-2<smiles>CC(=O)OC1(C)OC1CC/C(C)=C/CC/C(C)=C/Cc1c(O)cc(C)c(C=O)c1O</smiles>

Bromohydrin-2 prepared in last step was added into a slurry of methanol $(2 \mathrm{~mL})$ and $\mathrm{K}_{2} \mathrm{CO}_{3}(50 \mathrm{mg}$, $360 \mu \mathrm{mol}$ ), and stirred for $30 \mathrm{~min}$ at room temperature to yield racemic 4 .

b) Purification of racemic 4

The reaction slurry containing racemic $\mathbf{4}$ was evaporated to remove the methanol firstly, and the residue was extracted with ethyl acetate from water. The extract was subjected to a silica-gel column chromatography and eluted using hexane:ethyl acetate (1:9) to yield racemic 4 (1.7 mg, $4.6 \mu \mathrm{mol}$ ) as a clear oil.

\section{The mosher analysis of cylindrocarpol (4' ${ }^{7}$}

1. Synthesis of 4-O-methylated-4'<smiles>COc1cc(C)c(C=O)c(O)c1C/C=C(\C)CC/C=C(\C)CCC(O)C(C)(C)O</smiles>

A mixture of 4' $(2.0 \mathrm{mg})$, MeI $(20 \mu \mathrm{l})$, and $\mathrm{K}_{2} \mathrm{CO}_{3}(20 \mathrm{mg})$ in 2-butanone $(0.3 \mathrm{ml})$ was stirred at room temperature for $15 \mathrm{~h}$. The reaction mixture was diluted with EtOAc $(5 \mathrm{ml})$ and washed with $\mathrm{H}_{2} \mathrm{O}(5 \mathrm{ml})$ twice, and the organic layer was collected and concentrated to afford the methylated derivative (2.0 mg, pale yellow oil). 
'H NMR (partial assignment, 500 MHz, $\left.\mathrm{CDCl}_{3}\right) 12.4(1 \mathrm{H}, \mathrm{s}, 6-\mathrm{OH}), 10.1(1 \mathrm{H}, \mathrm{s}, \mathrm{H}-8), 6.28(1 \mathrm{H}, \mathrm{s}, \mathrm{H}-3)$, 5.17 (1H. m, H-10), 5.16 (1H, m, H-14), 3.89 (3H, s, 4-OMe), 3.34 (1H, m, H-18), 3.30 (2H, m, H-9), 2.56 (3H, s, H-7), 2.09 (2H, m, H-16), 2.02 (2H, m, H-13), 1.96 (2H, m, H-12), 1.76 (3H, brs, H-23), 1.59 (3H, brs, H-22), 1.41, 1.58 (2H, m, H-17), 1.19 (3H, brs, H-20), 1.14 (3H, brs, H-21).

Synthesis of $S$-mosher diester of 4-O-methylated-4'
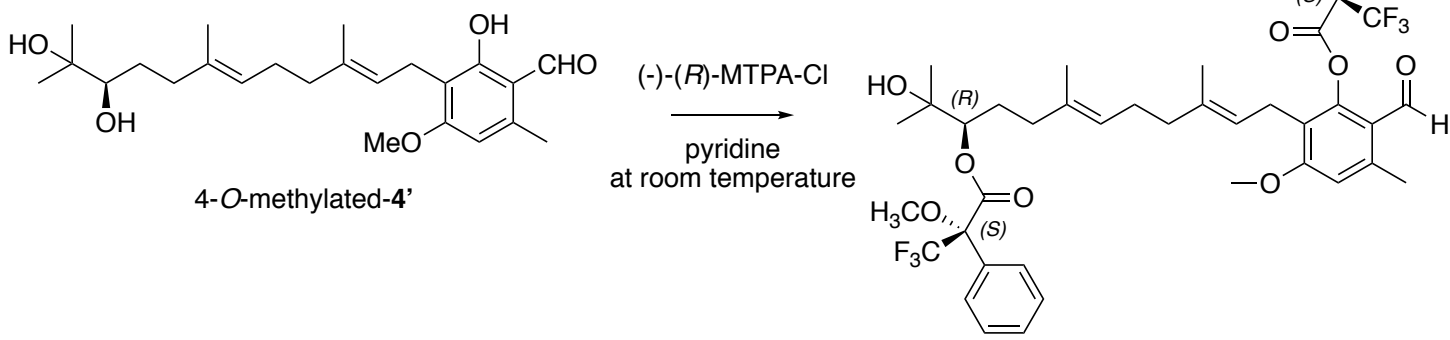

S-mosher diester of 4-O-methylated-4'

4-O-methylated-4' $(1.0 \mathrm{mg})$ was dissolved in pyridine ( $0.3 \mathrm{ml}$, dehydrated) and treated with excess amount of (-)-(R)-MTPA-Cl $(10 \mu \mathrm{l})$ at room temperature for $1 \mathrm{~h}$. The reaction mixture was diluted with EtOAc and washed with $\mathrm{H}_{2} \mathrm{O}$ and saturated $\mathrm{NaHCO}_{3}$. The organic layer was concentrated and purified by preparative HPLC (isocratic in $100 \% \mathrm{CH}_{3} \mathrm{CN}$ ) to afford a $\mathrm{S}$-mosher diester of 4-O-methylated-4' (ca. $0.5 \mathrm{mg}$ ).

'H NMR (partial assignment, $\left.500 \mathrm{MHz}, \mathrm{CDCl}_{3}\right) 9.99(1 \mathrm{H}, \mathrm{s}, \mathrm{H}-8), 6.64(1 \mathrm{H}, \mathrm{s}, \mathrm{H}-3), 5.00(1 \mathrm{H}, \mathrm{m}, \mathrm{H}-14)$, 4.97 (1H, m, H-18), 4.95 (1H, m, H-10), 3.89 (3H, s, 4-OMe), 3.66 (3H, s, 4-Mosher-OMe or 6-MosherOMe), 3.56 (3H, s, 4-Mosher-OMe or 6-Mosher-OMe), 3.10 (2H, m, H-9), 2.63 (3H, s, H-7), 1.99 (2H, m, $\mathrm{H}-13), 1.91$ (2H, m, H-12), 1.83 (2H, m, H-16), 1.62 (3H, s, H-23), 1.56, 1.66 (2H, m, H-17), 1.49 (3H, s, H-22), 1.20 (3H, brs, H-20), 1.14 (3H, brs, H-21).

2. Synthesis of $R$-mosher diester of $4-O$-methylated-4'
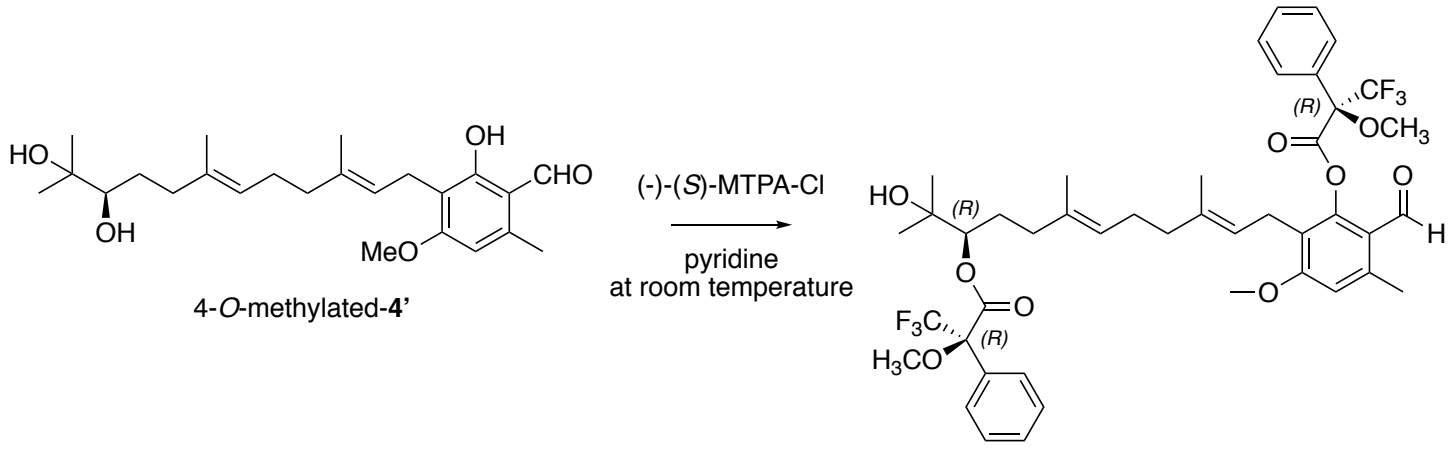

$R$-mosher diester of 4-O-methylated-4,

In the same manner, 4- $O$-methylated-4' $(1.0 \mathrm{mg})$ was treated with excess amount of $(+)-(S)$-MTPA-Cl (10 
$\mu \mathrm{l})$ at room temperature for $1 \mathrm{~h}$. The reaction mixture was diluted with EtOAc and washed with $\mathrm{H}_{2} \mathrm{O}$ and saturated $\mathrm{NaHCO}_{3}$. The organic layer was concentrated and subjected to NMR analysis without purification.

'H NMR (partial assignment, $\left.500 \mathrm{MHz}, \mathrm{CDCl}_{3}\right) 9.99(1 \mathrm{H}, \mathrm{s}, \mathrm{H}-8), 6.64(1 \mathrm{H}, \mathrm{s}, \mathrm{H}-3), 5.04(1 \mathrm{H}, \mathrm{m}, \mathrm{H}-14)$, 4.96 (1H, m, H-18), 4.75 (1H, m, H-10), 3.88 (3H, s, 4-OMe), 3.66 (3H, s, 4-Mosher-OMe or 6-MosherOMe), 3.57 (3H, s, 4-Mosher-OMe or 6-Mosher-OMe), 3.11 (2H, m, H-9), 2.63 (3H, s, H-7), 2.01 (2H, m, H-13), 1.93 (2H, m, H-16), 1.92 (2H, m, H-12), 1.63,1.71 (2H, m, H-17), 1.62 (3H, brs, H-23), 1.53 (3H, brs, $\mathrm{H}-22), 1.15$ (3H, brs, H-20), 1.11 (3H, brs, H-21).

\section{Analytical conditions}

Metabolites from the Aspergillus oryzae transformants and Fusarium sp. NBRC100844 were analyzed by HPLC, with a solvent system of $0.1 \%$ formic acid (solvent A) and acetonitrile containing $0.1 \%$ formic acid (solvent B), at a flow rate of $1.0 \mathrm{ml} / \mathrm{min}$ and a column temperature of $40{ }^{\circ} \mathrm{C}$. Separation was performed with solvent B/solvent A (50:50), a linear gradient from 50:50 to 80:20 within the following 15 min, a linear gradient from 80:20 to 100:0 within the following $5 \mathrm{~min}$, 100:0 for 5 additional min.

\section{Isolation of the metabolites from Fusarium sp. NBRC100844}

Fusarium sp. was cultured at $30 \mathrm{C}$ for 7 days in $2 \mathrm{~L}$ flasks containing $1 \mathrm{~L}$ DPY medium. After filtering, the mycelia were lyophilized to dryness. Dried mycelia were extracted by acetone. The extraction solution was concentrated in vacuo to remove the solvent. The extract (146 mg) was subjected to silica-gel column chromatography and eluted stepwise using a hexane:acetone gradient (100:0 to 70:30). Fractions containing 6 , $\mathbf{5}, \mathbf{1 a}$, and 7a were further purified by reverse-phase preparative HPLC equipped with an Ultimate AQ-C18 column (Welch Inc., Ellicott, MO, USA, $5 \mu \mathrm{m}, 10 \mathrm{~mm}$ i.d. x $250 \mathrm{~mm}$ ) using acetonitrile-water (70:30) as the eluting solvent (flow rate $3.0 \mathrm{~mL} / \mathrm{min})$ to yield $\mathbf{5}(2.1 \mathrm{mg}), \mathbf{6}(3.8 \mathrm{mg}), \mathbf{1 a}(24.9 \mathrm{mg})$ and $\mathbf{7 a}(10.1 \mathrm{mg})$. For, $\mathbf{1 b}$ and $\mathbf{7 b}$, Fusarium sp. was cultured at $30 \mathrm{C}$ for 7 days in two $2 \mathrm{~L}$ flasks containing $1 \mathrm{~L}$ CD-NaBr medium $\left(\mathrm{NaNO}_{3} 0.3 \%, \mathrm{~K}_{2} \mathrm{HPO}_{4} 0.1 \%, \mathrm{MgSO}_{4} \cdot 7 \mathrm{H}_{2} \mathrm{O} 0.05 \%, \mathrm{FeSO}_{4} \cdot 7 \mathrm{H}_{2} \mathrm{O} 0.002 \%\right.$, Glucose $\left.2 \%, \mathrm{NaBr} 0.35 \%, \mathrm{pH} 5.5\right)$ for each flask. After filtering, the mycelia were lyophilized to dryness. Dried mycelia were extracted by acetone. The extraction solution was concentrated in vacuo to remove the solvent. The extract $(720 \mathrm{mg})$ was subjected to silica-gel column chromatography and eluted stepwise using a hexane: acetone gradient (95:5 to 70:30). Fractions that contained $\mathbf{1 b}$ and $\mathbf{7 b}$ were further purified by reverse-phase preparative HPLC using acetonitrilewater (70:30) as the eluting solvent (flow rate $3.0 \mathrm{~mL} / \mathrm{min})$ to yield $\mathbf{1 b}(7.0 \mathrm{mg}), \mathbf{7 b}(35 \mathrm{mg})$.

\section{Isolation of the metabolites accumulated in Aspergillus oryzae transformants}

Isolation of AscABC product (2) from A. oryzae transformant 
The extract from $3 \mathrm{~L}$ culture of $A$. oryzae NSAR1 harboring asc $A B C$ was subjected to silica-gel column chromatography and eluted using chloroform:methanol (100:0). Fractions that contained 2 yield $21.0 \mathrm{mg}$ of a clear oil.

Isolation of AscABCEF product (5) from A. oryzae transformant

The extract from $1 \mathrm{~L}$ culture of $A$. oryzae NSAR1 harboring ascABCEF was subjected to silica-gel column chromatography and eluted stepwise using a chloroform:methanol gradient (100:0 to 90:10). Fractions that contained 5 were further purified by reverse-phase preparative HPLC (40\% aqueous acetonitrile, $3.0 \mathrm{~mL} / \mathrm{min}$ ) to yield $5.2 \mathrm{mg}$ of a clear oil.

Isolation of AscABCE product (4') from A. oryzae transformant

The extract from $1 \mathrm{~L}$ culture of $A$. oryzae NSAR1 harboring ascABCE and ascF (W130A, W131A) was subjected to silica-gel column chromatography and eluted stepwise using a chloroform:methanol gradient (100:0 to 90:10). Fractions that contained 4' were further purified by reverse-phase preparative HPLC (30\% aqueous acetonitrile, $3.5 \mathrm{~mL} / \mathrm{min}$ ) to yield $5.0 \mathrm{mg}$ of a clear oil.

Isolation of AscABCEFG product (6) from A. oryzae transformant

The extract from $1 \mathrm{~L}$ culture of $A$. oryzae NSAR1 harboring ascABCEFG was subjected to silica-gel column chromatography and eluted stepwise using a chloroform:methanol gradient (100:0 to 90:10). Fractions that contained 6 were further purified by reverse-phase preparative HPLC ( $40 \%$ aqueous acetonitrile, $3.0 \mathrm{~mL} / \mathrm{min}$ ) to yield $0.1 \mathrm{mg}$ of a white solid.

\section{Summary of analytical data}

Ascochlorin (1a): White solid; for NMR data see Table S6 (S13) and Figures S18 and S19; HR-ESI-MS found $m / z$ 403.1682 [M - H] (calcd 403.1676 for $\mathrm{C}_{23} \mathrm{H}_{28} \mathrm{O} \mathrm{Ol}$ ). The NMR data were in good agreement with the reported data.

3-Bromoascochlorin (1b): White solid; for NMR data see Table S6 (S13) and Figures S20 and S21; HR-ESIMS found $m / z 447.1176[\mathrm{M}-\mathrm{H}]$. (calcd 447.1171 for $\mathrm{C}_{23} \mathrm{H}_{28} \mathrm{O} \mathrm{Br}$ ). The NMR data were in good agreement with the reported data.

dechloroascochlorin (6): White solid; for NMR data see Table S6 (S13) and Figures S22 and S23; HR-ESI-MS found $m / z$ 369.2071 [M - H] (calcd 369.2066 for $\mathrm{C}_{23} \mathrm{H}_{29} \mathrm{O}_{4}$ ). The NMR data were in good agreement with the reported data. 
12,13-dihydroascochlorin (7a): White solid; for NMR data see Table S6 (S14) and Figures S24 and S25; HRESI-MS found $m / z, 405.1838[\mathrm{M}-\mathrm{H}]\left(\right.$ calcd 405.1833 for $\left.\mathrm{C}_{23} \mathrm{H}_{30} \mathrm{O}_{4} \mathrm{Cl}\right)$. The NMR data were in good agreement with the reported data.

3-bromo-12,13-dihydroascochlorin (7b): White solid; for NMR data see Table S6 (S14) and Figures S26 and S27; HR-ESI-MS found $m / z 449.1310$ [M - H] (calcd 449.1333 for $\mathrm{C}_{23} \mathrm{H}_{30} \mathrm{O}_{4} \mathrm{Br}$ ). The NMR data were in good agreement with the reported data.

dechloro-12,13-dihydroascochlorin (5): White solid; for NMR data see Table S6 (S14) and Figures S28 and S29; HR-ESI-MS found $m / z 371.2225[\mathrm{M}-\mathrm{H}]$ ( calcd 371.2228 for $\mathrm{C}_{23} \mathrm{H}_{31} \mathrm{O}_{4}$ ). The NMR data were in good agreement with the reported data.

LL-Z1272 $\beta$ (2): Clear oil; for NMR data see Table S6 (S15) and Figures S30 and S31; HR-ESI-MS found $\mathrm{m} / z$ 355.2259 [M - H] (calcd 355.2279 for $\left.\mathrm{C}_{23} \mathrm{H}_{31} \mathrm{O}_{3}\right)$. The NMR data were in good agreement with the reported data.

cylindrocarpol (4'): Clear oil; for NMR data see Table S6 (S15) and Figures S32 and S33; HR-ESI-MS found $m / z 389.2307[\mathrm{M}-\mathrm{H}]$ (calcd 389.2333 for $\mathrm{C}_{23} \mathrm{H}_{33} \mathrm{O}_{s}$ ). The NMR data were in good agreement with the reported data.

4-O-methylated-4': pale yellow oil; for NMR data see "The mosher analysis of cylindrocarpol” and Figures S34, S35, S36, S37 and S38; HR-ESI-MS found $m / z, 405.2625[\mathrm{M}+\mathrm{H}]^{+}\left(\right.$calcd 405.2636 for $\left.\mathrm{C}_{24} \mathrm{H}_{33} \mathrm{O}_{5}\right)$.

$S$-mosher diester of 4-O-methylated-4': for partial NMR data see "The mosher analysis of cylindrocarpol" and Figures S39 and S40; HR-ESI-MS found $m / z 859.3248$ [M - H] (calcd 859.3251 for $\mathrm{C}_{44} \mathrm{H}_{8 \mathrm{~s}} \mathrm{O}_{9} \mathrm{~F}_{6} \mathrm{Na}$ ).

$R$-mosher diester of 4- $O$-methylated-4': for partial NMR data see "The mosher analysis of cylindrocarpol" and Figures S41 and S42; HR-ESI-MS found $m / z 859.3249$ [M - H] (calcd 859.3251 for $\mathrm{C}_{44} \mathrm{H}_{8 \mathrm{~s}} \mathrm{O}_{9} \mathrm{~F}_{6} \mathrm{Na}$ ). 
Table S1. Primers used for fungal expression plasmids construction

\begin{tabular}{l|l}
\hline Primer & Sequence (5' to 3') $^{\prime}$ \\
\hline Smal-ascA-Fw & TCGAGCTCGGTACCCATGGGTGCCACAACGAG \\
Smal-ascA-Rv & CTACTACAGATCCCCTTATTTCCCTCGGTGAGCATTC \\
ascA-Mid-Fw & GCAAACAGGCTTCTGTTG \\
ascA-Mid-Rv & CAGAAGCCTGTTGCCGAC \\
pAdeA-Spel-Fw & TAGAGGATCTACTAGCGATATCATGGTGTTTTGATC \\
pAdeA-Spel-Rv & AATCCATATGACTAGCTTTCCTATAATAGACTAGCGTG \\
Smal-ascB-Fw & TCGAGCTCGGTACCCATGGGTTCTGCCATGG \\
Smal-ascB-Rv & CTACTACAGATCCCCCTACTTCTTCAGGTATCCAATC \\
Smal-ascC-Fw & TCGAGCTCGGTACCCATGGCCCCCAAACGC \\
Smal-ascC-Rv & CTACTACAGATCCCCCTATGCGAATAGTGCGGGAG \\
pTA_Prm_Fw1 & GCTCGCGAGCGCGTTCCACTGCATCATCAGTCTAG \\
pTA_Tmn_Rv1 & AACGCGCTCGCGAGCAAGTACCATACAGTACCGCG \\
KpnI-ascE-Fw & CTGAATTCGAGCTCGGTACCATGAGTTGCGAAATTCCTC \\
Kpnl-ascE-Rv & ACTACAGATCCCCGGGTACCCTAAGAGAAAATCTCGCTGGC \\
KpnI-ascF-Fw & CTGAATTCGAGCTCGGTACCATGGCATTCAACGAC \\
Kpnl-ascF-Rv & ACTACAGATCCCCGGGTACCTTAAAGCTCCTTTCCTTC \\
pUSA-Prm-Fw1 & GCTCGCGAGCGCGTTCGATATCATGGTGTTTGATC \\
pUSA-Tmn-Rv1 & AACGCGCTCGCGAGCCTTCCTATAATAGACTAGCGTG \\
Smal-ascG-Fw & TCGAGCTCGGTACCCATGGATAACCTATCGTCACTCG \\
Smal-ascG-Rv & CTACTACAGATCCCCTTACATCTTTCTACGCTTAAACTCAAG \\
pPTRI-HIndIII-Fw & TGATTACGCCAAGCTCGATATCATGGTGTTTGATC \\
pPTRI-HindIII-Rv & GCAGGCATGCAAGCTCTTTCCTATAATAGACTAGCGTG \\
KpnI-ascD-Fw & CTGAATTCGAGCTCGGTACCATGGCTGCCCAAATTC \\
Kpnl-ascD-Rv & ACTACAGATCCCCGGGTACCTTAAGCCGAGACGTCAAC \\
ascF-M1-Fw & GACGGCTCATTATAGCGCGGCGTCGTGGTGGATGGGC \\
ascF-M1-Rv & GCTATAATGAGCCGTCGCGC \\
ascF-M2-Fw & CATTATAGCTGGGCGTCGGCGGCGATGGGCAACGGC \\
ascF-M2-Rv & CGACGCCCAGCTATAATGAG \\
ascF-M3-Fw & GAACATCAGCTACGGAGCGGCTGCGTATACCTGGCCCGAG \\
ascF-M3-Rv & TCCGTAGCTGATGTTCAGGC \\
ascF-M4-Fw & GCCGGCAATCTTCCTTGCGGGAATCACCACCGTC \\
ascF-M4-Rv & AAGGAAGATTGCCGGCTC \\
&
\end{tabular}


Table S2. Plasmids constructed for fungal transformation and their PCR conditions

\begin{tabular}{|c|c|c|c|c|c|}
\hline plasmid & vector & insert & primer 1 & primer 2 & PCR template \\
\hline \multirow{2}{*}{ pUNA-ascA } & \multirow{2}{*}{ pUNA digested with Smal } & ascA-F & Smal-ascA-Fw & ascA-Mid-Rv & \multirow{2}{*}{ gDNA } \\
\hline & & ascA-R & ascA-Mid-Fw & Smal-ascA-Rv & \\
\hline \multirow{2}{*}{ pAdeA-ascA } & \multirow{2}{*}{ pAdeA digested with Spel } & Prm-ascA-F & pAdeA-Spel-Fw & ascA-Mid-Rv & \multirow{2}{*}{ pUNA-ascA } \\
\hline & & ascA-R-Tmn & ascA-Mid-Fw & pAdeA-Spel-Rv & \\
\hline pUNA-ascB & pUNA digested with Smal & ascB & Smal-ascB-Fw & Smal-ascB-Rv & cDNA \\
\hline pTAex3-ascC & pTAex3 digested with Smal & ascC & Smal-ascC-Fw & Smal-ascC-Rv & gDNA \\
\hline \multirow{2}{*}{ PTAex3-ascB+ascC } & \multirow{2}{*}{ pTAex3 digested with Smal } & ascB+Tmn & Smal-ascB-Fw & pTA_Tmn_Rv1 & pUNA-ascB \\
\hline & & Prm+ascC & pTA_Prm_Fw1 & Smal-ascC-Rv & pTAex3-ascC \\
\hline pUSA-ascE & pUSA digested with KpnI & ascE & Kpnl-ascE-Fw & Kpnl-ascE-Rv & gDNA \\
\hline pUSA-ascF & pUSA digested with KpnI & ascF & Kpnl-ascF-Fw & Kpnl-ascF-Rv & gDNA \\
\hline \multirow{2}{*}{ pUSA-ascF+ascE } & \multirow{2}{*}{ pUSA digested with Kpnl } & ascF+Tmn & Kpnl-ascE-Fw & pUSA-Tmn-Rv1 & pUSA-ascE \\
\hline & & Prm+ascE & pUSA-Prm-Fw1 & Kpnl-ascF-Rv & pUSA-ascF \\
\hline pUNA-ascG & pUNA digested with Smal & ascG & Smal-ascG-Fw & Smal-ascG-Rv & gDNA \\
\hline pPTRI-ascG & pPTRI digested with HindIII & Prm-ascG-Tmn & pPTRI-HIndIII-Fw & pPTRI-HindIII-Rv & pUNA-ascG \\
\hline pUSA-ascD & pUSA digested with KpnI & ascD & Kpnl-ascD-Fw & Kpnl-ascD-Rv & cDNA \\
\hline pBARI-ascD & pBARI digested with HindIII & Prm-ascD-Tmn & pPTRI-HIndIII-Fw & pPTRI-HindIII-Rv & pUSA-ascD \\
\hline \multirow{2}{*}{ pUSA-ascF(mutant1)+ascE } & \multirow{2}{*}{ pUSA digested with KpnI } & ascF(mutant1)-F & Kpnl-ascF-Fw & ascF-M1-Fw & \multirow{2}{*}{ pUSA-ascF+ascE } \\
\hline & & ascF(mutant1)-R+ascE & ascF-M1-Rv & Kpnl-ascE-Rv & \\
\hline \multirow{2}{*}{ pUSA-ascF(mutant2)+ascE } & \multirow{2}{*}{ pUSA digested with KpnI } & ascF(mutant2)-F & Kpnl-ascF-Fw & ascF-M2-Fw & \multirow{2}{*}{ pUSA-ascF+ascE } \\
\hline & & ascF(mutant2)-R+ascE & ascF-M2-Rv & Kpnl-ascE-Rv & \\
\hline \multirow{2}{*}{ pUSA-ascF(mutant3)+ascE } & \multirow{2}{*}{ pUSA digested with Kpnl } & ascF(mutant3)-F & Kpnl-ascF-Fw & ascF-M3-Fw & \multirow{2}{*}{ pUSA-ascF+ascE } \\
\hline & & ascF(mutant3)-R+ascE & ascF-M3-Rv & Kpnl-ascE-Rv & \\
\hline \multirow{2}{*}{ pUSA-ascF(mutant4)+ascE } & \multirow{2}{*}{ pUSA digested with KpnI } & ascF(mutant4)-F & Kpnl-ascF-Fw & ascF-M4-Fw & \multirow{2}{*}{ pUSA-ascF+ascE } \\
\hline & & ascF(mutant4)-R+ascE & ascF-M4-Rv & Kpnl-ascE-Rv & \\
\hline
\end{tabular}

Table S3. A. oryzae transformants constructed in this study

\begin{tabular}{l|l|l}
\hline Strain constructed & Host strain & Plasmid used in transformation \\
\hline A. oryzae/ascA & A. oryzae NSAR1 & pAdeA-ascA \\
A. oryzae/ascABC & A. oryzae/ascA & pTAex3-ascB+ascC \\
A. oryzae/ascABCEF & A. oryzae/ascABC & pUSA-ascF+ascE \\
A. oryzae/ascABCEFG & A. oryzae/ascABCEF & pPTRI-ascG \\
A. oryzae/ascABCEFD & A. oryzae/ascABCEF & pBARl-ascD \\
A. oryzae/ascABCEF(W127A) & A. oryzae/ascABC & pUSA-ascF(mutant1)+ascE \\
A. oryzae/ascABCEF(W130A, W131A) & A. oryzae/ascABC & pUSA-ascF(mutant2)+ascE \\
A. oryzae/ascABCEF(W207A, W209A) & A. oryzae/ascABC & pUSA-ascF(mutant3)+ascE \\
A. oryzae/ascABCEF(W228A) & A. oryzae/ascABC & pUSA-ascF(mutant4)+ascE
\end{tabular}


Table S4. Primers used for cloning and mutagenesis study

\begin{tabular}{l|l}
\hline Primer & Sequence (5' to 3') $^{\prime}$ \\
\hline Ndel-AscD-Fw & CGCGCGGCAGCCATATGGCTGCCCAAATTCCCAAGAAG \\
HindIII-AscD-Rv & GTGCGGCCGCAAGCTTAAGCCGAGACGTCAACACCAG \\
Ndel-AscE-Fw & ATCATCATCATCATATGAGTTGCGAAATTCCTCGC \\
HindIII-AscE-Rv & GCAGGTCGACAAGCTTCTACTAAGAGAAAATCTCGCTGGC \\
EcoRI-AscF-Fw & TTGAAAATTCGAATCATGGCATTCAACGACGTCCCTC \\
BgllI-AscF-Rv & TTAAGAGCTCAGATCtTAAAGCTCCTTTCCTTCATGTCG \\
AscF-W130A-Fw & CATTATAGCTGGGCGTCGGCGTGGATGGGCAACGGCATTG \\
AscF-W130A-Rv & CAATGCCGTTGCCCATCCACGCCGACGCCCAGCTATAATG \\
AscF-W131A-Fw & CATTATAGCTGGGCGTCGTGGGCGATGGGCAACGGCATTG \\
AscF-W131A-Rv & CAATGCCGTTGCCATCGCCCACGACGCCCAGCTATAATG \\
AscF-W207W209A-Fw & GAACATCAGCTACGGAGCGGCTGCGTATACCTGGCCCGAG \\
AscF-W207W209A-Rv & CTCGGGCCAGGTATACGCAGCCGCTCCGTAGCTGATGTTC \\
AscF-W228A-Fw & GCCGGCAATCTTCCTTGCGGGAATCACCACCGTC \\
AscF-W228A-Rv & GACGGTGGTGATTCCCGCAAGGAAGATTGCCGGC \\
AscF-E61A-Fw & CCAACAACTTTGCTGGGcGATGACGTATGCCTTGTATGTGG \\
AscF-E61A-Rv & CCACATACAAGGCATACGTCATCgCCCAGGCAAAGTTGTTGG \\
AscF-E61Q-Fw & CCAACAACTTGCCTGGcAGATGACGTATGCCTTGTATGTGG \\
AscF-E61Q-Rv & CCACATACAAGGCATACGTCATCTgCCAGGCAAAGTTGTTGG \\
AscF-D235A-Fw & GAATCACCACCGTCTGCGcCATTGTGTACGCCATTGTC \\
AscF-D235A-Rv & GACAATGGCGTACACAATGgCGCAGACGGTGGTGATTC \\
AscF-D235N-Fw & GAATCACCACCGTCTGCaACATTGTGTACGCCATTGTC \\
AscF-D235N-Rv & GACAATGGCGTACACAATGTtGCAGACGGTGGTGATTC
\end{tabular}

Table S5. Plasmids constructed for in vitro assay

\begin{tabular}{|c|c|c|c|c|c|}
\hline Plasmid & Vector & Insert & Primer1 & Primer2 & PCR template \\
\hline pET28a-AscD & pET28a digested with Ndel and HindIII & AscD & Ndel-AscD-Fw & HindIII-AscD-Rv & cDNA of AscD \\
\hline pColdII-AscE & pColdll digested with Ndel and HindIII & AscE & Ndel-AscE-Fw & HindIII-AscE-Rv & cDNA of AscE \\
\hline pESC-URA-AscF & pESC-URA digested with EcoRI and BgIII & AscF & EcoRl-AscF-Fw & Bglll-AscF-Rv & cDNA of AscF \\
\hline pESC-URA-AscF(W130A) & - & - & AscF-W130A-Fw & AscF-W130A-Rv & pESC-URA-AscF \\
\hline pESC-URA-AscF(W131A) & - & - & AscF-W131A-Fw & AscF-W131A-Rv & pESC-URA-AscF \\
\hline pESC-URA-AscF(W207AW209A) & - & - & AscF-W207W209A-Fw & AscF-W207W209A-Rv & pESC-URA-AscF \\
\hline pESC-URA-AscF(W228A) & - & - & AscF-W228A-Fw & AscF-W228A-Rv & pESC-URA-AscF \\
\hline pESC-URA-AscF(E61A) & - & - & AscF-E61A-Fw & AscF-E61A-Rv & pESC-URA-AscF \\
\hline pESC-URA-AscF(E61Q) & - & - & AscF-E61Q-Fw & AscF-E61Q-Rv & pESC-URA-AscF \\
\hline pESC-URA-AscF(D235A) & - & - & AscF-D235A-Fw & AscF-D235A-Rv & pESC-URA-AscF \\
\hline pESC-URA-AscF(D235N) & - & - & AscF-D235N-Fw & AscF-D235N-Rv & pESC-URA-AscF \\
\hline
\end{tabular}


Table S6. NMR data of the isolated compounds

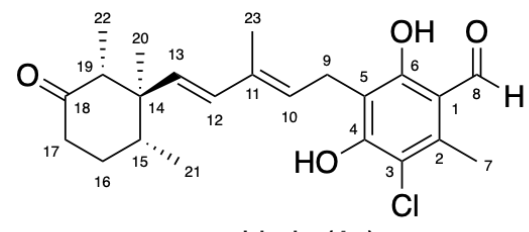

ascochlorin (1a)

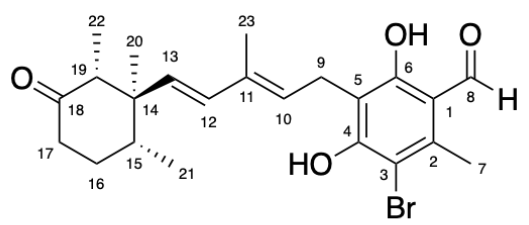

3-bromoascochlorin (1b)

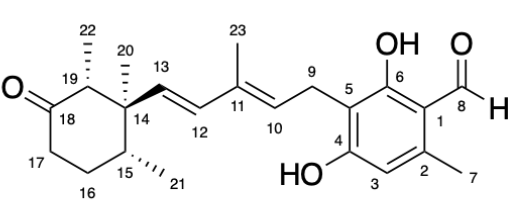

dechloroascochlorin (6)

\begin{tabular}{|c|c|c|c|c|c|c|}
\hline \multirow{2}{*}{ Position } & \multicolumn{2}{|l|}{ ascochlorin (1a) } & \multicolumn{2}{|c|}{ 3-bromoascochlorin (1b) } & \multicolumn{2}{|c|}{ dechloroascochlorin (6) } \\
\hline & $\delta_{\mathrm{H}}(\mathrm{mult}, \mathrm{Hz})$ & $\delta_{\mathrm{C}}(\mathrm{Hz})$ & $\delta_{\mathrm{H}}(\mathrm{mult}, \mathrm{Hz})$ & $\delta_{\mathrm{C}}(\mathrm{Hz})$ & $\delta_{\mathrm{H}}(\mathrm{mult}, \mathrm{Hz})$ & $\delta_{\mathrm{C}}(\mathrm{Hz})$ \\
\hline 1 & - & 113.9 & - & 114.4 & - & 111.9 \\
\hline 2 & - & 137.9 & - & 139.9 & - & 142.2 \\
\hline 3 & - & 113.3 & - & 106.2 & $6.22(1 \mathrm{H}, \mathrm{s})$ & 110.6 \\
\hline 4 & - & 156.3 & - & 157.0 & - & 163.8 \\
\hline 5 & - & 113.8 & - & 113.9 & - & 113.5 \\
\hline 6 & - & 162.3 & - & 162.8 & - & 161.6 \\
\hline 7 & $2.60(3 \mathrm{H}, \mathrm{s})$ & 14.3 & $2.65(3 \mathrm{H}, \mathrm{s})$ & 14.3 & $2.49(3 \mathrm{H}, \mathrm{s})$ & 18.1 \\
\hline 8 & $10.13(1 \mathrm{H}, \mathrm{s})$ & 193.4 & $10.16(1 \mathrm{H}, \mathrm{s})$ & 193.6 & $10.1(1 \mathrm{H}, \mathrm{s})$ & 193.1 \\
\hline 9 & $3.53(2 \mathrm{H}, \mathrm{d}, J=7.4 \mathrm{~Hz})$ & 22.4 & $3.56(2 \mathrm{H}, \mathrm{d}, J=7.4 \mathrm{~Hz})$ & 22.6 & $3.50(2 \mathrm{H}, \mathrm{d}, J=7.4 \mathrm{~Hz})$ & 21.4 \\
\hline 10 & $5.52(1 \mathrm{H}, \mathrm{t}, J=7.3 \mathrm{~Hz})$ & 127.7 & $5.52(1 \mathrm{H}, \mathrm{t}, J=7.5 \mathrm{~Hz})$ & 127.7 & $5.52(1 \mathrm{H}, \mathrm{t}, J=7.2 \mathrm{~Hz})$ & 127.5 \\
\hline 11 & - & 134.2 & - & 134.3 & - & 136.4 \\
\hline 12 & $5.89(1 \mathrm{H}, \mathrm{d}, J=16.0 \mathrm{~Hz})$ & 133.3 & $5.90(1 \mathrm{H}, \mathrm{d}, J=16.0 \mathrm{~Hz})$ & 133.4 & $5.92(1 \mathrm{H}, \mathrm{d}, J=16.1 \mathrm{~Hz})$ & 132.9 \\
\hline 13 & $5.36(1 \mathrm{H}, \mathrm{d}, J=16.0 \mathrm{~Hz})$ & 135.8 & $5.38(1 \mathrm{H}, \mathrm{d}, J=16.0 \mathrm{~Hz})$ & 135.8 & $5.40(1 \mathrm{H}, \mathrm{d}, J=15.8 \mathrm{~Hz})$ & 135.4 \\
\hline 14 & - & 48.6 & - & 48.6 & - & 48.6 \\
\hline 15 & $1.95-1.92(1 \mathrm{H}, \mathrm{m})$ & 41.0 & $1.98-1.92(1 \mathrm{H}, \mathrm{m})$ & 41.0 & $1.98-1.90(1 \mathrm{H}, \mathrm{m})$ & 40.9 \\
\hline 16 & $1.95-1.92(1 \mathrm{H}, \mathrm{m})$ & 31.3 & $1.98-1.92(1 \mathrm{H}, \mathrm{m})$ & 31.3 & $1.98-1.90(1 \mathrm{H}, \mathrm{m})$ & 31.2 \\
\hline & $1.61(1 \mathrm{H}, \mathrm{m})$ & & $1.61(1 \mathrm{H}, \mathrm{m})$ & & $1.62(1 \mathrm{H}, \mathrm{m})$ & \\
\hline 17 & $2.39(2 \mathrm{H}, \mathrm{m})$ & 41.7 & $2.39(2 \mathrm{H}, \mathrm{m})$ & 41.7 & $2.38(2 \mathrm{H}, \mathrm{m})$ & 41.7 \\
\hline 18 & - & 212.9 & - & 212.9 & - & 212.9 \\
\hline 19 & $2.39(1 \mathrm{H}, \mathrm{m})$ & 53.7 & $2.39(1 \mathrm{H}, \mathrm{m})$ & 53.7 & $2.38(1 \mathrm{H}, \mathrm{m})$ & 53.7 \\
\hline 20 & $0.69(3 \mathrm{H}, \mathrm{s})$ & 10.5 & $0.70(3 \mathrm{H}, \mathrm{s})$ & 10.5 & $0.70(3 \mathrm{H}, \mathrm{s})$ & 10.4 \\
\hline 21 & $0.83(3 \mathrm{H}, \mathrm{d}, J=6.8 \mathrm{~Hz})$ & 16.5 & $0.83(3 \mathrm{H}, \mathrm{d}, J=6.7 \mathrm{~Hz})$ & 16.5 & $0.84(3 \mathrm{H}, \mathrm{d}, J=6.7 \mathrm{~Hz})$ & 16.4 \\
\hline 22 & $0.80(3 \mathrm{H}, \mathrm{d}, J=6.6 \mathrm{~Hz})$ & 9.0 & $0.81(3 \mathrm{H}, \mathrm{d}, J=6.6 \mathrm{~Hz})$ & 9.1 & $0.81(3 \mathrm{H}, \mathrm{d}, J=6.7 \mathrm{~Hz})$ & 9.0 \\
\hline 23 & $1.92(3 \mathrm{H}, \mathrm{s})$ & 12.8 & $1.92(3 \mathrm{H}, \mathrm{s})$ & 12.8 & $1.94(3 \mathrm{H}, \mathrm{s})$ & 12.8 \\
\hline
\end{tabular}

'H NMR: $500 \mathrm{MHz}$, ${ }^{\mathrm{C}} \mathrm{NMR}: 125 \mathrm{MHz}$ (in $\mathrm{CDCl}_{3}$ ) 


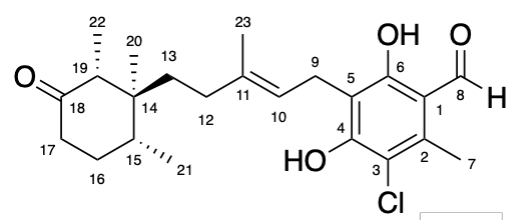

dechloro-12, 13-ascochlorin (7a)

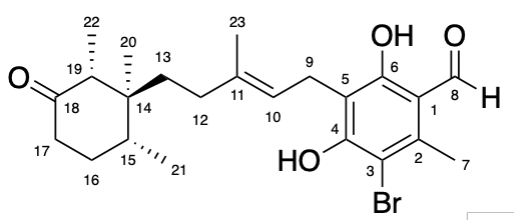

3-bromo-dechloro-12, 13-ascochlorin (7b)

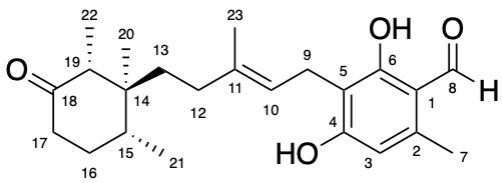

dechloro-12, 13-dihydroascochlorin (5)

\begin{tabular}{|c|c|c|c|c|c|c|}
\hline \multirow{2}{*}{ Position } & \multicolumn{2}{|c|}{ 12,13-dihydroascochlorin (7a) } & \multicolumn{2}{|c|}{ 3-bromo-12,13-dihydroascochlorin (7b) } & \multicolumn{2}{|c|}{ dechloro-12,13-dihydroascochlorin (5) } \\
\hline & $\delta_{\mathrm{H}}(\mathrm{mult}, \mathrm{Hz})$ & $\delta_{\mathrm{C}}(\mathrm{Hz})$ & $\delta_{\mathrm{H}}(\mathrm{mult}, \mathrm{Hz})$ & $\delta_{\mathrm{C}}(\mathrm{Hz})$ & $\delta_{\mathrm{H}}(\mathrm{mult}, \mathrm{Hz})$ & $\delta_{\mathrm{C}}(\mathrm{Hz})$ \\
\hline 1 & - & 113.3 & - & 114.3 & - & 112.2 \\
\hline 2 & - & 137.8 & - & 139.8 & - & 142 \\
\hline 3 & - & 113.8 & - & 106.2 & $6.24(1 \mathrm{H}, \mathrm{s})$ & 110.8 \\
\hline 4 & - & 156.4 & - & 157.1 & - & 163.9 \\
\hline 5 & - & 114.4 & - & 114.5 & - & 113.3 \\
\hline 6 & - & 162.4 & - & 162.9 & - & 162.5 \\
\hline 7 & $2.45(1 \mathrm{H}, \mathrm{m})$ & 50.6 & $2.45(1 \mathrm{H}, \mathrm{m})$ & 50.6 & $2.48(3 \mathrm{H}, \mathrm{s})$ & 18.1 \\
\hline 8 & $10.1(1 \mathrm{H}, \mathrm{s})$ & 193.4 & $10.2(1 \mathrm{H}, \mathrm{s})$ & 193.6 & $10.06(1 \mathrm{H}, \mathrm{s})$ & 193.4 \\
\hline 9 & $3.39(2 \mathrm{H}, \mathrm{d}, J=7.1 \mathrm{~Hz})$ & 22.2 & $3.41(2 \mathrm{H}, \mathrm{d}, J=7.2 \mathrm{~Hz})$ & 22.5 & $3.37(2 \mathrm{H}, \mathrm{d}, J=7.1 \mathrm{~Hz})$ & 21.3 \\
\hline 10 & $5.25(1 \mathrm{H}, \mathrm{t}, J=7.1 \mathrm{~Hz})$ & 121 & $5.24(1 \mathrm{H}, \mathrm{t}, J=7.5 \mathrm{~Hz})$ & 121 & $5.27(1 \mathrm{H}, \mathrm{t}, J=7.2 \mathrm{~Hz})$ & 121.5 \\
\hline 11 & - & 136.8 & - & 136.8 & - & 138.3 \\
\hline 12 & $2.00(1 \mathrm{H}, \mathrm{m})$ & 32.8 & $1.98(1 \mathrm{H}, \mathrm{m})$ & 32.8 & $1.97(1 \mathrm{H}, \mathrm{m})$ & 32.8 \\
\hline & $1.84(1 \mathrm{H}, \mathrm{m})$ & & $1.84(1 \mathrm{H}, \mathrm{m})$ & & $1.88(1 \mathrm{H}, \mathrm{m})$ & \\
\hline 13 & $1.39(2 \mathrm{H}, \mathrm{m})$ & 35.7 & $1.39(2 \mathrm{H}, \mathrm{m})$ & 35.7 & $1.40(2 \mathrm{H}, \mathrm{m})$ & 35.7 \\
\hline 14 & - & 43.6 & - & 43.6 & - & 43.7 \\
\hline 15 & $2.00(1 \mathrm{H}, \mathrm{m})$ & 36.2 & $1.98(1 \mathrm{H}, \mathrm{m})$ & 36.2 & $2.00(1 \mathrm{H}, \mathrm{m})$ & 36.2 \\
\hline 16 & $1.84(1 \mathrm{H}, \mathrm{m})$ & 31.1 & $1.83(1 \mathrm{H}, \mathrm{m})$ & 31.1 & $1.84(1 \mathrm{H}, \mathrm{m}), 1.61(1 \mathrm{H}, \mathrm{m})$ & 31.1 \\
\hline & $1.63(1 \mathrm{H}, \mathrm{m})$ & & $1.61(1 \mathrm{H}, \mathrm{m})$ & & & \\
\hline 17 & $2.32(2 \mathrm{H}, \mathrm{m})$ & 41.7 & $2.31(2 \mathrm{H}, \mathrm{m})$ & 41.7 & $2.33(2 \mathrm{H}, \mathrm{m})$ & 41.7 \\
\hline 18 & - & 214.3 & - & 214.3 & - & 215.1 \\
\hline 19 & $2.45(1 \mathrm{H}, \mathrm{m})$ & 50.6 & $2.45(1 \mathrm{H}, \mathrm{m})$ & 50.6 & $2.47(1 \mathrm{H}, \mathrm{m})$ & 50.7 \\
\hline 20 & $0.56(3 \mathrm{H}, \mathrm{s})$ & 15.5 & $0.56(3 \mathrm{H}, \mathrm{s})$ & 15.5 & $0.57(3 \mathrm{H}, \mathrm{s})$ & 15.5 \\
\hline 21 & $0.87(1 \mathrm{H}, \mathrm{d}, J=6.7 \mathrm{~Hz})$ & 15.2 & $0.88(1 \mathrm{H}, \mathrm{d}, J=6.8 \mathrm{~Hz})$ & 15.2 & $0.88(3 \mathrm{H}, \mathrm{d}, J=6.6 \mathrm{~Hz})$ & 15.2 \\
\hline 22 & $0.90(3 \mathrm{H}, \mathrm{d}, J=6.7 \mathrm{~Hz})$ & 7.7 & $0.91(3 \mathrm{H}, \mathrm{d}, J=6.8 \mathrm{~Hz})$ & 7.7 & $0.92(3 \mathrm{H}, \mathrm{d}, J=6.7 \mathrm{~Hz})$ & 7.7 \\
\hline 23 & $1.81(3 \mathrm{H}, \mathrm{s})$ & 16.5 & $1.81(3 \mathrm{H}, \mathrm{s})$ & 16.5 & $1.83(3 \mathrm{H}, \mathrm{s})$ & 16.5 \\
\hline
\end{tabular}

'H NMR: $500 \mathrm{MHz}$, "C NMR: $125 \mathrm{MHz}$ (in $\mathrm{CDCl}_{3}$ ) 
<smiles>CC(C)=CCCC(C)=CCCC(C)=CCc1c(O)cc(C)c(C=O)c1O</smiles>

LL-Z1272 $\beta$ (2)

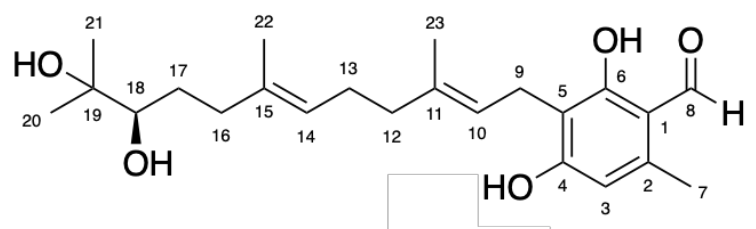

cylindrocarpol (4')

\begin{tabular}{|c|c|c|c|c|}
\hline \multirow{2}{*}{ Position } & \multicolumn{2}{|l|}{ LL-Z1272ß (2) } & \multicolumn{2}{|l|}{ cylindrocarpol (4') } \\
\hline & $\delta_{\mathrm{H}}($ mult, $\mathrm{Hz})$ & $\delta_{\mathrm{C}}(\mathrm{Hz})$ & $\delta_{\mathrm{H}}($ mult, $\mathrm{Hz})$ & $\delta_{\mathrm{C}}(\mathrm{Hz})$ \\
\hline 1 & & 113.2 & - & 113.2 \\
\hline 2 & & 142.1 & - & 141.9 \\
\hline 3 & $6.22(1 \mathrm{H}, \mathrm{s})$ & 111.0 & $6.19(1 \mathrm{H}, \mathrm{s})$ & 110.8 \\
\hline 4 & & 162.9 & - & 162.7 \\
\hline 5 & & 112.2 & - & 112.4 \\
\hline 6 & & 163.9 & - & 163.7 \\
\hline 7 & $2.47(3 \mathrm{H}, \mathrm{s})$ & 18.0 & $2.47(3 \mathrm{H}, \mathrm{s})$ & 18.1 \\
\hline 8 & $10.0(1 \mathrm{H}, \mathrm{s})$ & 193.0 & $10.0(1 \mathrm{H}, \mathrm{s})$ & 192.3 \\
\hline 9 & $3.40(2 \mathrm{H}, \mathrm{d}, J=7.2 \mathrm{~Hz})$ & 21.2 & $3.35(2 \mathrm{H}, \mathrm{d}, J=6.6 \mathrm{~Hz})$ & 21.1 \\
\hline 10 & $5.27(2 \mathrm{H}, \mathrm{t}, \mathrm{J}=7.2 \mathrm{~Hz})$ & 121.2 & $5.17(1 \mathrm{H}, \mathrm{t}, J=6.9 \mathrm{~Hz})$ & 122.3 \\
\hline 11 & & 138.7 & - & 137.6 \\
\hline 12 & $2.04(2 \mathrm{H}, \mathrm{m})$ & 39.7 & $2.05(2 \mathrm{H}, \mathrm{m})$ & 39.3 \\
\hline 13 & $2.07(2 \mathrm{H}, \mathrm{m})$ & 26.7 & $2.08(2 \mathrm{H}, \mathrm{m})$ & 25.5 \\
\hline 14 & $5.08(1 \mathrm{H}, \mathrm{m})$ & 124.5 & $5.12(1 \mathrm{H}, \mathrm{t}, J=7.8 \mathrm{~Hz})$ & 124.8 \\
\hline 15 & & 135.5 & - & 135.2 \\
\hline 16 & $2.11(2 \mathrm{H}, \mathrm{m})$ & 39.8 & $2.13,2.17(2 \mathrm{H}, \mathrm{m})$ & 36.6 \\
\hline 17 & $1.97(2 \mathrm{H}, \mathrm{m})$ & 26.4 & $1.42,1.62(2 \mathrm{H}, \mathrm{m})$ & 29.8 \\
\hline 18 & $5.08(1 \mathrm{H}, \mathrm{m})$ & 123.7 & $3.39(1 \mathrm{H}, \mathrm{dd}, J=12.6,1.8)$ & 78.3 \\
\hline 19 & & 131.5 & - & 73.5 \\
\hline 20 & $1.67(3 \mathrm{H}, \mathrm{brs})$ & 25.7 & $1.18(3 \mathrm{H}, \mathrm{brs})$ & 26.5 \\
\hline 21 & $1.59(3 \mathrm{H}, \mathrm{brs})$ & 17.7 & $1.12(3 \mathrm{H}, \mathrm{brs})$ & 23.4 \\
\hline 22 & $1.59(3 \mathrm{H}, \mathrm{brs})$ & 16.3 & $1.58(3 \mathrm{H}, \mathrm{brs})$ & 14.3 \\
\hline 23 & $1.82(3 \mathrm{H}, \mathrm{brs})$ & 16.1 & $1.76(3 \mathrm{H}, \mathrm{brs})$ & 16.1 \\
\hline $6-\mathrm{OH}$ & $12.7(1 \mathrm{H}, \mathrm{s})$ & & $12.7(1 \mathrm{H}, \mathrm{s})$ & \\
\hline
\end{tabular}

'H NMR: $500 \mathrm{MHz}$, ${ }^{\mathrm{C}} \mathrm{C}$ NMR: $125 \mathrm{MHz}$ (in $\mathrm{CDCl}_{3}$ ) 
The asc gene cluster from Fusarium sp. NBRC100844 ca. 23.6 kb

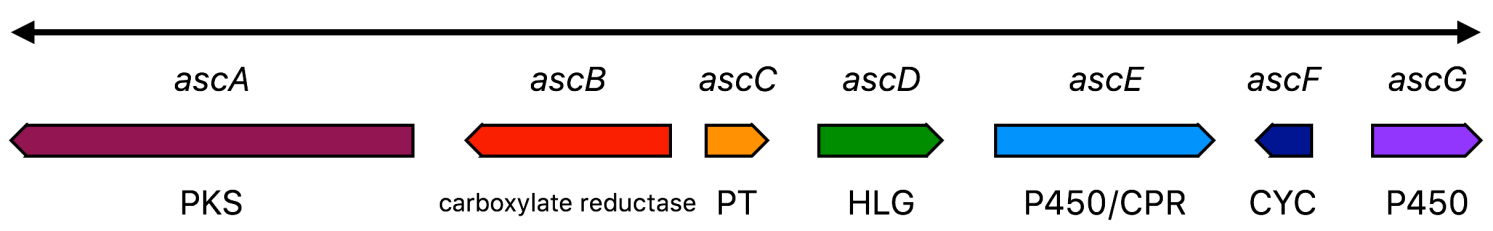

\begin{tabular}{l|l|l|c|l}
\hline Genes & Amino acids (base pairs) & Protein homologue, origin organism & Identities / Similarities & Predicted Function \\
\hline asc $A$ & $2118(6527)$ & StbA, Stachybotrys bisbyi & $60 \% / 76 \%$ & Polyketide synthase (PKS) \\
ascB & $1064(3316)$ & StbB, Stachybotrys bisbyi & $61 \% / 76 \%$ & NRPS-like carboxylate reductase \\
ascC & $333(1002)$ & StbC, Stachybotrys bisbyi & $57 \% / 69 \%$ & UbiA prenyltransferase (PT) \\
ascD & $560(1995)$ & AclH, Aspergillus oryzae RIB40 & $57 \% / 72 \%$ & Flavin-dependent halogenase (HLG) \\
ascE & $1069(3535)$ & AoCYP505A3, Aspergillus oryzae RIB40 & $47 \% / 64 \%$ & Cytochrome P450/Cytochrome P450 reductase (P450/CPR) \\
ascF & $267(894)$ & AndB, Emericella variecolor & $30 \% / 49 \%$ & Terpene cyclase (CYC) \\
ascG & $533(1755)$ & AtaF, Aspergillus terreus NIH2624 & $33 \% / 51 \%$ & Cytochrome P450 (P450)
\end{tabular}

Figure S1. Schematic representation and annotation of $\operatorname{asc} A-G$ 


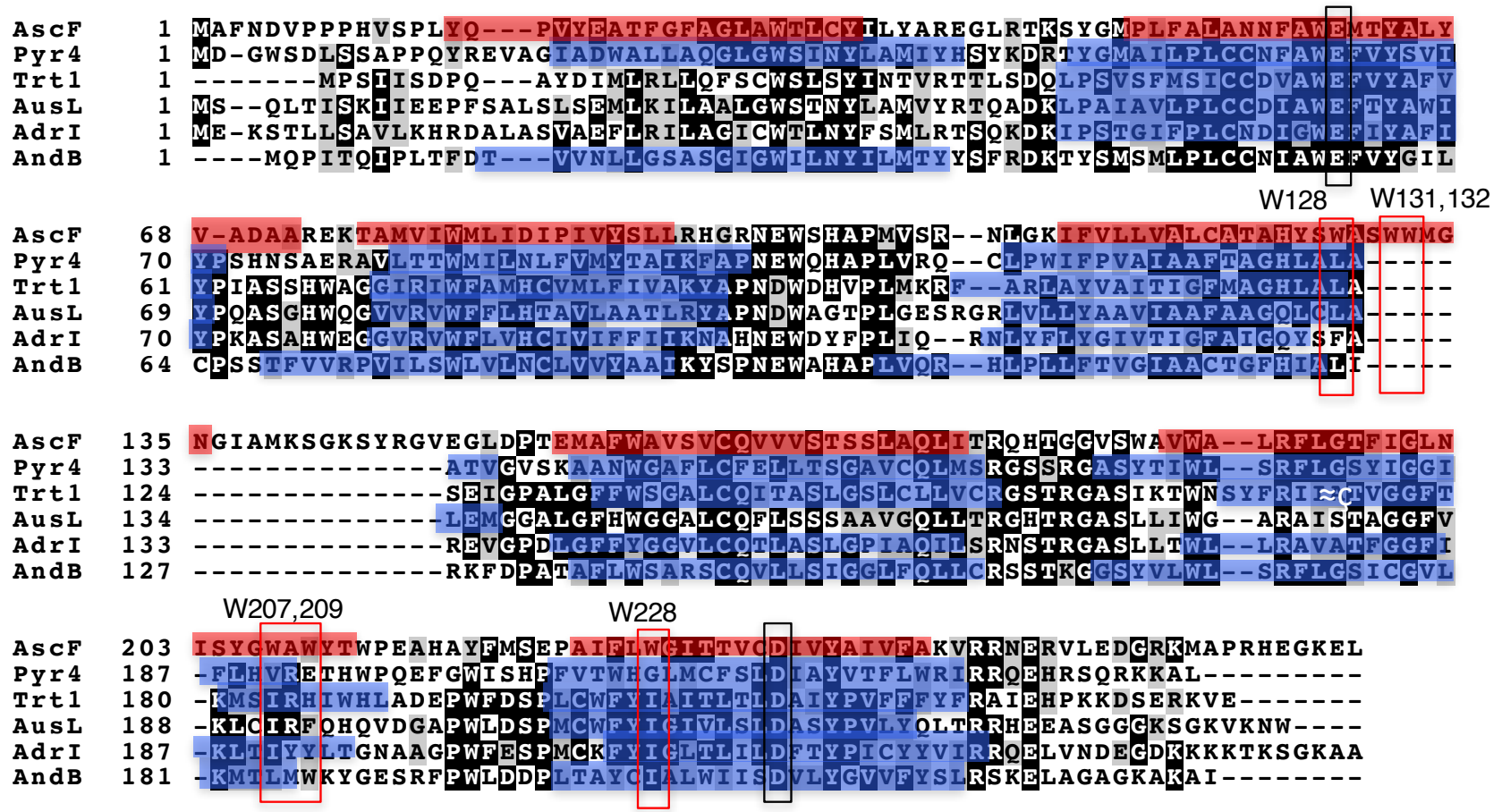

Figure S2. Sequence alignment between AscF, Pyr4, Trt1, AusL, AdrI, and AndB

Red flames indicate the amino acids mutated into alanine in this work, black flames indicate catalytic acid and base residues identified in Pyr4 study (T. Itoh, K. Tokunaga, Y. Matsuda, I. Fujii, I. Abe, Y. Ebizuka, T. Kushiro, Nat. Chem., 2010, 2, 858-864). Red and blue markers are transmembrane region predicted by TMHMM server. 


\section{A)}

AS CE 1 -MS CEIPRPRGL PVIGGILDIDPSDAVASIGGLAEIHGSTYKL KLAGSEKVF ISSRDLMD P450BM3 1 MTIKEMPQPKTFGELKNLPLLNTDKPVQALMEIADELGEIFKFEAPGRVTRYLSSQRLIK

AS CE 60 EVSDETRFTRLVSGPIAQLRNAVGDS GFTAH Y DEHWTGVAHRIIMPAMGPLAIRGMF DEM P450BM3 61 EACDESRFDENLSQALKFVRDFAGDGLFTSWTHEKWWKKAHNILLPSF SQQAMKGYHAMM

AS CE 120 HDLASQLVTKWARFG PHDTINVT SDFTRLTLDTIALCSMGTRFNSFYHEEMHPFIGSMIG P450BM3 121 VDIAVQLVQKWERLNADEHIEVPEDMTRLTLDTIGLCGFNYRFNSFYRDQPEPFITSMVR

ASCE 180 LIEESGRRAPRPEWANYLLPGAQAQYDTDTQTLRRVAADVLADRRAHPNKKKDILNALIV P450BM3 181 ALDEAMNKL QRANPDDPAYDENKRGFQEDIKVMNDLVDKI IADRKASGEQSDDLLTHMLN

ASCE 240 GSDSKTGERMSDESTLNNMIVFITAGHETTSGLLSFLFFYLLKYYDVMEKAOEEVDRVVG P450BM3 241 GKDPETGEPLDDENIRYQIITELIAGHETTSGLLSFAL Y FLVENPHVL QKAAEEAARVLV

ASCE 300 RGAITIEHMSKLPYLEACZRETLRLHPTAPVITUQPRPDLPVEKTTLADGKYEVHRGQGI P450BM3 301 DPVPSYKQVKQLKYVGMVINGALRLWPTAPAFSLY YKE-----DIVLGGEYPLEKGDEL

ASCE 360 VADLIQIQRDPAVYGPDANGFRAERMLDENF NKLPKNSWKPFGEGIRGCIGRAFAWQESL P450BM3 355 MVIIPQLHRDKTIWGDDVEGFRPERFE--NPSAIPQHAFEPFGNGQRACIGQQFALHEAT heme

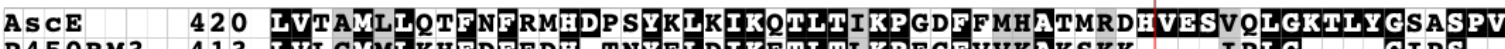
P450BM3 413 LVLGMMLKHFDEEDH-TNYELDIKETLTLKPEGGVVKAKSKK----IPLG----GIPS-$\longrightarrow$ $P-450$

ASCE 480 ANGVNGHATPRKEQVHG--KAVTNGHATKPMAILFGGESGTCETMAQTLARAAPARGYHA P450BM3 $462-\cdots---$ PSTEOSAKIVRKKAENAHNTBLLVIY GS NMGTAGGTARDLADIAMSKGFAP P450 reductase

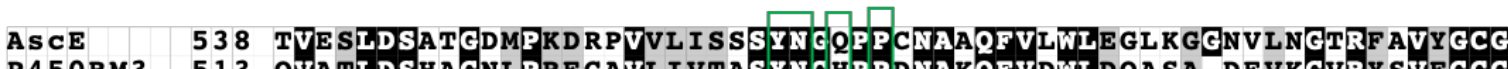
P450BM3 513 QVATLDSHAGNLPREGAVL IVTASYNGHPPDWAREFVDWLDQASA-DEVKGVRY SVFGCG

ASCE 598 NRDYGPTFHRIPKLLNSEZEKNGAARLAE IGLGDVIAGDIF SDFEK区̄ODEHLWTALGAGT P450BM3 572 DKNWATYYQKVPAFIDETLAAKGAENIADRGEADA-S DDFEGTYGEWR-EHMẄDVAAYF FMN

ASCE 658 TADNGD----IGFEVQIDR--HSRP-SELREDVEEAVVLKNGVLTAPGEPAKRLVVLKI P450BM3 630 NLDIENSEDKRSTLSL OFVDSAADMPLAKMHGAFSTNVVASKGLQQPGSARSTBHLEIEL

ASCE 710 PEGMEYRSGDHISVLPLADWGTVRRVLQWANTPLDAVITIPSG--SNTTLPTGRAISVWD P450BM3 690 PKEASYQEGDHL GVIBREYEGIVNRVTARFGLDASQQIRLEAEGEKLAHLPLAKTVSVEE

ASCE 768 ULSGYVELS QPATRKNVLRMAACTEDEEAR--KRITALEEDF DNSITLKRRS ITDMIEEF P450BM3 750 -LLQZVELQDBVTRTQLRAMAAKTVCPPHKVELEALLEKQAYKEQVLAERLTMLELLEKY

ASCE 826 PSVSLSVSEYLAMLPPMRARKYAASSPLADASIVTLIFEVTDKESPLRSNKRLLGIAST P450BM3 809 PACEMKFSEFIALLPSIRPRYYIISSPRVDEKQASITVSUUSGE-AWSGYGEYKGIASN

ASCE 886 YLARLQEGESTHVAVKPALRLFRPPSDVGNTPCIMACAGTGLAPFRAFVEERAAHAKAGK P450BM3 868 YLAELQEGDTITCFITPQSEFTLPKDP-ETPLIMVGPGTGVAPFRGFVQARKQLEQGQ

ASCE 946 DLA PAYLFIGCRDPAKDAIVVDELKQWEEAGITKVFYAFSRASKKSNGCKY RQDRLWRER P450BM3 927 SLGEAHLFGCRSPHEYLYQEELENAQSEGITTHTAFSRMPNQPK- TYVQHVMEQDNADPH

ASCE 1006 EVVEKCIIEREGNFYVCGGAGV-GKGVDQIMKRIYAEKMISGGESKDADQWVQEZKT-TRY P450BM3 984 GKKLIELIDQGAHFYICGDGSQVAPAVEATLMKSYADVH-QVSEADARLWLOQLEERGRY ASCE 1064 ASEIFS-

P450вM3 1043 AKDVWAG 
B)

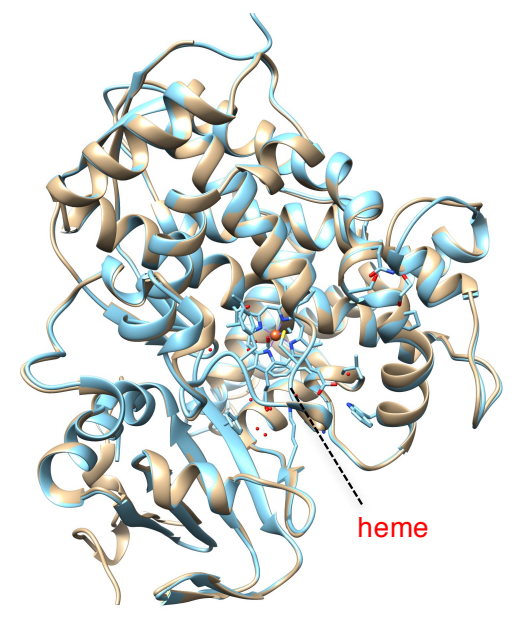

D)<smiles>CCCCCCCCCCCCC(=O)O</smiles>

C)

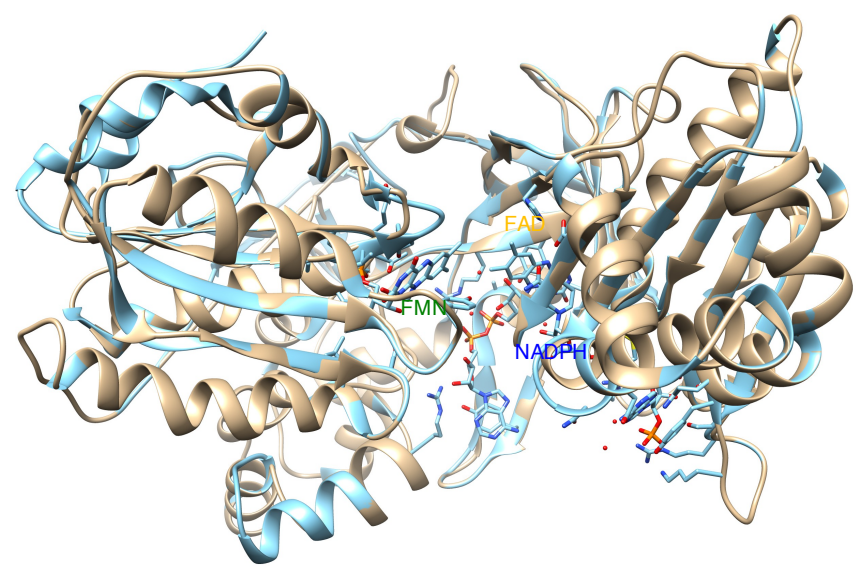<smiles>CC(O)C(CCCCCCCCCC(=O)O)C(O)C(O)C(=O)O</smiles><smiles>C=CCCCCC</smiles>

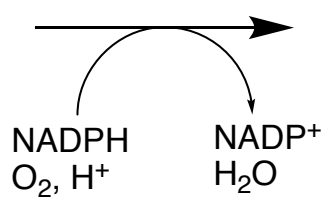<smiles>CCCC[C@H]1CO1</smiles>

Figure S3. Comparison between AscE and P450 BM-3

Alignment between AscE and P450 BM-3 (A), homology model of P450 domain (B) and flavinNADP+ binding domain (C), and the reaction of P450 BM-3 (D) Heme, FAD, NADP+, and FMN binding sites of P450BM-3 ${ }^{8,9}$ were shown in the alignment. Homology model was built by Phyre2 server (http://www.sbg.bio.ic.ac.uk/phyre2/). The model of AscE P450 domain (1-462) (brown) was built by using the PDB model 4H23 (cyan) as a template, and that of flavin-NADP+ binding domain (504-1069) (brown) was built by using 1J9Z (cyan) as a template. 

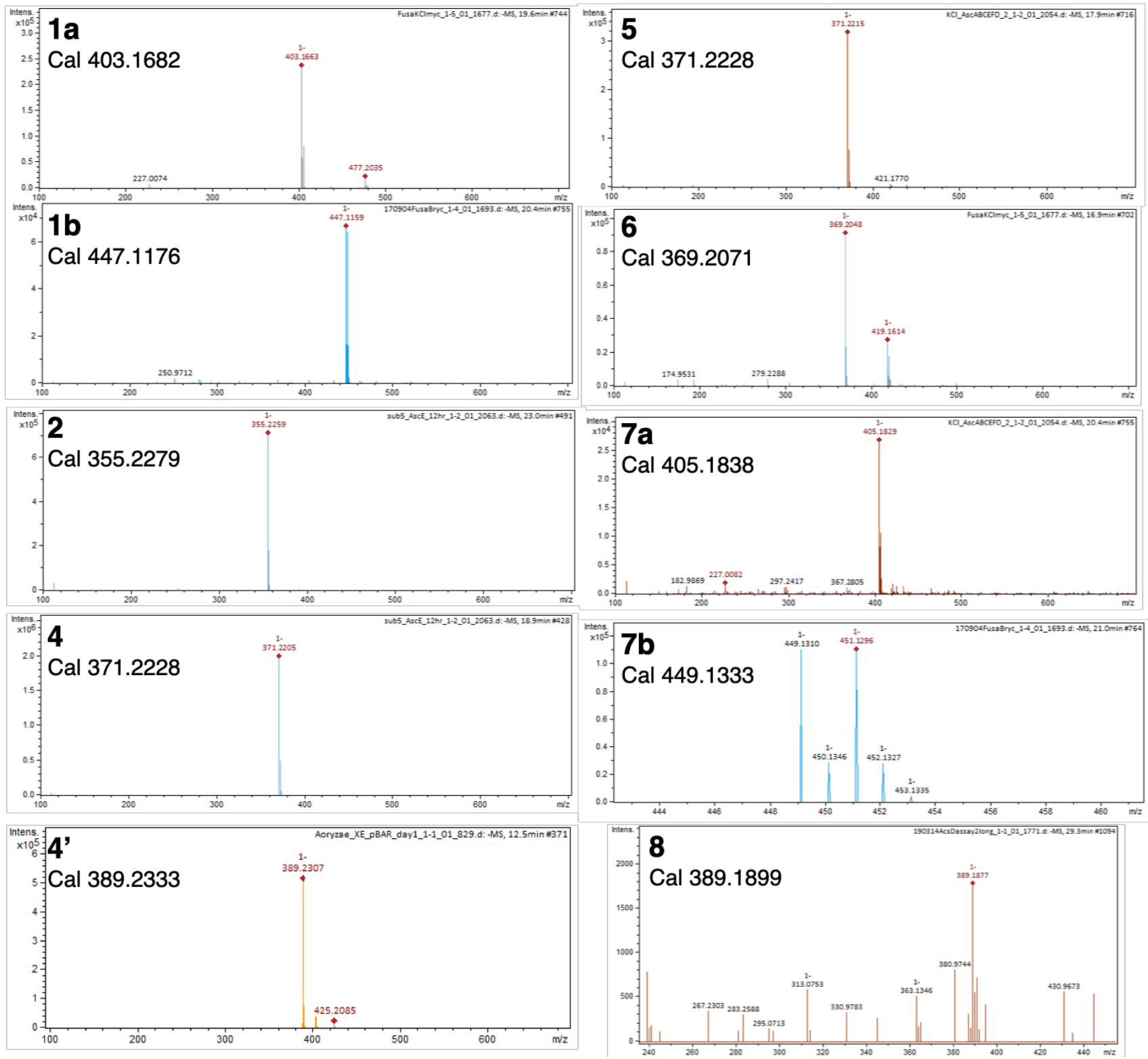

Figure S4. MS spectra of the compounds in this study 


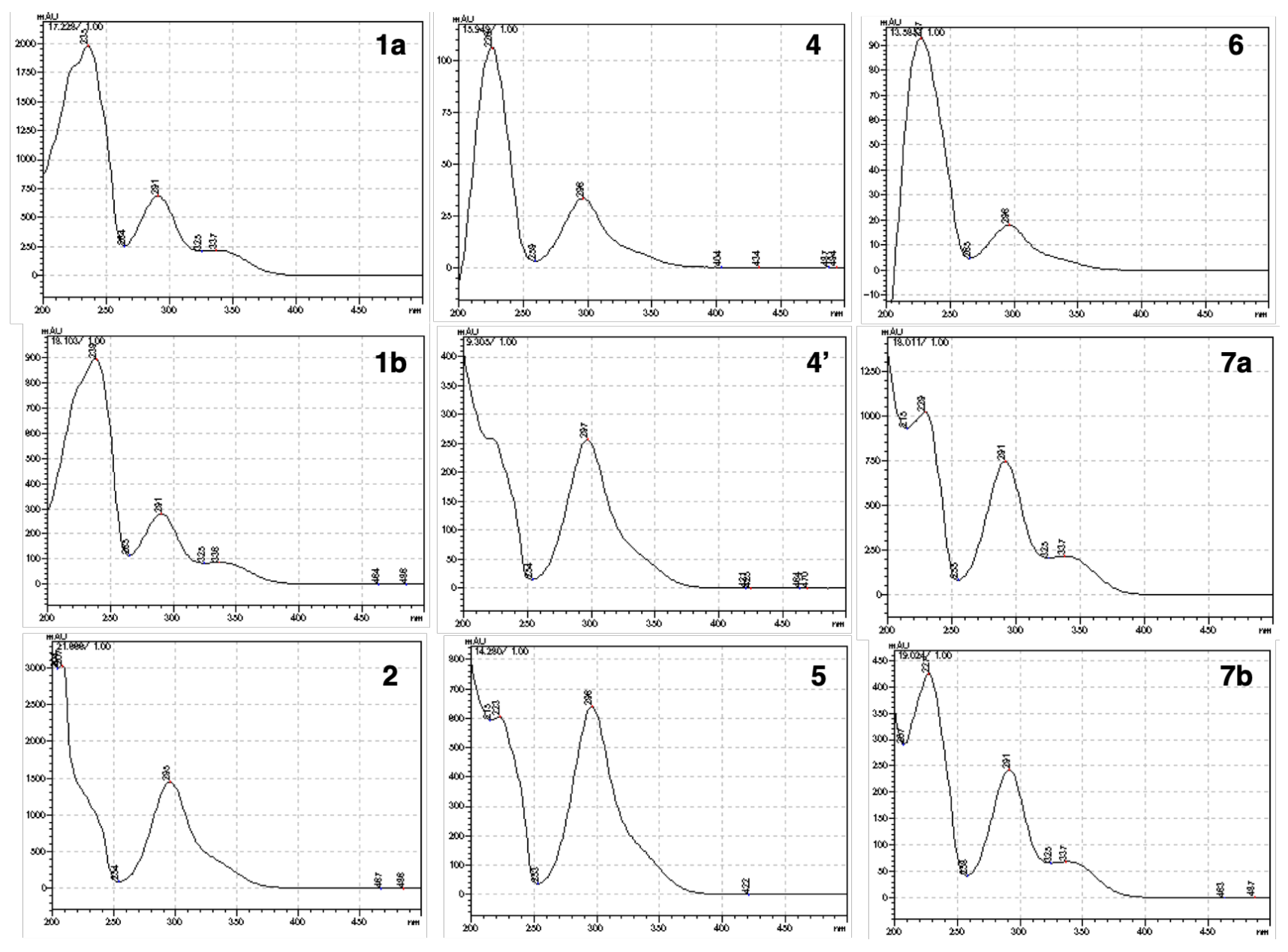

Figure S5. UV spectra of the compounds isolated in this study 


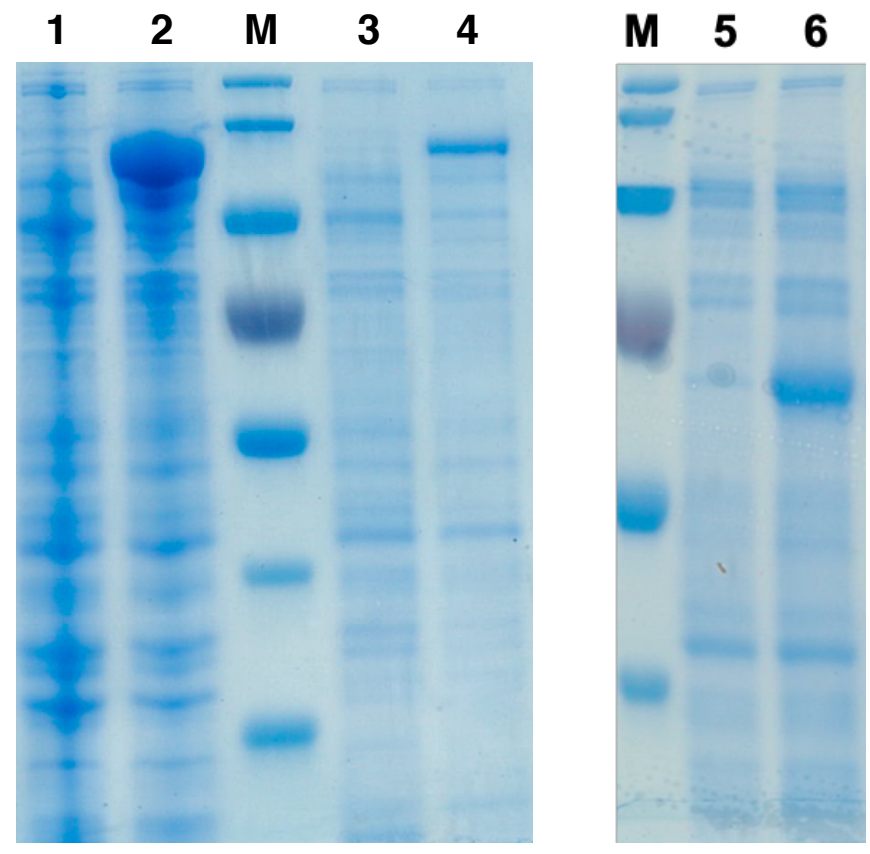

Figure S6. SDS-PAGE analysis of the recombinant AscE and AscD

From Rosetta2/pColdII-AscE (Lane2 \& 4; insoluble \& soluble fraction), negative control Rosetta2/pColdII (Lane1 \& 3; insoluble \& soluble fraction), Rosetta2/pET28a-AscD (Lane6; soluble fraction), and negative control Rosetta2/pET28a (Lane5; soluble fraction). Molecular weight of AscE is $120 \mathrm{kDa}$, and that of AscD is $63 \mathrm{kDa}$. M; Thermo Scientific PageRuler Prestained Protein Ladder (170, 130,70 (purple), 55, 40, $35 \mathrm{kDa}$ )
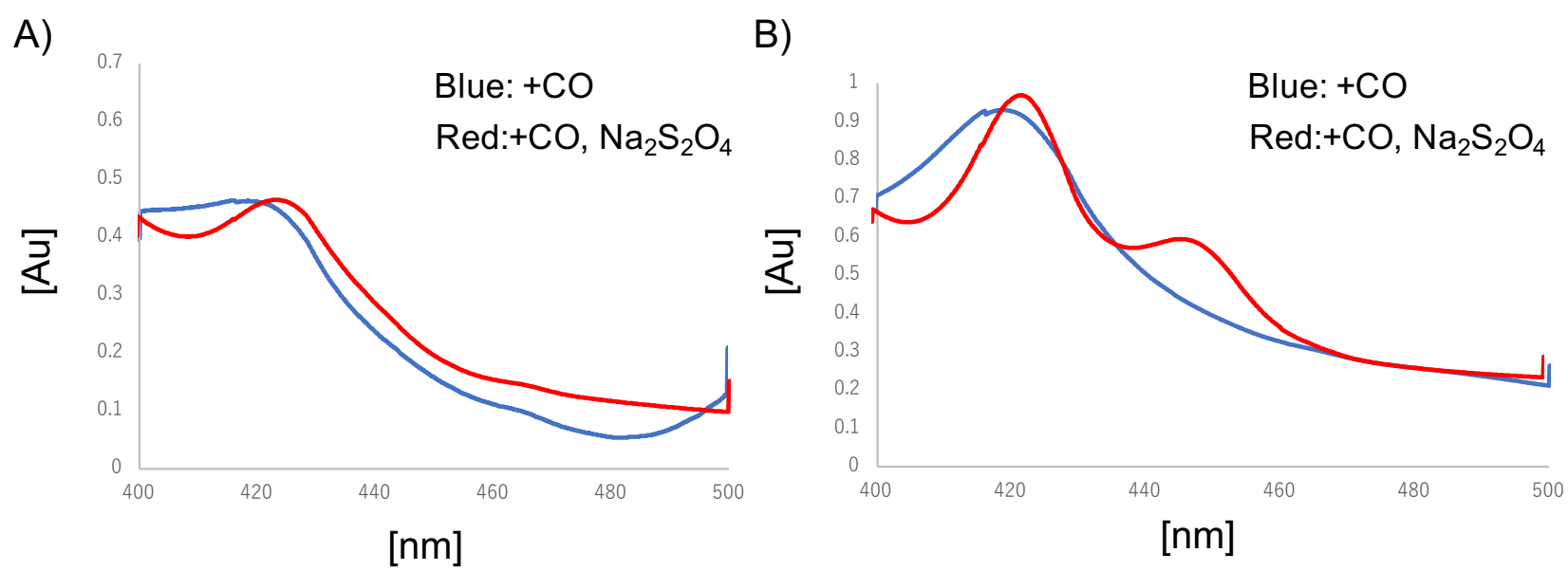

Figure S7. Absorption spectra of the recombinant AscE

Soluble fraction of Rosetta2/pColdII-AscE (B), and negative control Rosetta2/pColdII (A). 
<smiles>C/C(=C\CC/C(C)=C/CC[Ge](CO)(C[PH2+])C(C)(C)C)CC/C=C(\C)Cc1c(O)cc(C)c(C=O)c1O</smiles>

4<smiles>C/C(=C\CC/C(C)=C/CC/C(C)=C/CC[C@H](O)C(C)(C)O)CO</smiles>

cylindrocarpol (4')

Figure S8. 4 was hydrolyzed to $4^{\prime}$ in $S_{\mathbb{}} 2$ manner.

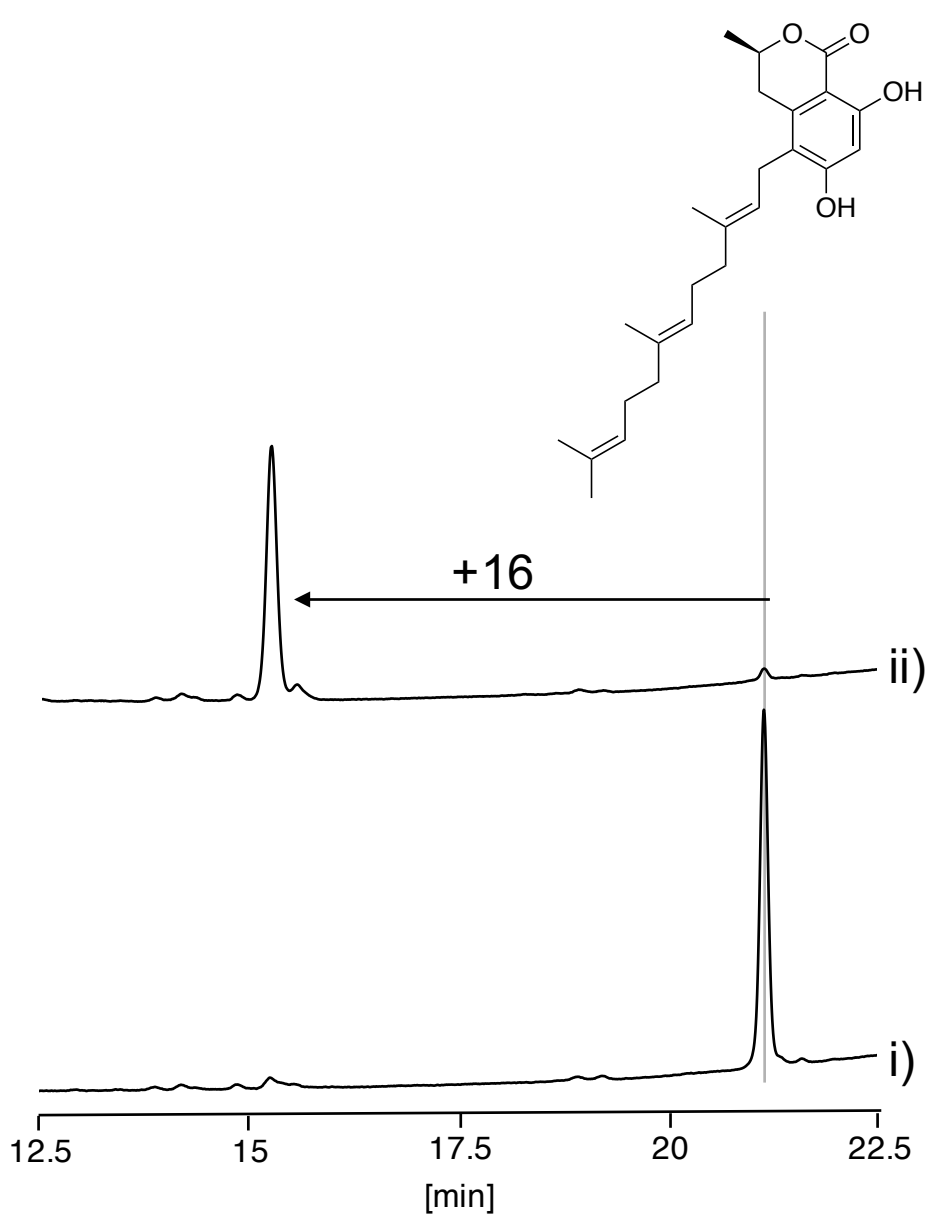

Figure S9. HPLC profile of in vitro assay of AscE by using 5-farnesyl-6-hydroxymellein as a substrate. Lane i shows a negative control, and lane ii shows complete reaction. The substrate $(\mathrm{m} / \mathrm{z}=397$ [M$\mathrm{H}]$ ) was converted into the product $(\mathrm{m} / \mathrm{z}=413[\mathrm{M}-\mathrm{H}])$. The chromatograms were monitored at 295 $\mathrm{nm}$. 


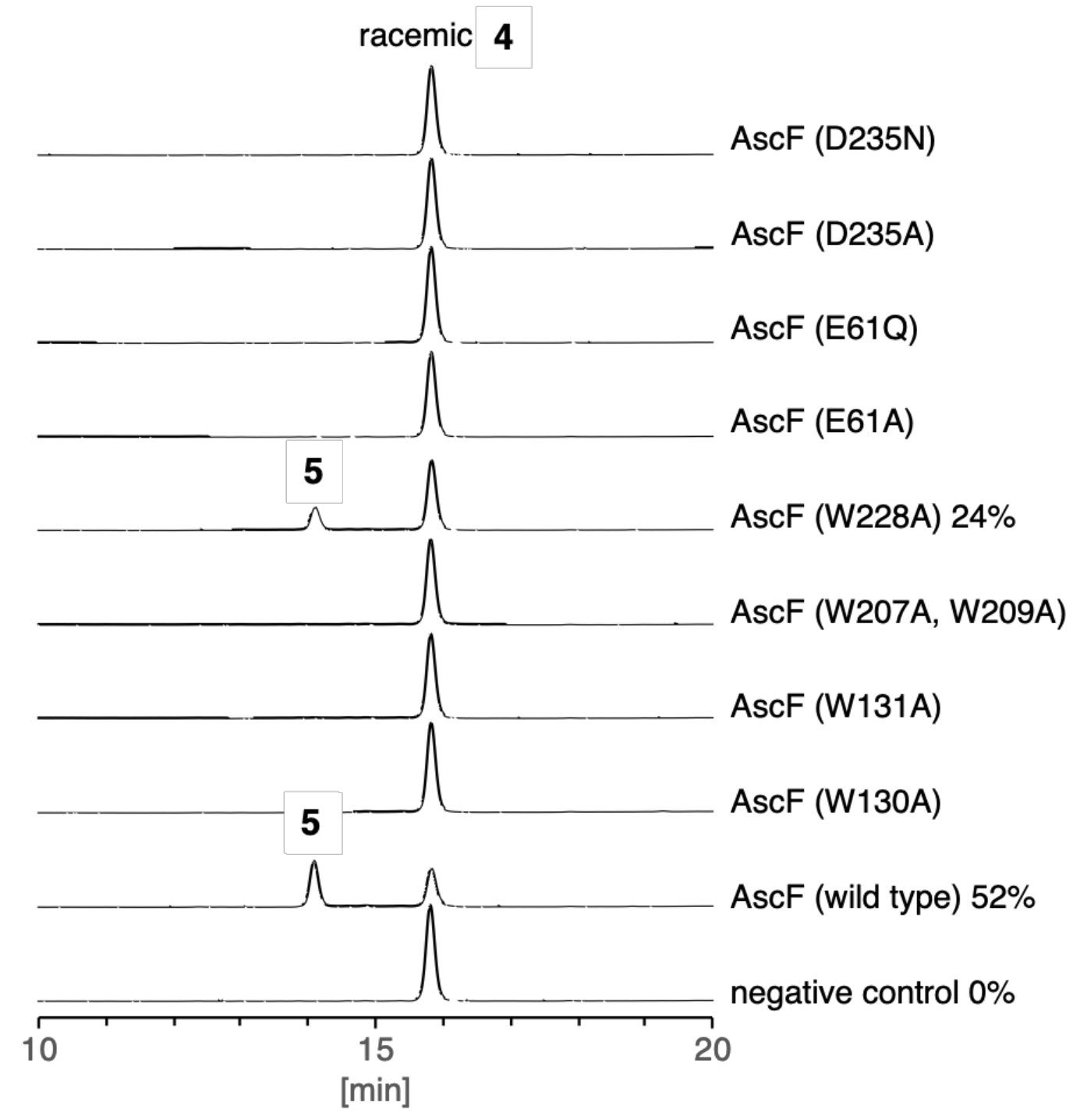

Figure S10. HPLC analysis of the AscF mutants in vitro assay. Percentage showed the consumption of substrate. UV absorbance was $295 \mathrm{~nm}$. 


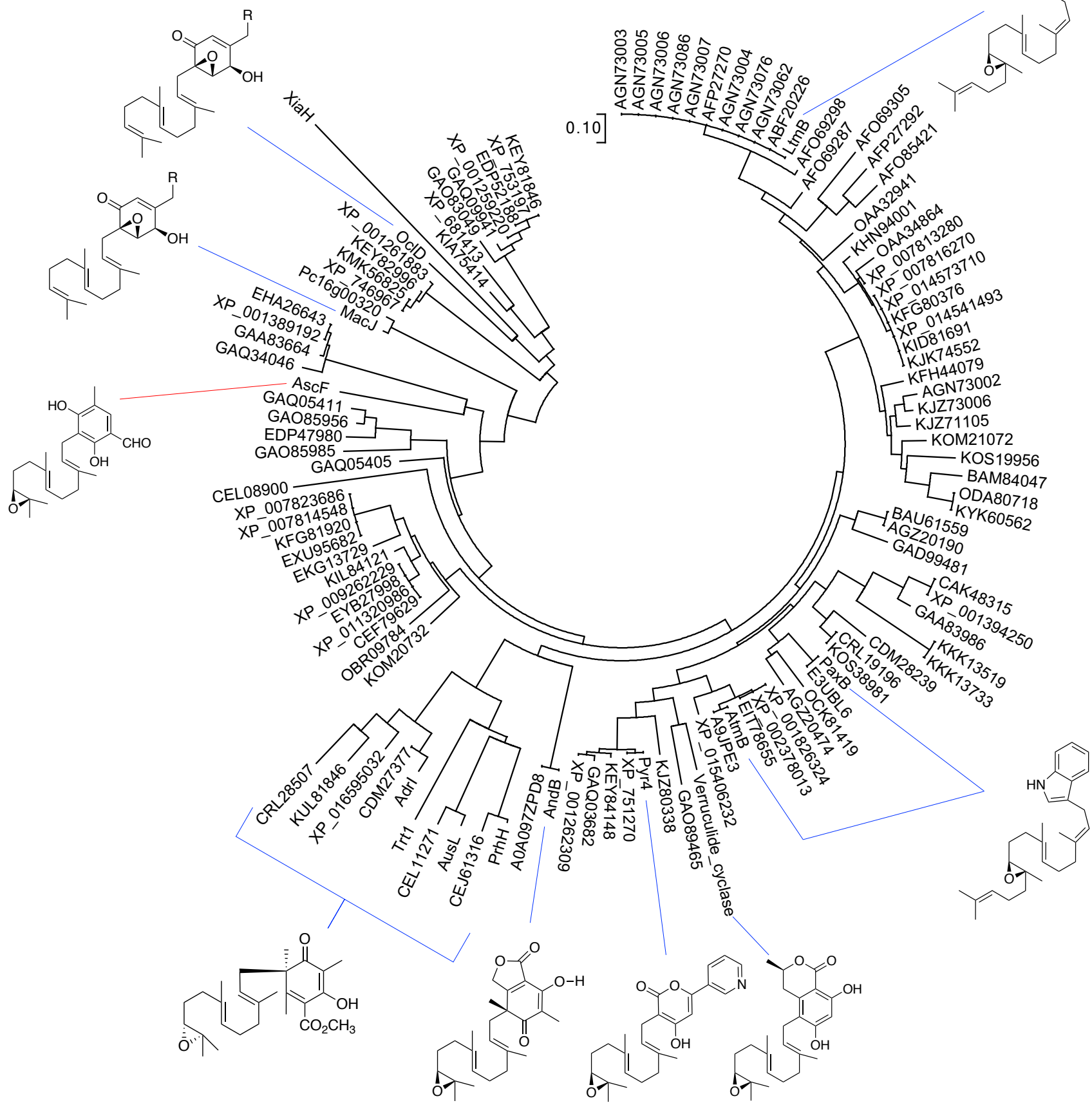

Figure S11. Phylogenetic tree analysis of meroterpenoid terpene cyclases

Multiple sequence alignment, performed with ClustalW. The scale represents 0.10 amino acid substitutions per site. XiaH from Streptomyces sp. SCSIO 02999 was employed as out group.

Accession numbers: AndB from Emericella variecolor, AtmB Aspergillus flavus, AusL Aspergillus nidulans FGSC A4, LtmB Epichloe festucae var. lolii, MacJ Penicillium terrestris, AdrI Penicillium chrysogenum, PaxM Penicillium paxilli, LtmB Epichloe festucae var. lolii, MacJ Penicillium terrestris, OclD Penicillium oxalicum 114-2, PaxB Penicillium paxilli, PrhH Penicillium brasilianum NBRC6234, Pyr4 Aspergillus fumigatus F37, Trt1 Aspergillus terreus, AscF Fusarium sp., Verruculide_cyclase Penicillium verruculosum, AFO69287 Periglandula ipomoeae, AFO69298 Epichloe 
gansuensis, AFO69305 Aciculosporium take, AFO85421 Claviceps paspali, AFP27270 Epichloe festucae, AFP27292 Claviceps purpurea, AGN73002 Epichloe aotearoae, AGN73003 Epichloe occultans, AGN73004 Epichloe siegelii, AGN73005 Neotyphodium sp. FaTG-3, AGN73006 Neotyphodium sp. FaTG-2, AGN73007 Neotyphodium sp. FaTG-2, AGN73062 Epichloe funkii, AGN73076 Epichloe coenophiala, AGN73086 Neotyphodium sp. FaTG-4, AGZ20190 Penicillium crustosum, AGZ20474 Penicillium janthinellum, ABF20226 Epichloe festucae var. lolii, BAM84047 Tolypocladium album, BAU61559 Penicillium simplicissimum, CAK48315 Aspergillus niger, CDM27377 Penicillium roqueforti FM164, CDM28239 Penicillium roqueforti FM164, CEF79629 Fusarium graminearum, CEJ61316 Penicillium brasilianum, CEL08900 Aspergillus calidoustus, CEL11271 Aspergillus calidoustus, CRL19196 Penicillium camemberti, CRL28507 Penicillium camemberti, EDP47980 Aspergillus fumigatus A1163, EDP52188 Aspergillus fumigatus A1163, EHA26643 Aspergillus niger ATCC 1015, EIT78655 Aspergillus oryzae 3.042, EKG13729 Macrophomina phaseolina MS6, EXU95682 Metarhizium robertsii, EYB27998 Fusarium graminearum, GAA83664 Aspergillus kawachii IFO 4308, GAA83986 Aspergillus kawachii IFO 4308, GAD99481 Byssochlamys spectabilis No. 5 , GAO83049 Aspergillus udagawae, GA085956 Aspergillus udagawae, GAO85985 Aspergillus udagawae, GAO89465 Aspergillus udagawae, GAQ03682 Aspergillus lentulus, GAQ05405 Aspergillus lentulus, GAQ05411 Aspergillus lentulus, GAQ09941 Aspergillus lentulus, GAQ34046 Aspergillus niger, KEY81846 Aspergillus fumigatus var. RP-2014, KEY82996 Aspergillus fumigatus var. RP-2014, KEY84148 Aspergillus fumigatus var. RP-2014, KFG80376 Metarhizium anisopliae, KFG81920 Metarhizium anisopliae, KFH44079 Acremonium chrysogenum ATCC 11550, KHN94001 Metarhizium album ARSEF 1941, KIA75414 Aspergillus ustus, KID81691 Metarhizium guizhouense ARSEF 977, KIL84121 Fusarium avenaceum, KJK74552 Metarhizium anisopliae BRIP 53293, KJZ71105 Hirsutella minnesotensis 3608, KJZ73006 Hirsutella minnesotensis 3608, KJZ80338 Hirsutella minnesotensis 3608 , KKK13519 Aspergillus rambellii, KKK13733 Aspergillus ochraceoroseus, KMK56825 Aspergillus fumigatus Z5, KOM20732 Ophiocordyceps unilateralis, KOM21072 Ophiocordyceps unilateralis, KOS19956 Escovopsis weberi, KOS38981 Penicillium nordicum, KUL81846 Talaromyces verruculosus, KYK60562 Drechmeria coniospora, B6H6U3 Penicillium chrysogenum ATCC 28089, OAA32941 Aschersonia aleyrodis RCEF 2490, OAA34864 Metarhizium rileyi RCEF 4871, OBR09784 Colletotrichum higginsianum IMI 349063, OCK81419 Lepidopterella palustris CBS 459.81, ODA80718 Drechmeria coniospora, XP_681413 Aspergillus nidulans FGSC A4, XP_746967 Aspergillus fumigatus Af293, XP_751270 Aspergillus fumigatus Af293, XP_753197 Aspergillus fumigatus Af293, XP_001259220 Aspergillus fischeri NRRL 181, XP_001261883 Aspergillus fischeri NRRL 181, XP_001262309 Aspergillus fischeri NRRL 181, XP_001389192 Aspergillus niger CBS 513.88, XP_001394250 Aspergillus niger CBS 513.88, XP_001826324 Aspergillus oryzae RIB40, XP_002378013 Aspergillus flavus NRRL3357, XP_007813280 Metarhizium acridum CQMa 102, XP_007814548 Metarhizium acridum CQMa 102, XP_007816270 Metarhizium robertsii ARSEF 23, XP_007823686 Metarhizium robertsii ARSEF 23, XP_009262229 Fusarium pseudograminearum CS3096, XP_011320986 Fusarium graminearum PH-1, XP_014541493 Metarhizium brunneum ARSEF 3297, XP_014573710 Metarhizium majus ARSEF 297, XP_015406232 Aspergillus nomius NRRL 13137, XP_016595032 Penicillium expansum 


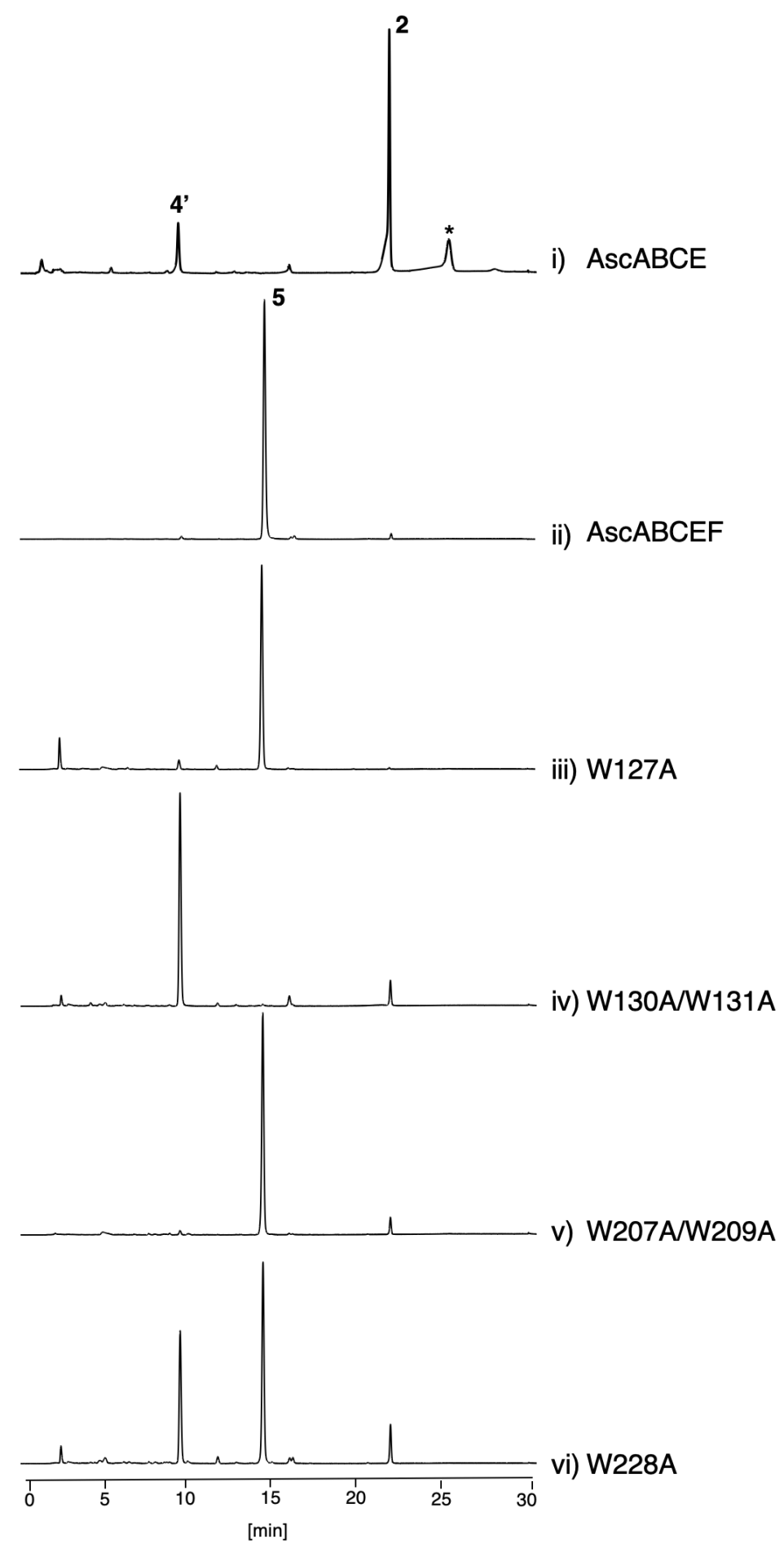

Figure S12. HPLC analysis of the product accumulated in $A$. oryzae/AscABCE i), $A$. oryzae/AscABCEF ii), W127A iii), W130A/W131A iv), W207A/W209A v), W228A vi). UV absorbance was $295 \mathrm{~nm}$. The compound labeled as * is an unidentified compound which has UVmax at 272 and $282 \mathrm{~nm}$. 


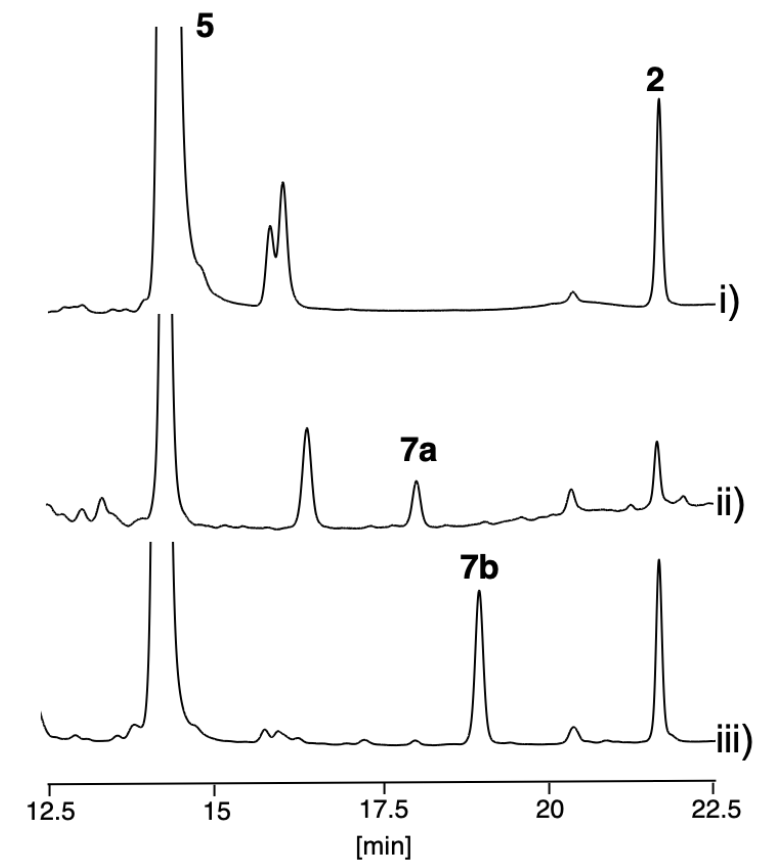

Figure S13. HPLC analysis of the products accumulated in A. oryzae/AscABCEF i), AscABCDEF incubated with $\mathrm{KCl}$ ii), incubated with $\mathrm{KBr}$ iii). UV absorbance was $295 \mathrm{~nm}$.

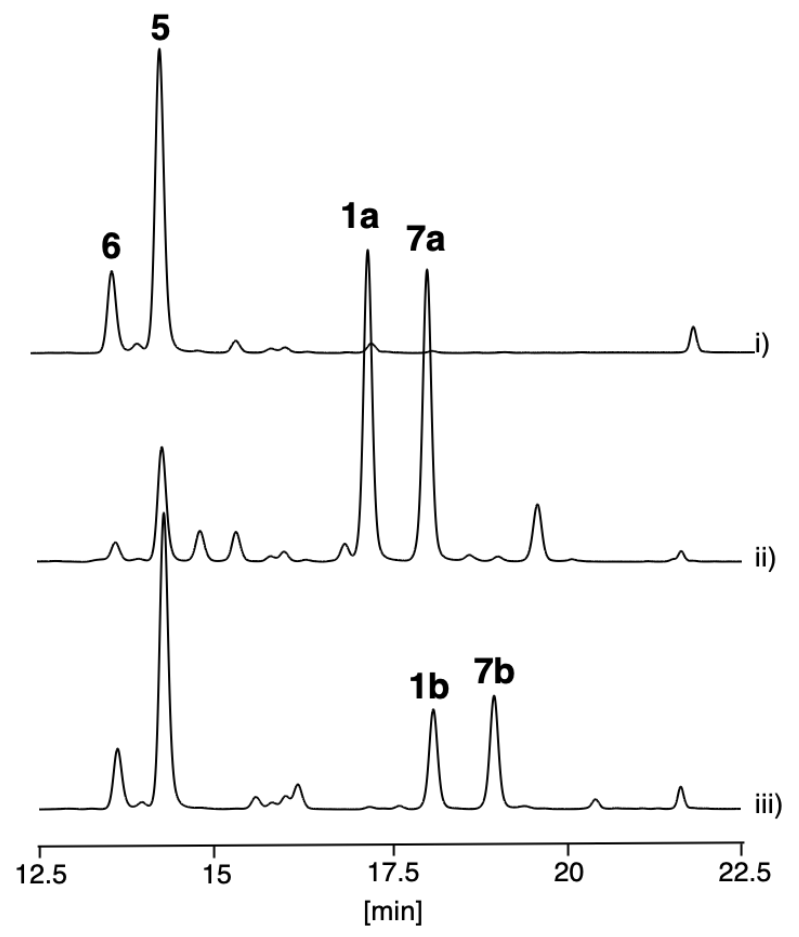

Figure S14. HPLC analysis of the products accumulated in Fusarium sp. incubated without any halogen source i) with $\mathrm{KCl}$ ii), with $\mathrm{KBr}$ iii). UV absorbance was $295 \mathrm{~nm}$. 

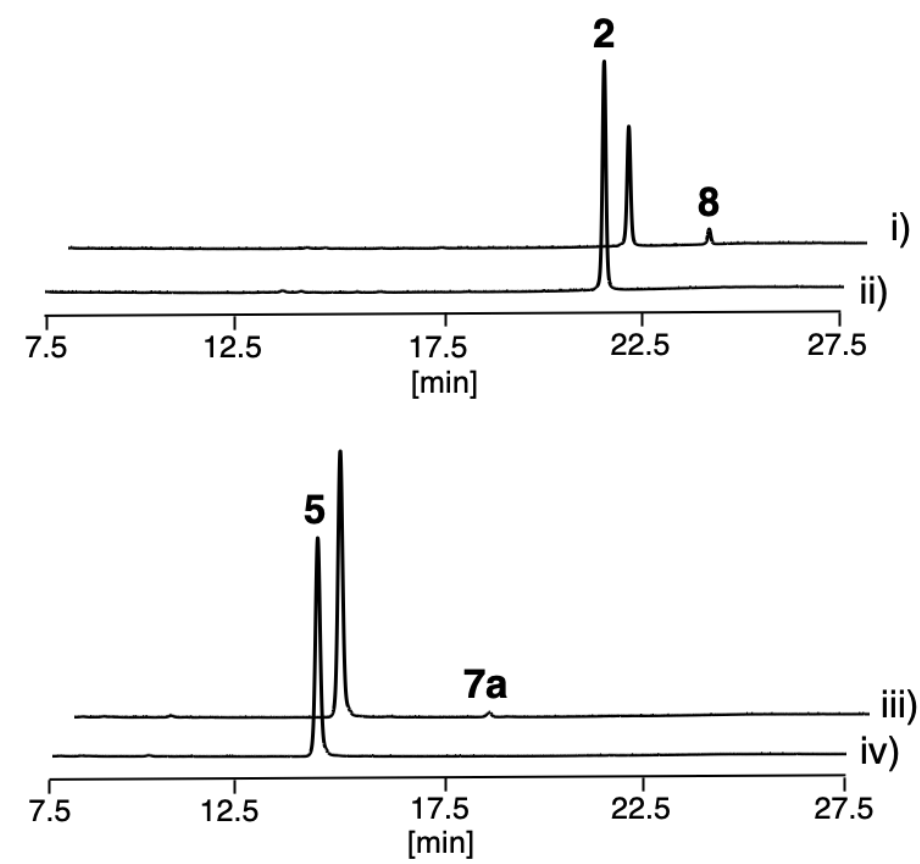

Figure S15. HPLC profile of AscD in vitro assay. 2 was incubated with soluble protein extract from Rosetta2/pET28a-AscD i), and the extract from Rosetta2/pET28 ii), and 5 was incubated with soluble protein extract from Rosetta2/pET28a-AscD iii), and the extract from Rosetta2/pET28 iv). The chromatograms were monitored at $295 \mathrm{~nm}$.

A)

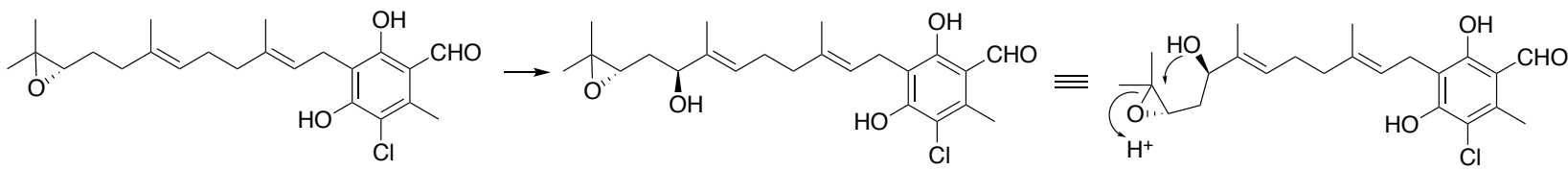

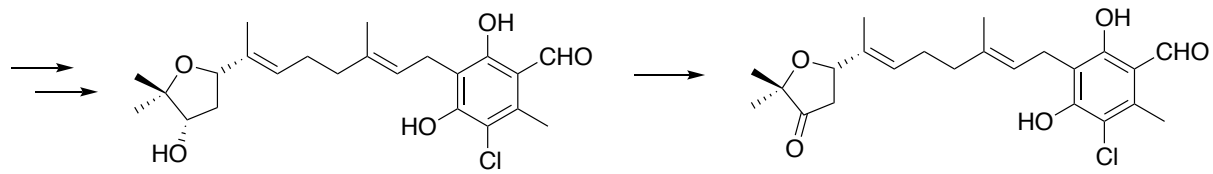

ascofuranol

ascofuranone

B)<smiles>C=C1CCCC(C)(C)[C@H]1CC[C@H]1CCc2c(cc(C)c(C(=O)O)c2O)O1</smiles>

Figure S16. The biosynthetic pathway of ascofuranone (A) and putative pathway of siccanochromenic acid (B) 
A)

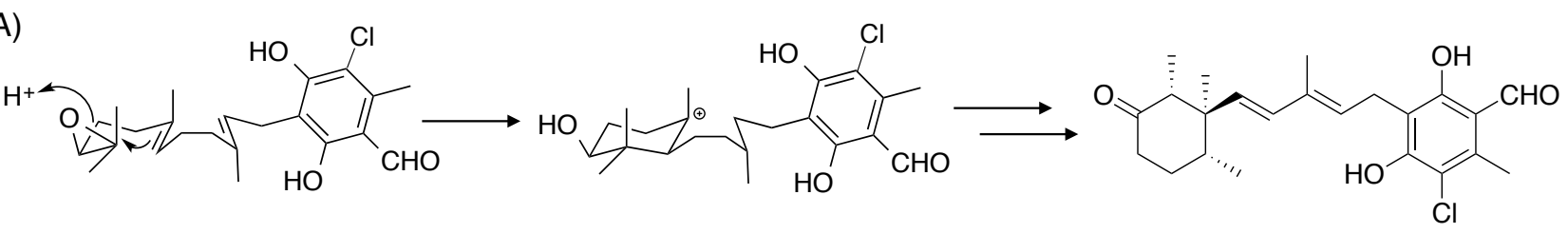

B)

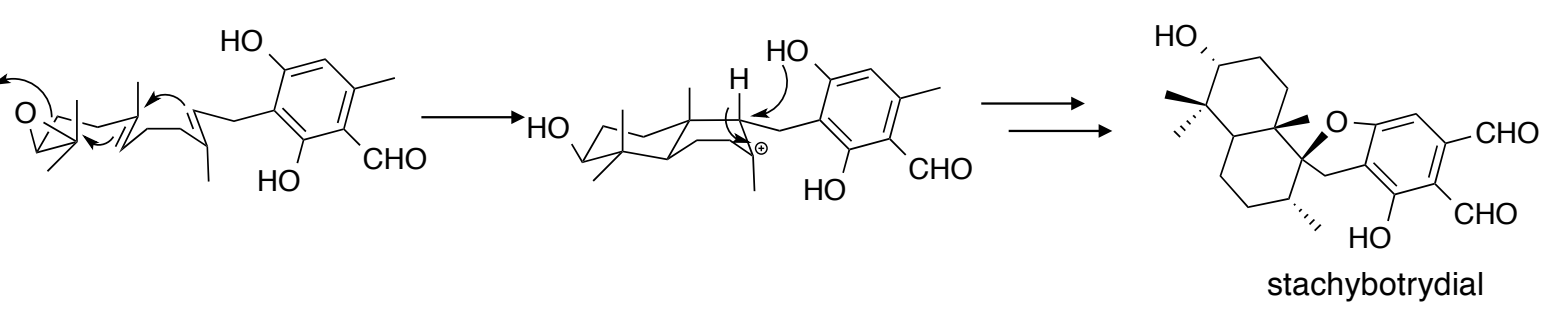

Figure S17. Comparison of terpene cyclization between ascochlorin and stachybotrydial 


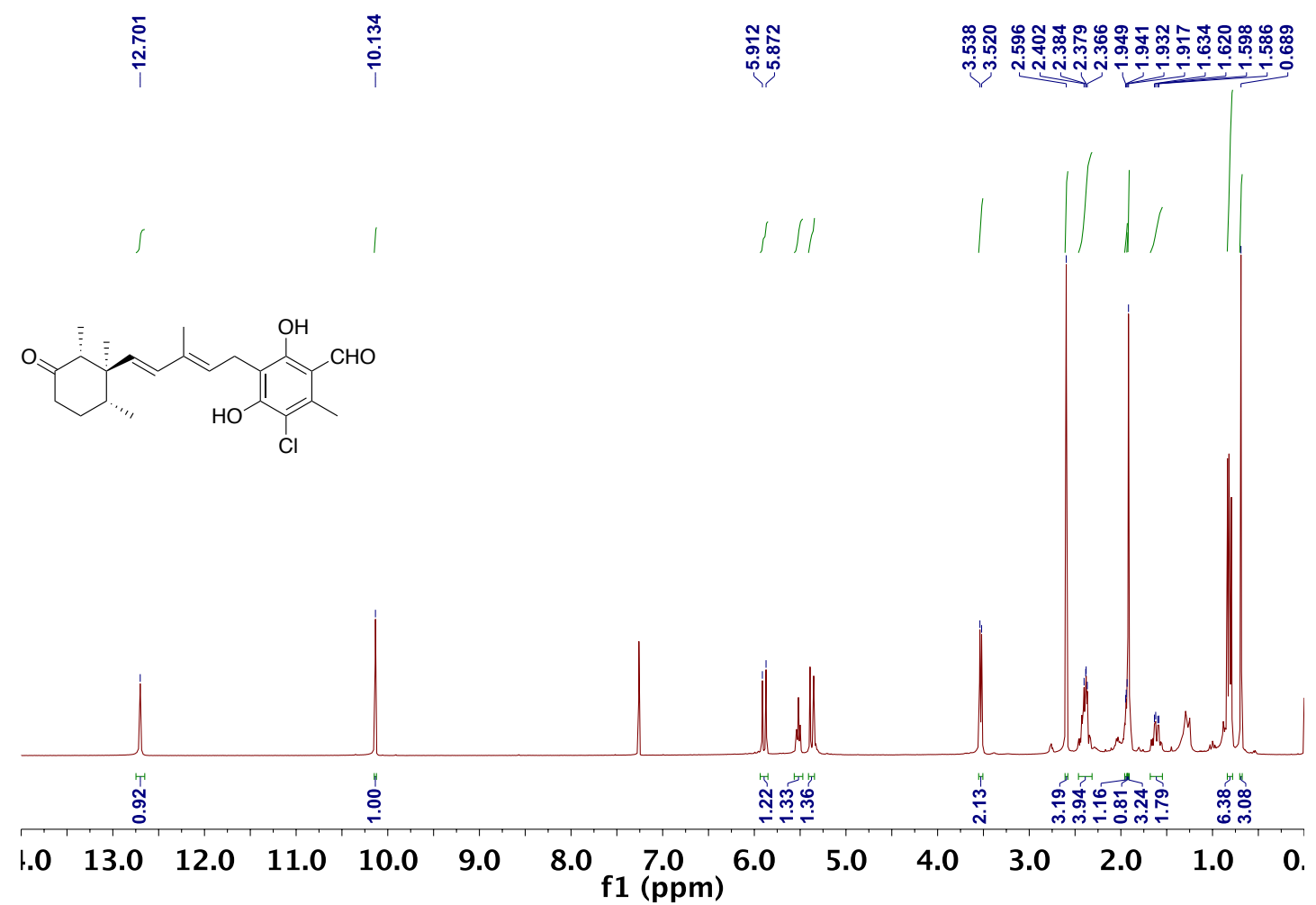

Figure S18. 'H NMR spectrum of ascochlorin (1a)

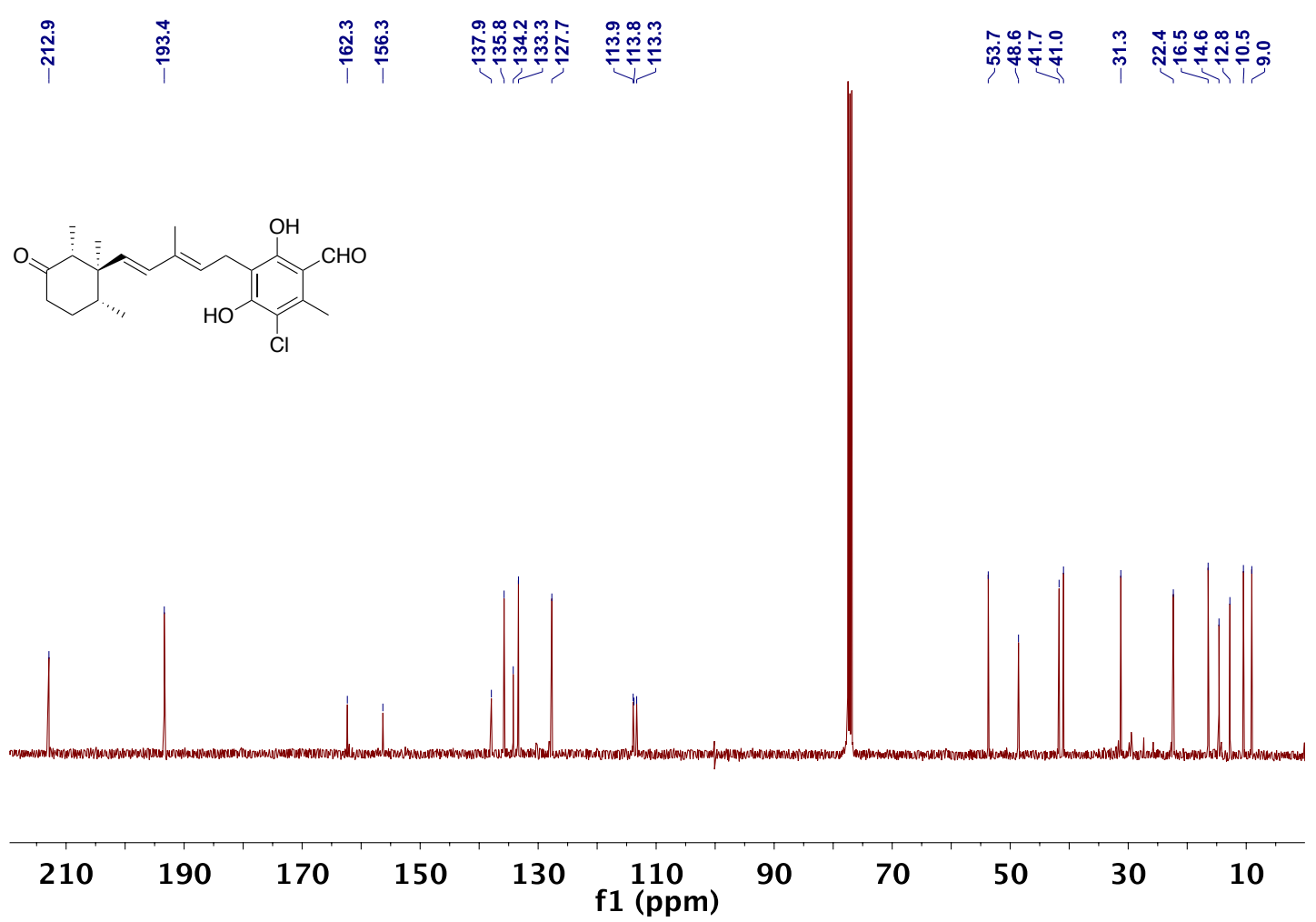

Figure S19. "C NMR spectrum of ascochlorin (1a) 


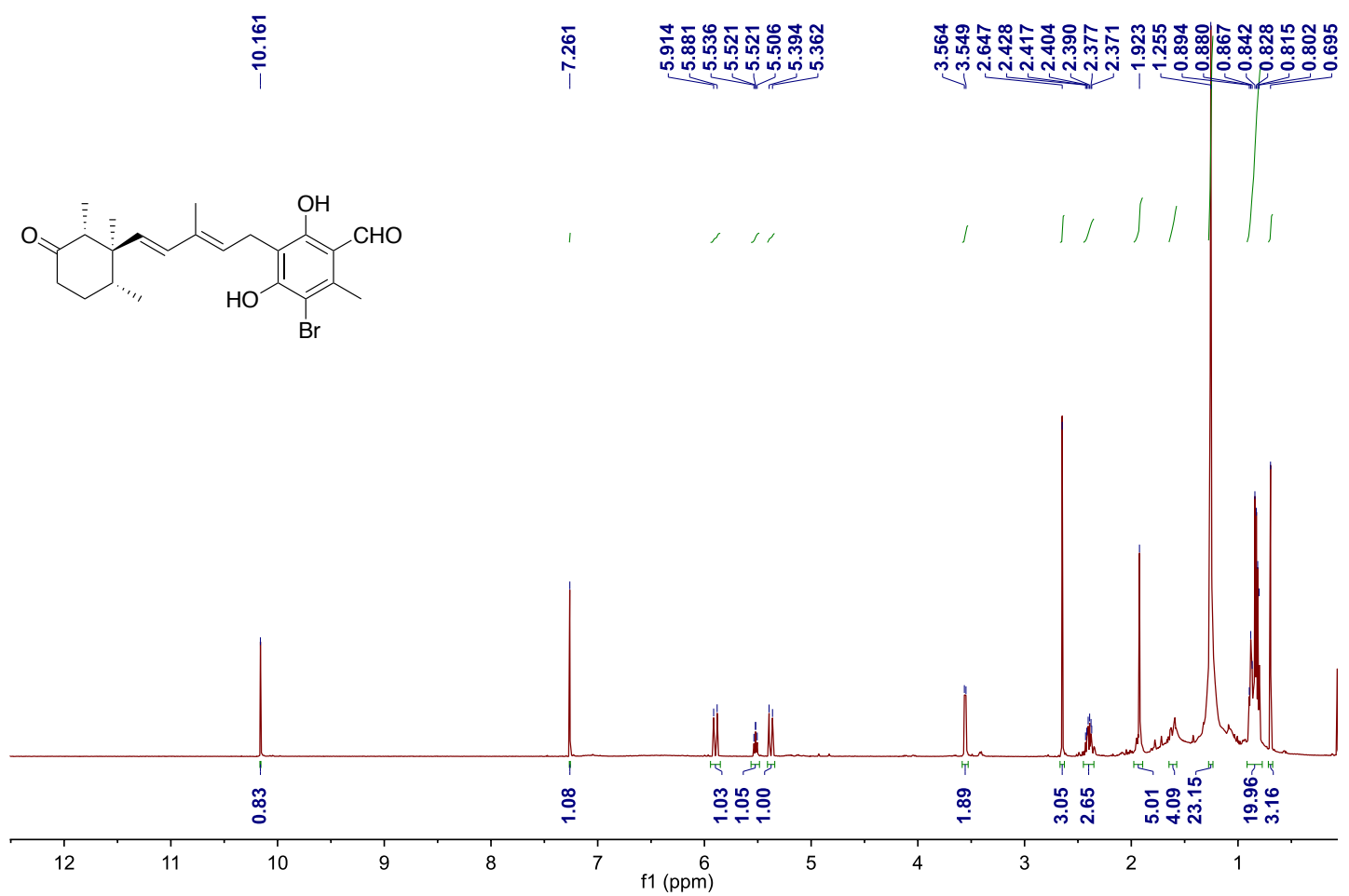

Figure S20. 'H NMR spectrum of 3-bromoascochlorin (1b)
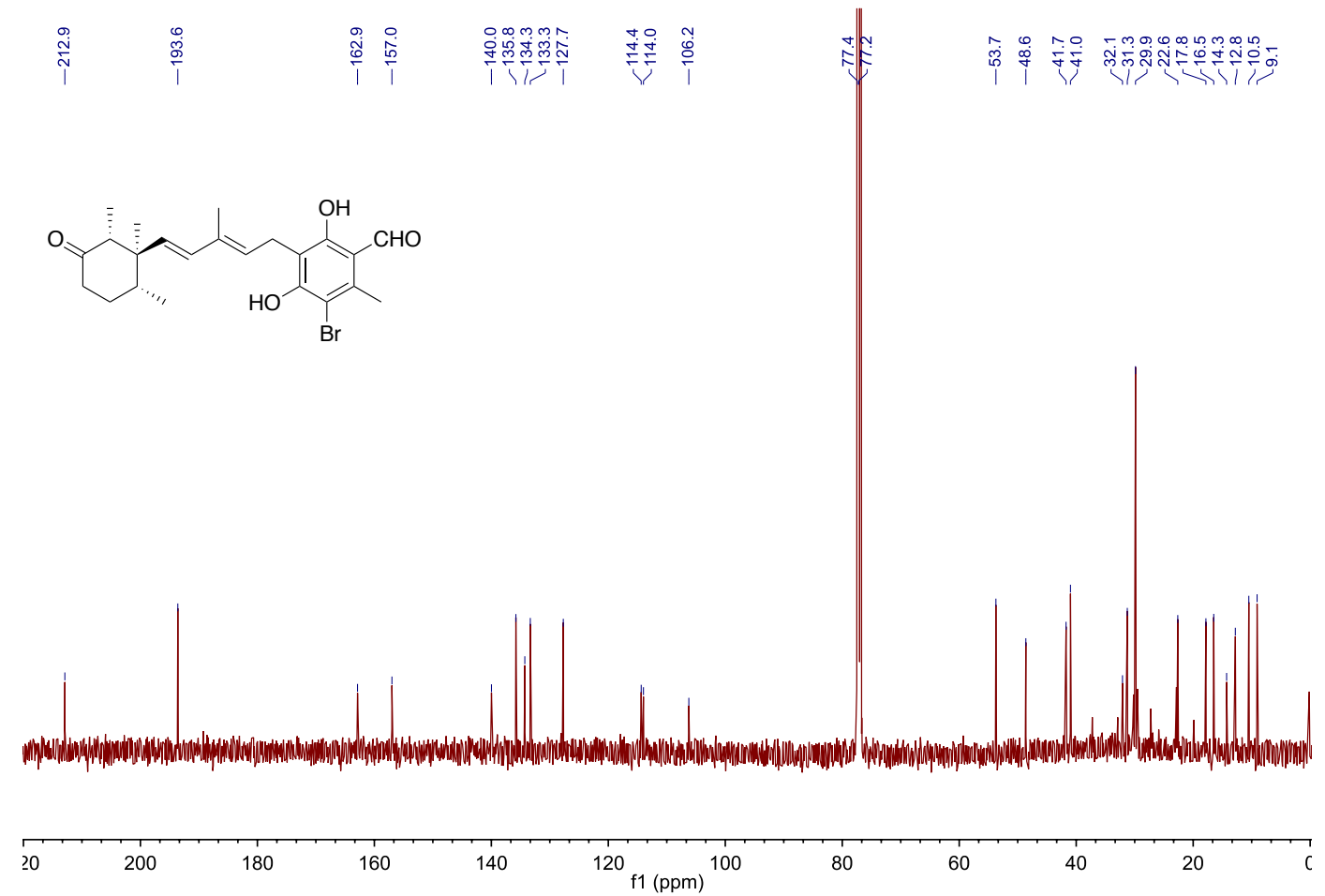

Figure S21. ${ }^{13}$ C NMR spectrum of 3-bromoascochlorin (1b) 


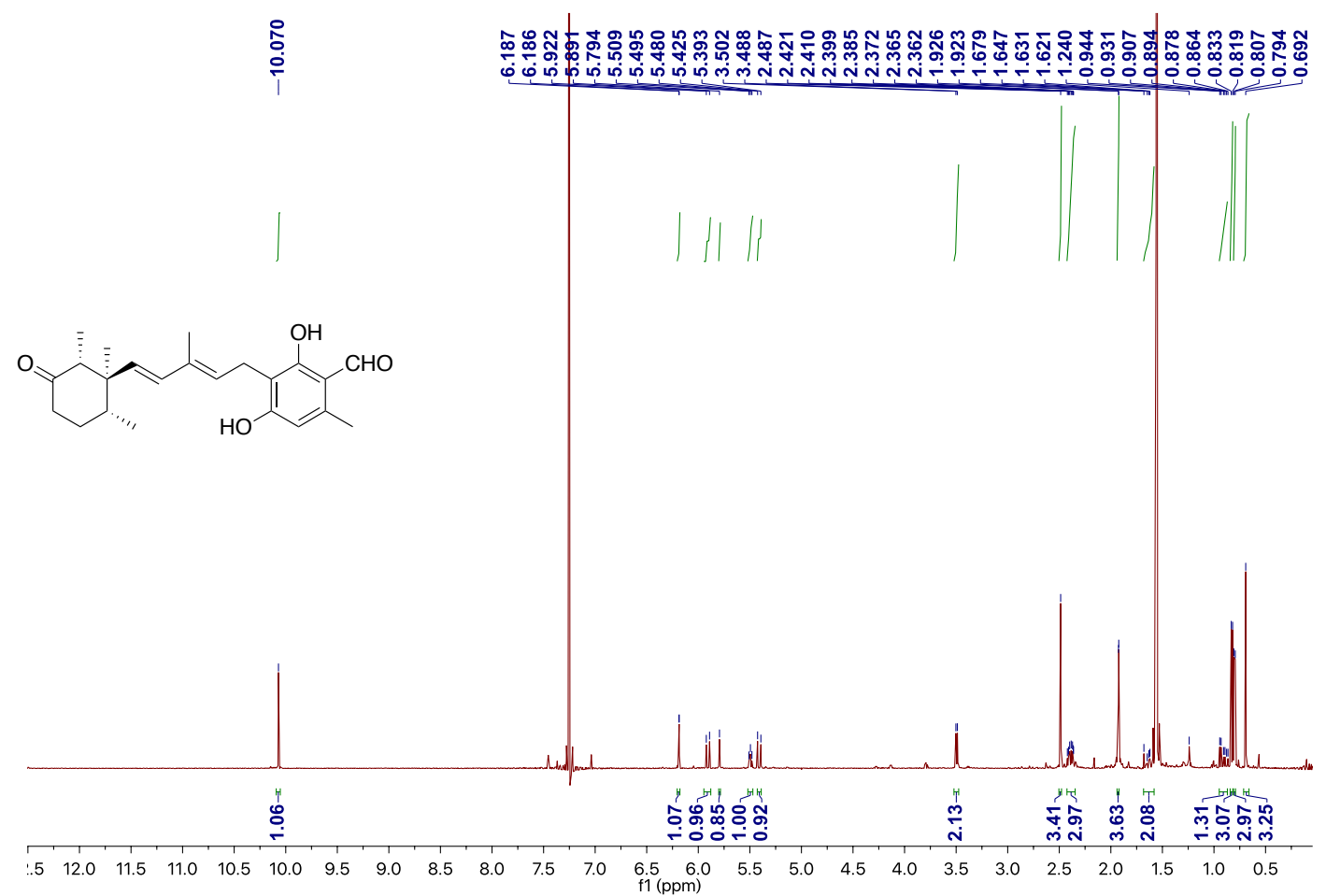

Figure S22. 'H NMR spectrum of dechloroascochlorin (6)

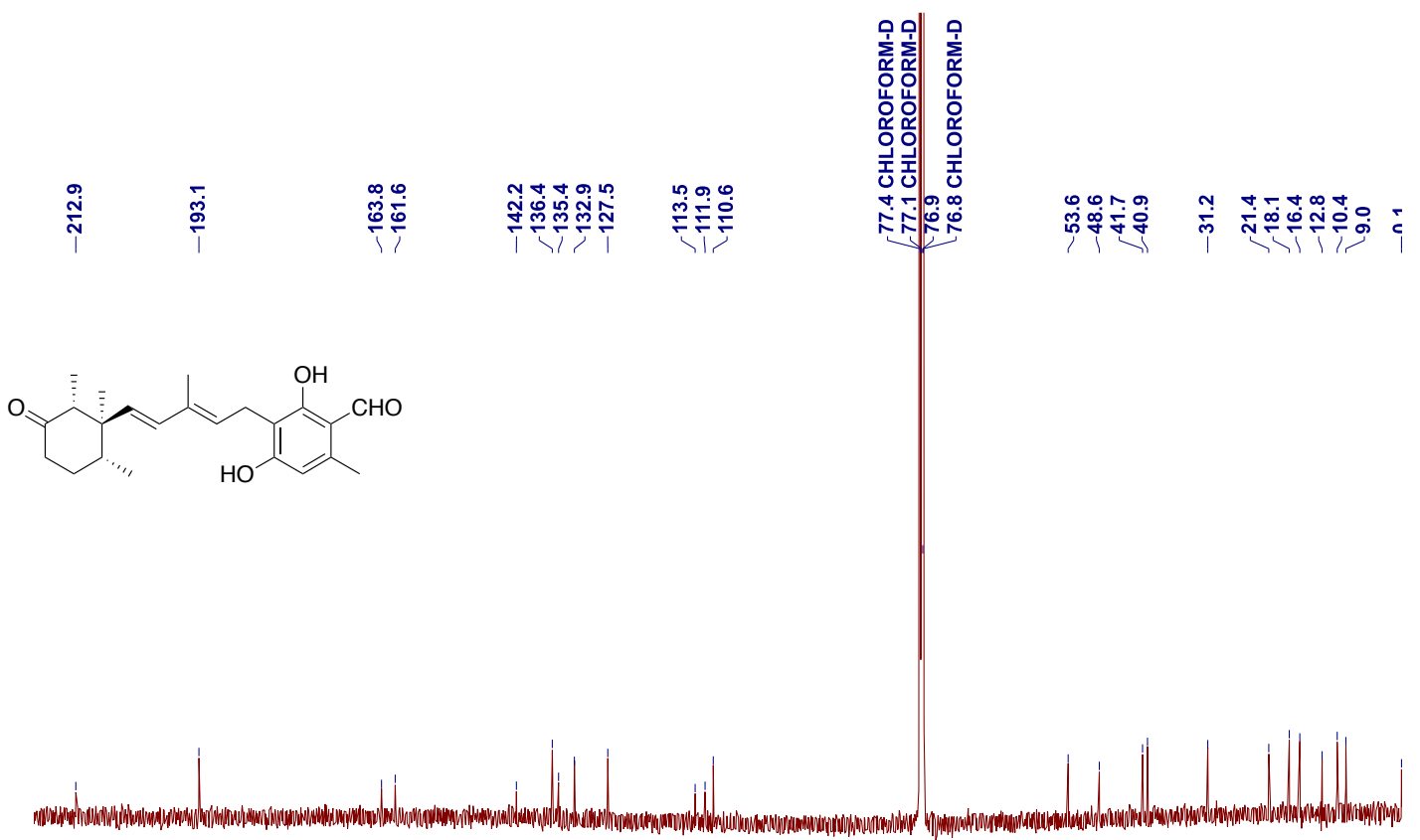

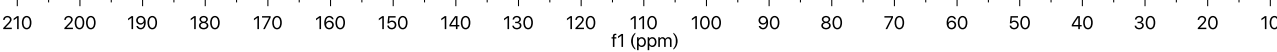

Figure S23. ${ }^{13} \mathrm{C}$ NMR spectrum of dechloroascochlorin (6) 


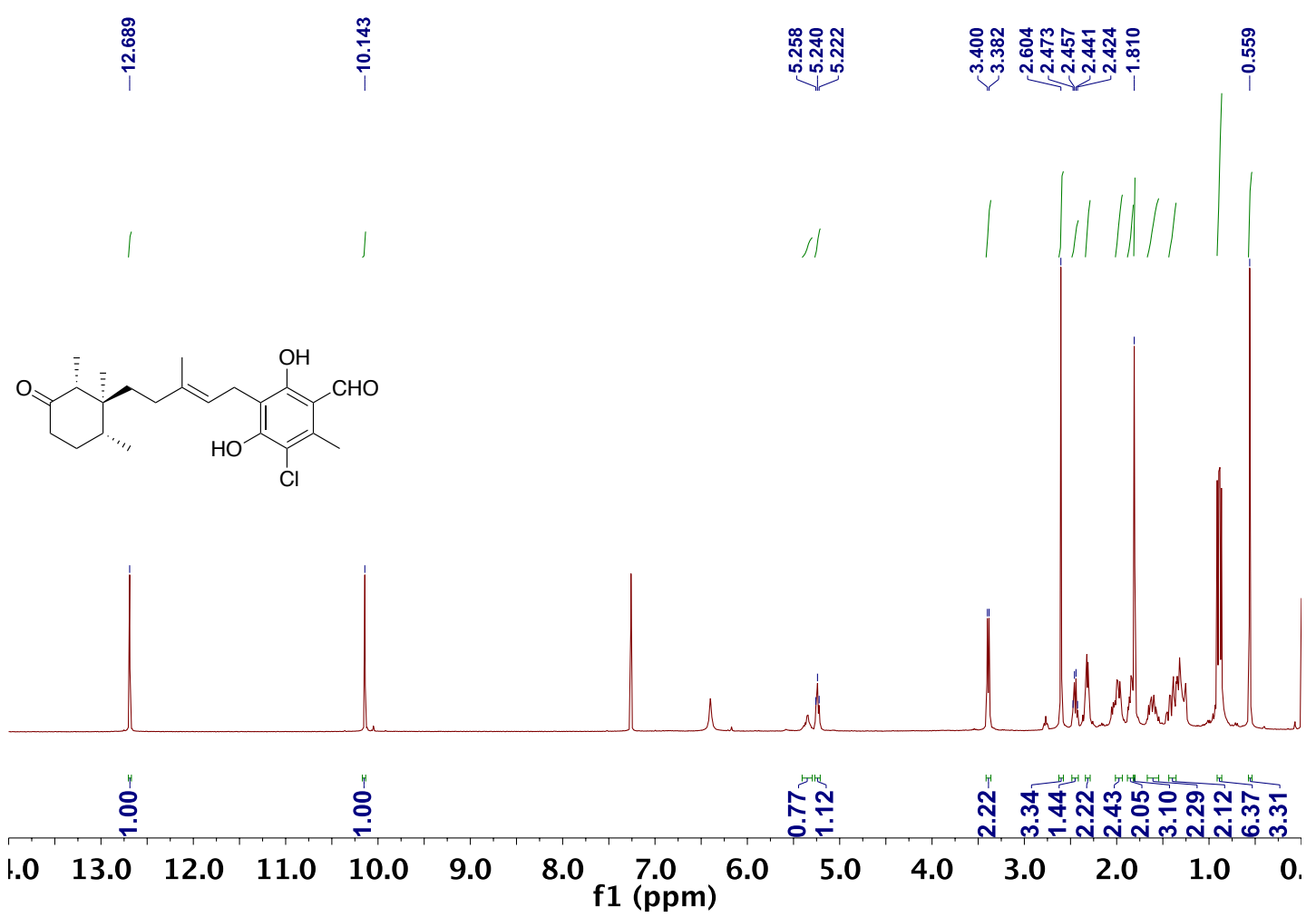

Figure S24. 'H NMR spectrum of 12,13-dihydroascochlorin (7a)
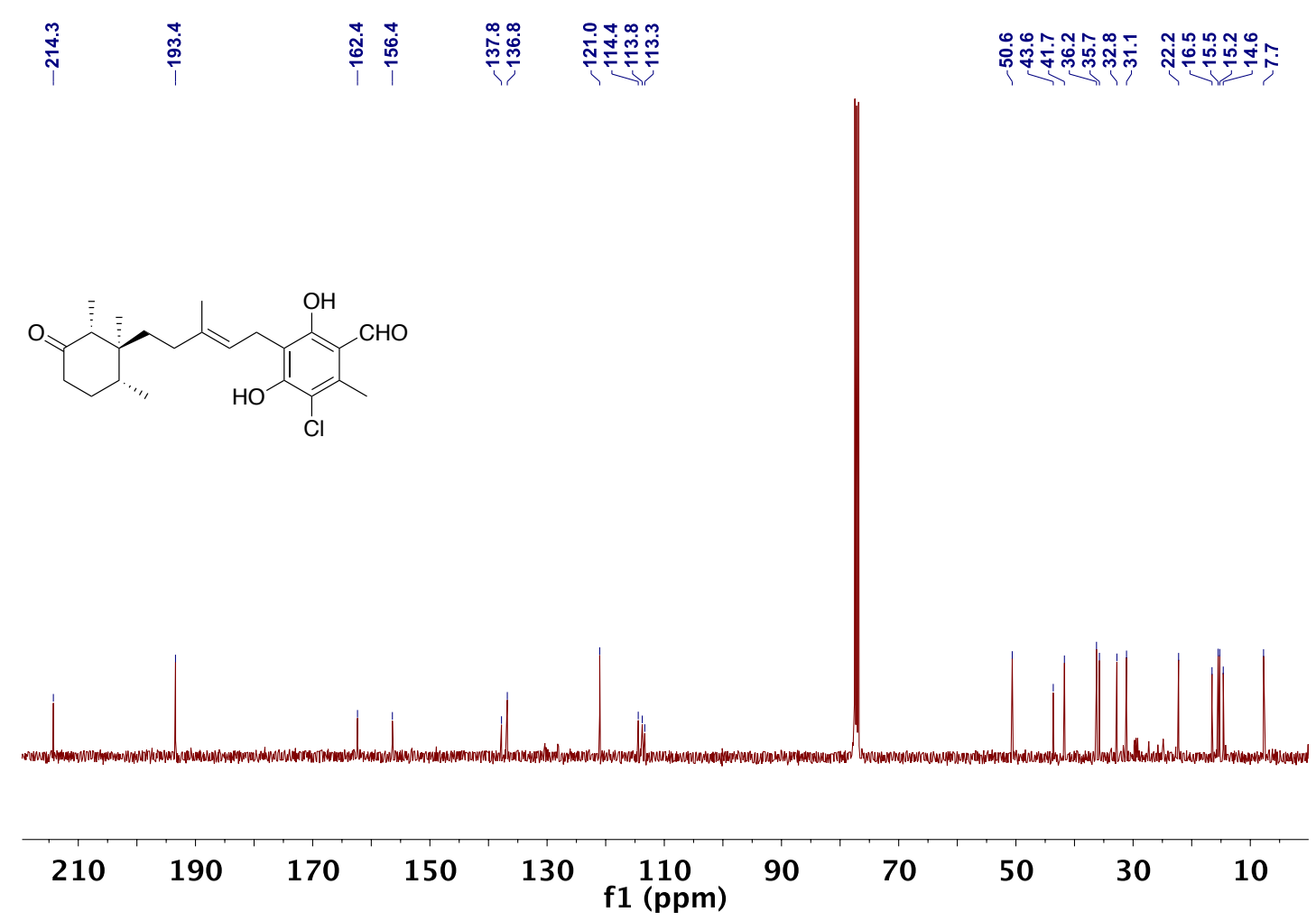

Figure S25. ${ }^{\text {C }}$ NMR spectrum of 12,13-dihydroascochlorin (7a) 


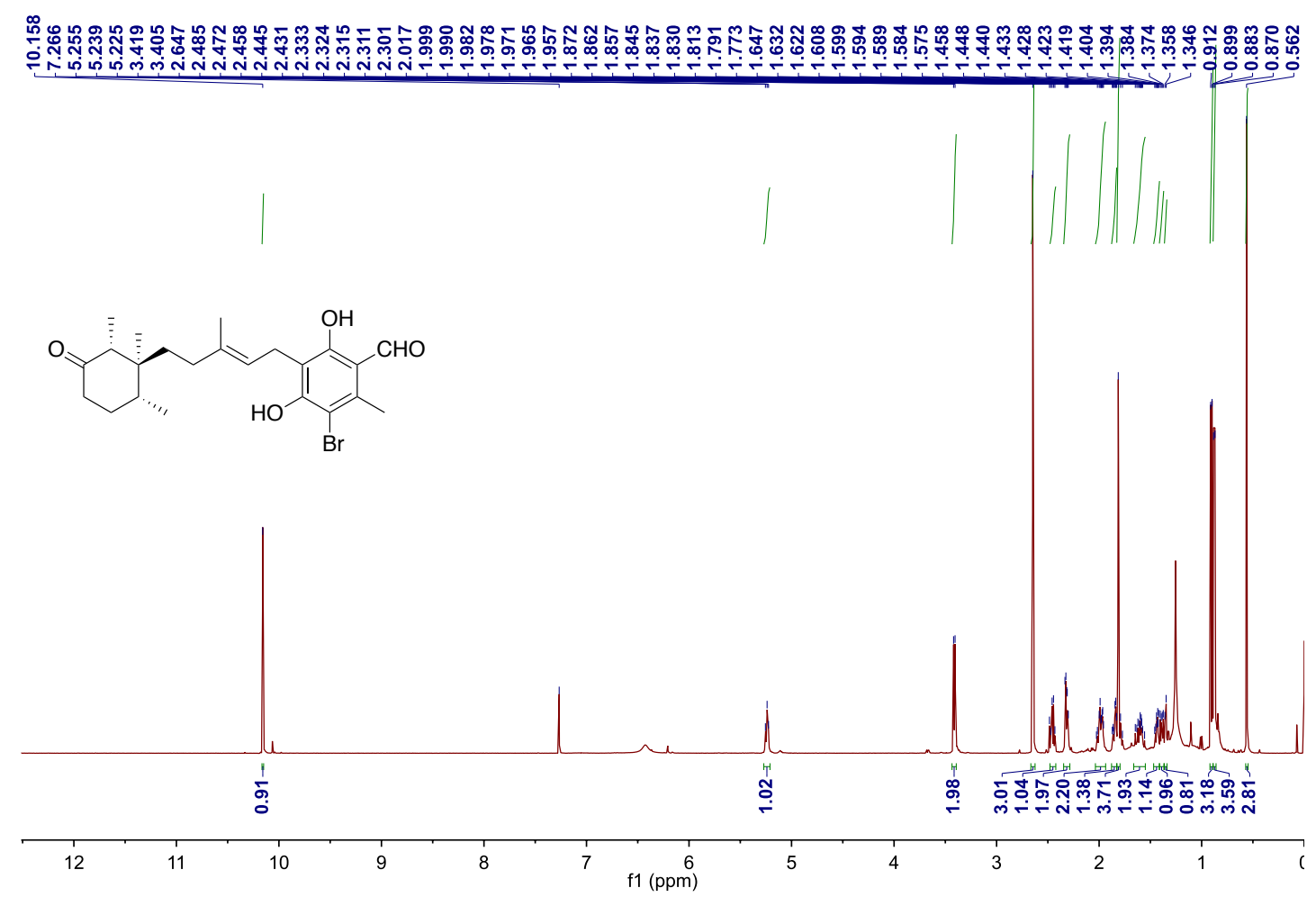

Figure S26. 'H NMR spectrum of 3-bromo-12,13-dihydroascochlorin (7b)
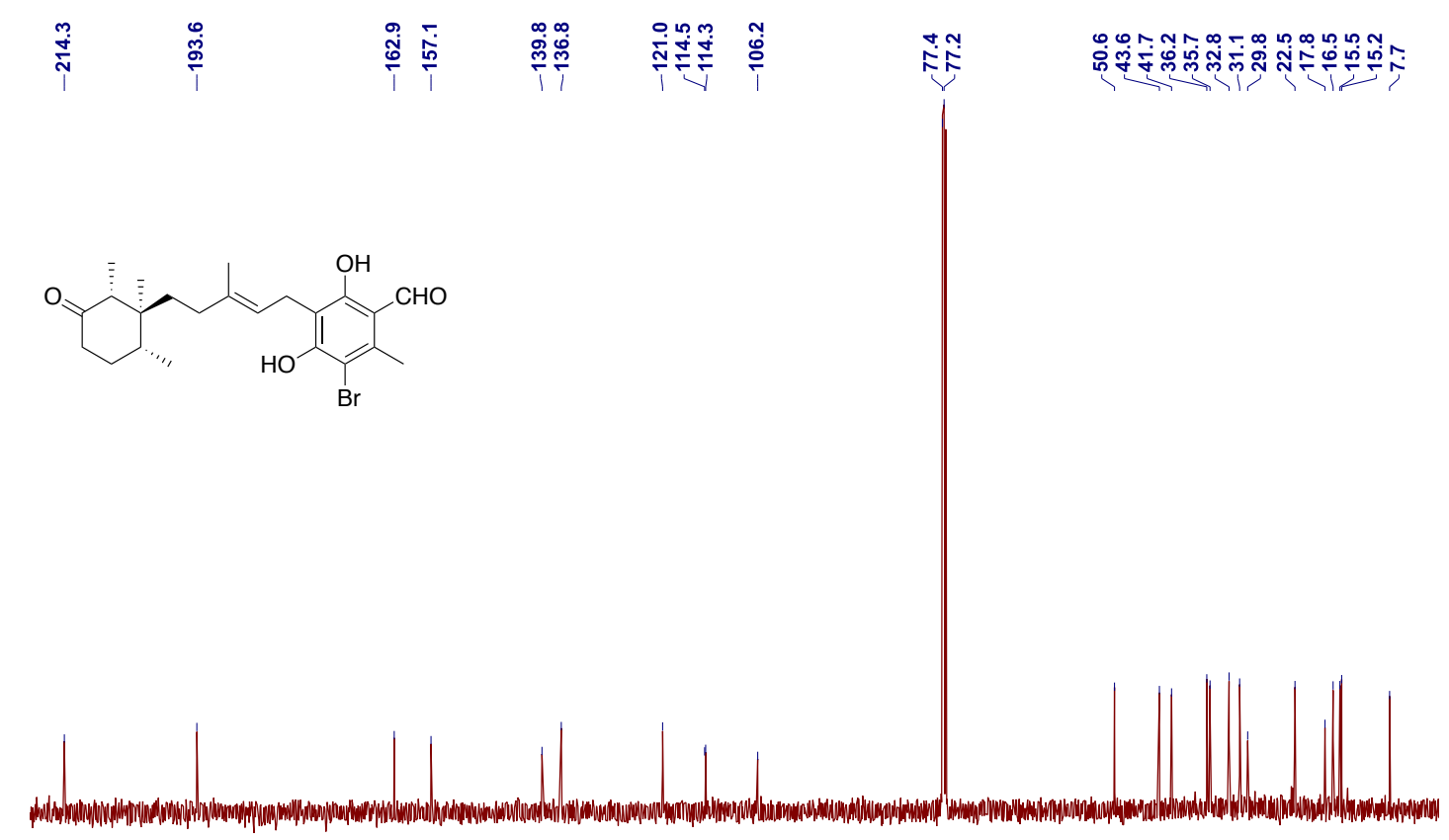

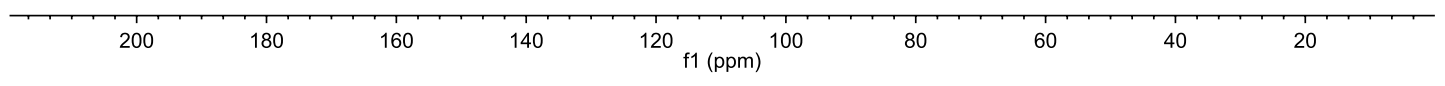

Figure S27. ${ }^{1} \mathrm{C}$ NMR spectrum of 3-bromo-12,13-dihydroascochlorin (7b) 


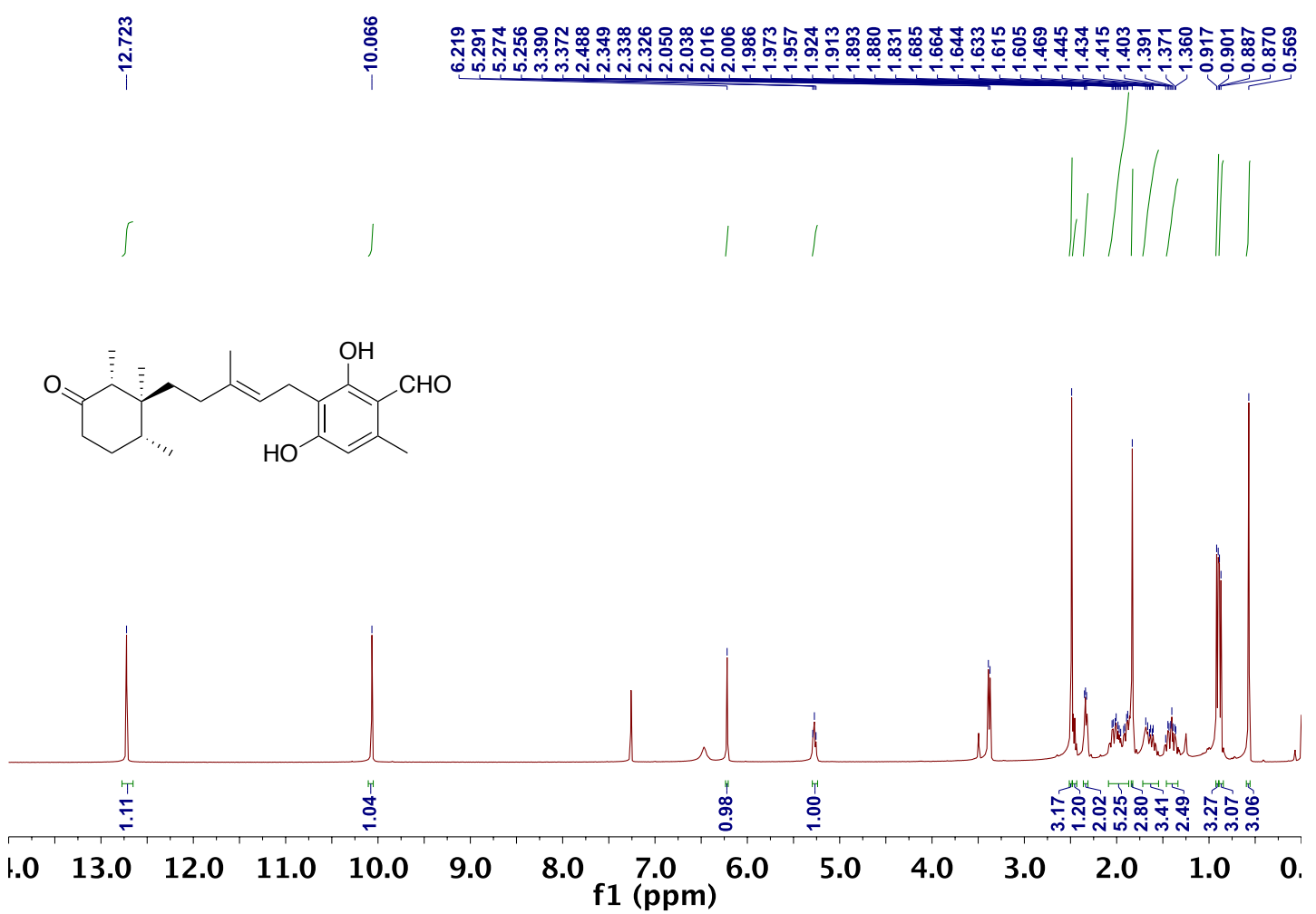

Figure S28. 'H NMR spectrum of dechloro-12,13-dihydroascochlorin (5)
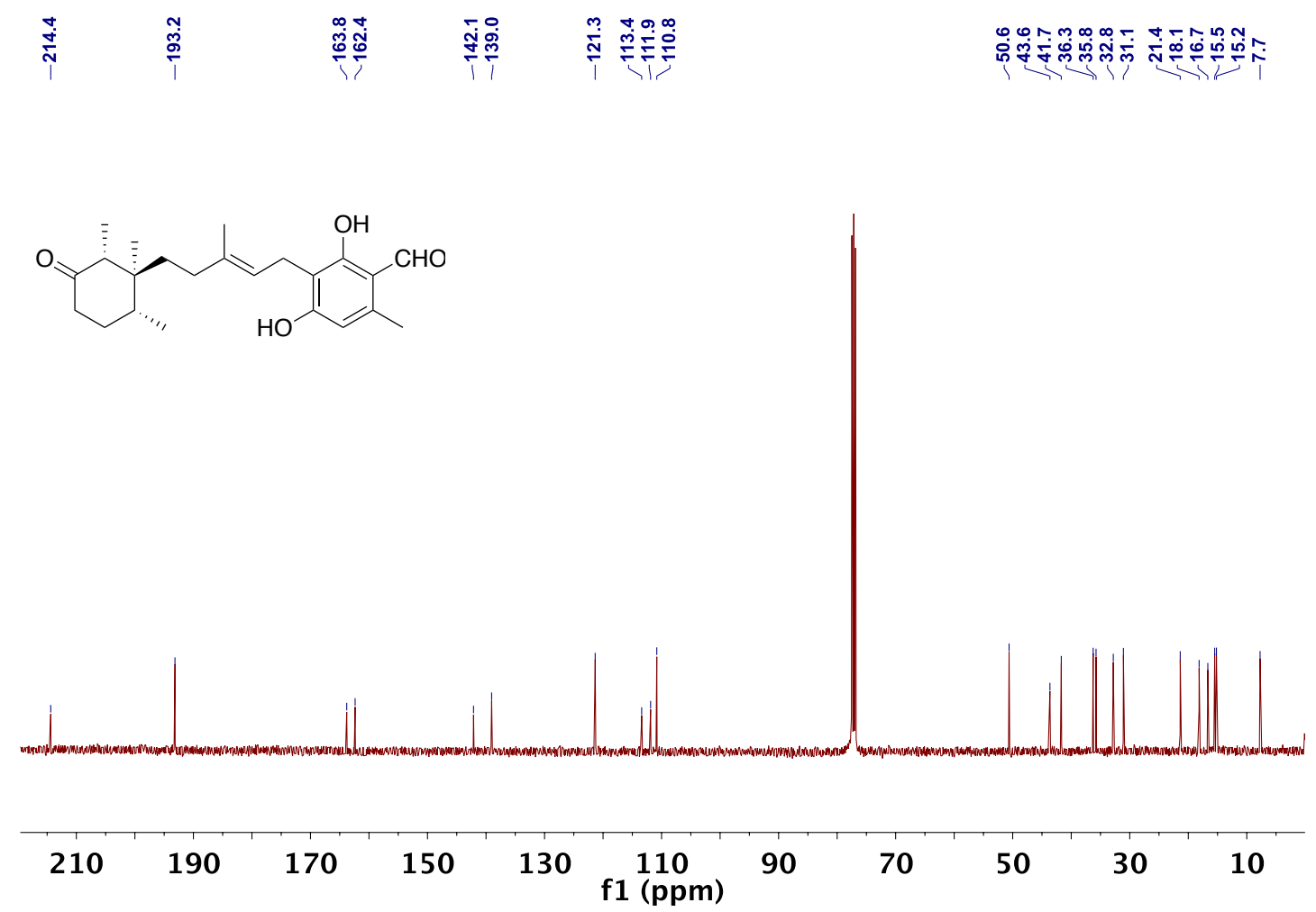

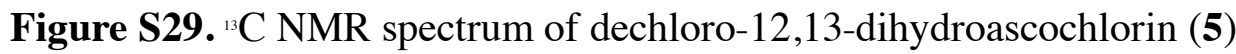




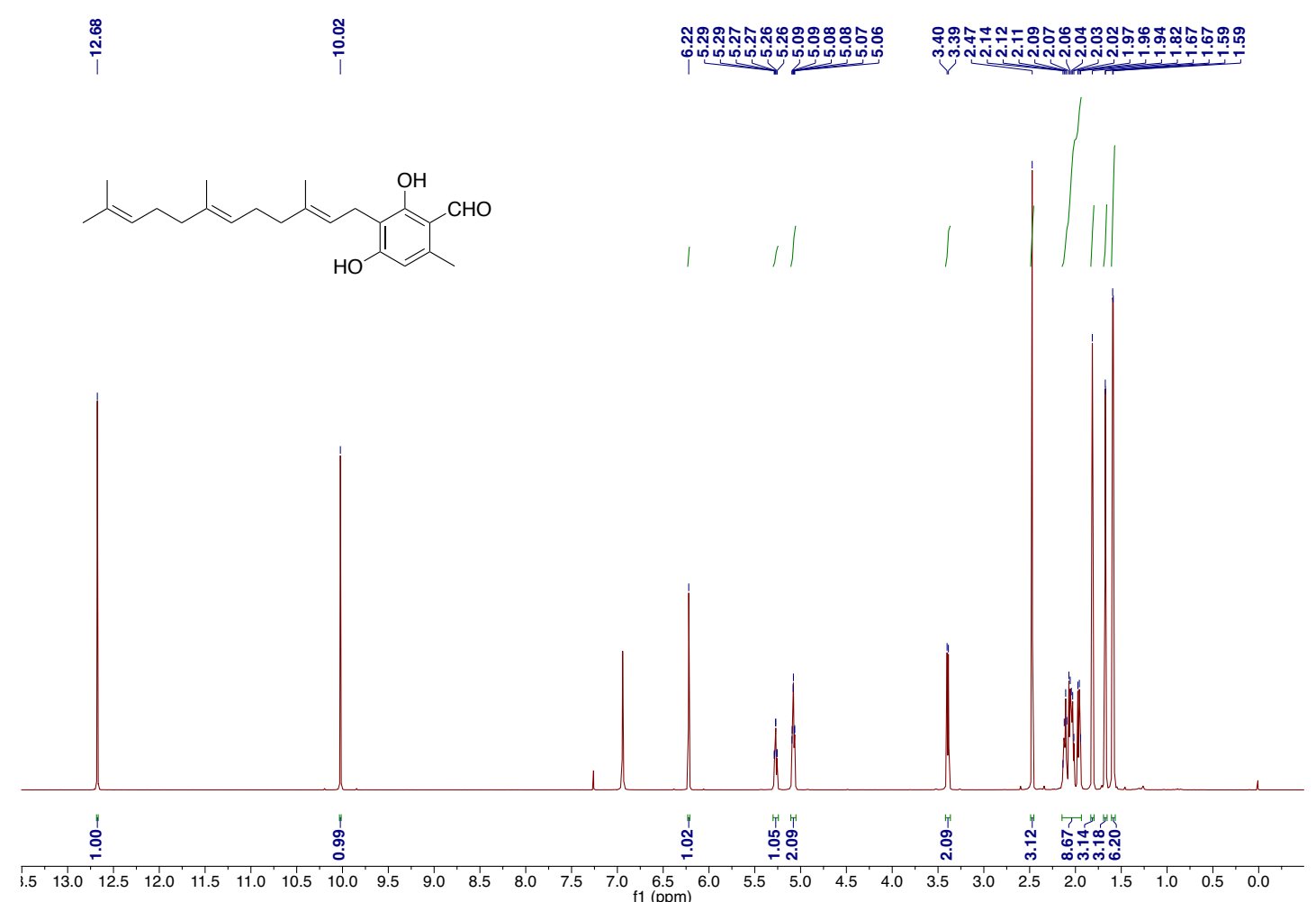

Figure S30. 'H NMR spectrum of LL-Z1272 $\beta$ (2)
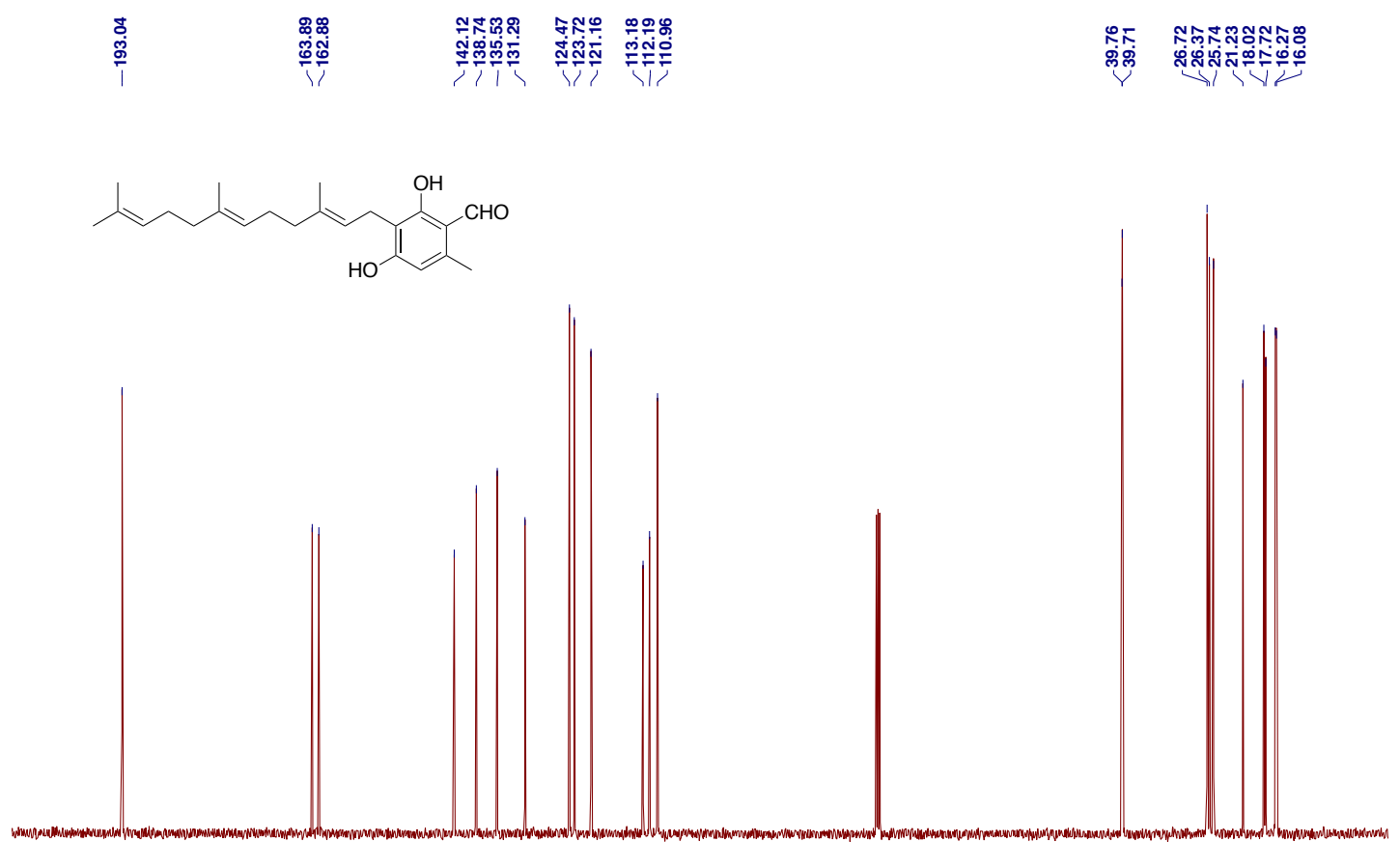

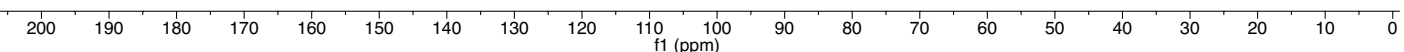

Figure S31. ${ }^{13} \mathrm{C}$ NMR spectrum of LL-Z1272 $\beta$ (2) 

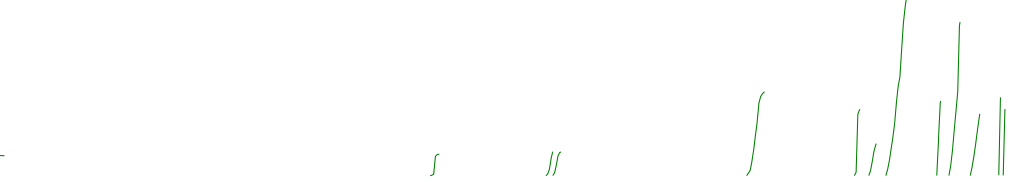<smiles>C/C(=C\CC[C@H](O)C(C)(C)O)CC/C=C(\C)Cc1c(O)cc(C)c(C=O)c1O</smiles>

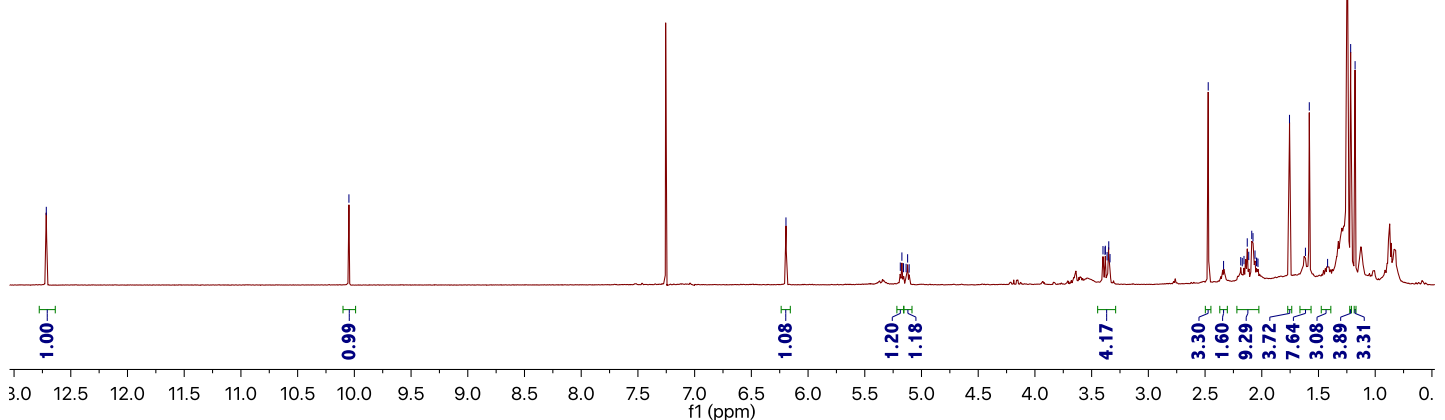

Figure S32. 'H NMR spectrum of cylindrocarpol (4')
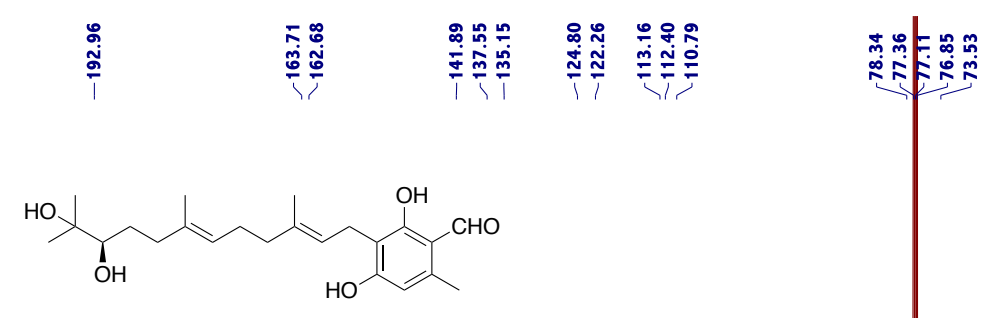

พิ่

กิำ
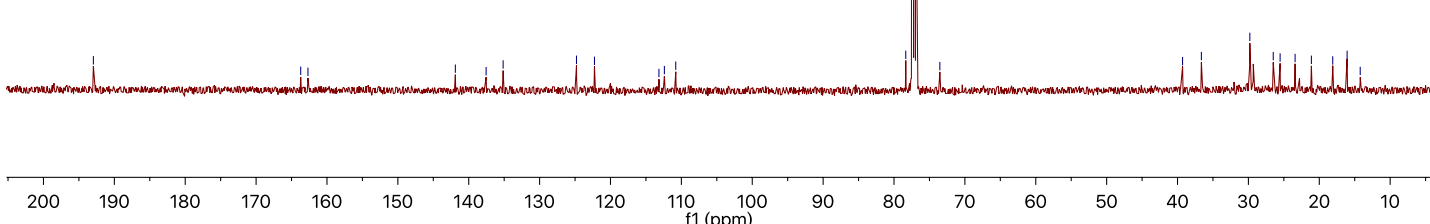

Figure S33. ${ }^{13} \mathrm{C}$ NMR spectrum of cylindrocarpol (4') 


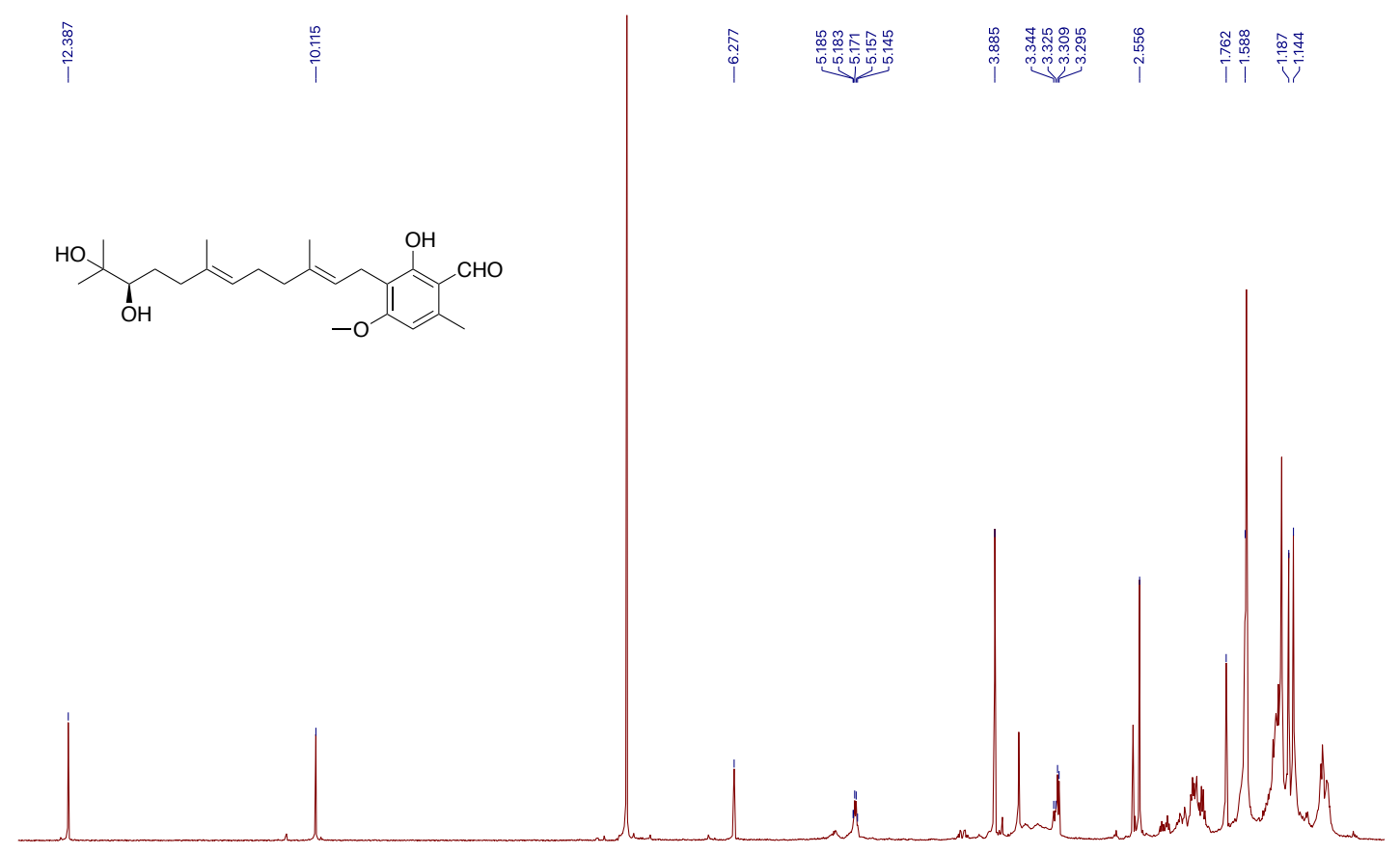

$\begin{array}{lllllllllllllllllllllllllll}12.5 & 12.0 & 11.5 & 11.0 & 10.5 & 10.0 & 9.5 & 9.0 & 8.5 & 8.0 & 7.5 & 7.0 & 6.5 & 6.0 & 5.5 & 5.0 & 4.5 & 4.0 & 3.5 & 3.0 & 2.5 & 2.0 & 1.5 & 1.0 & 0.5\end{array}$

Figure S34. 'H NMR spectrum of 4- $O$-methylated-4'

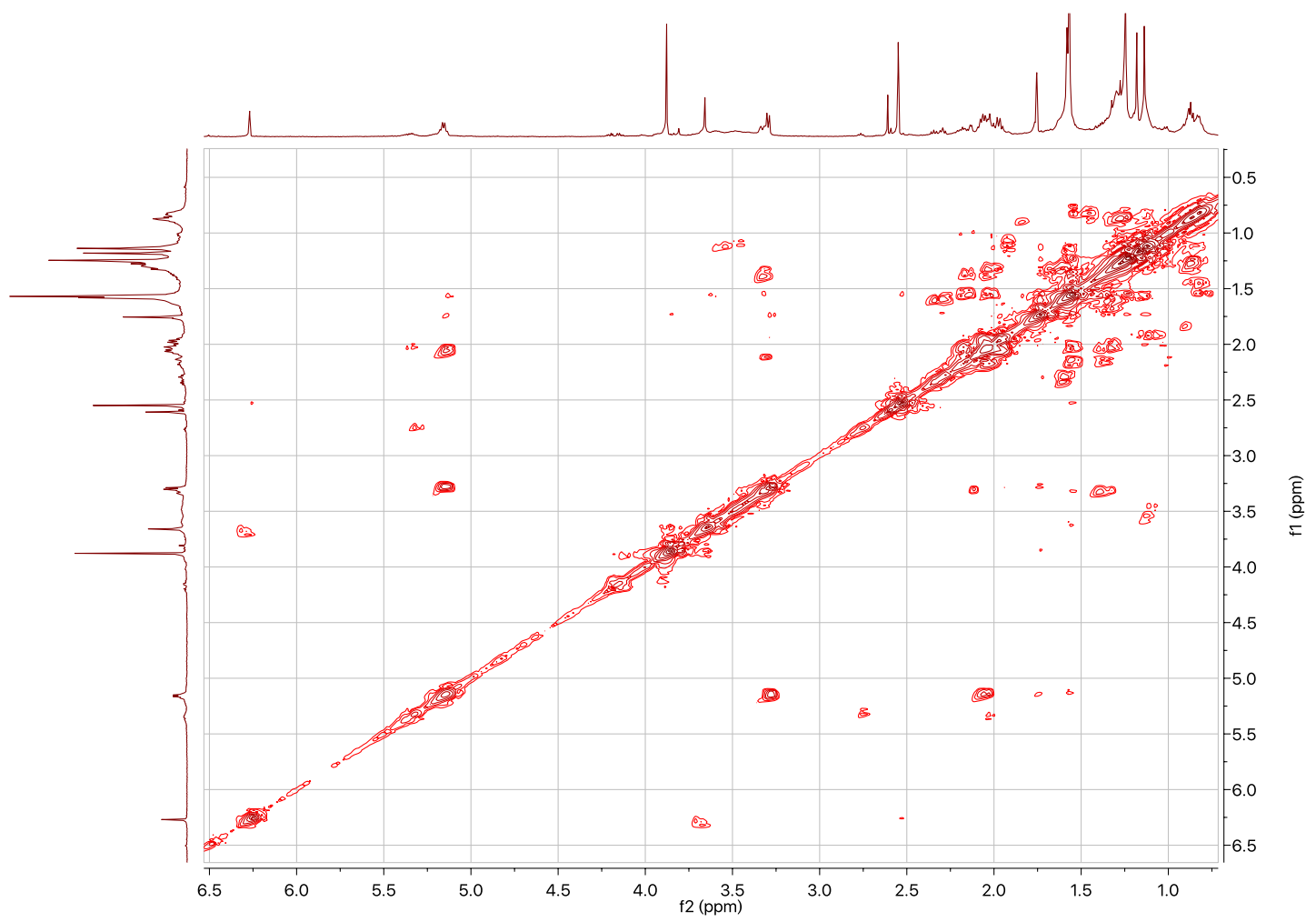

Figure S35. COSY spectrum of 4-O-methylated-4' 


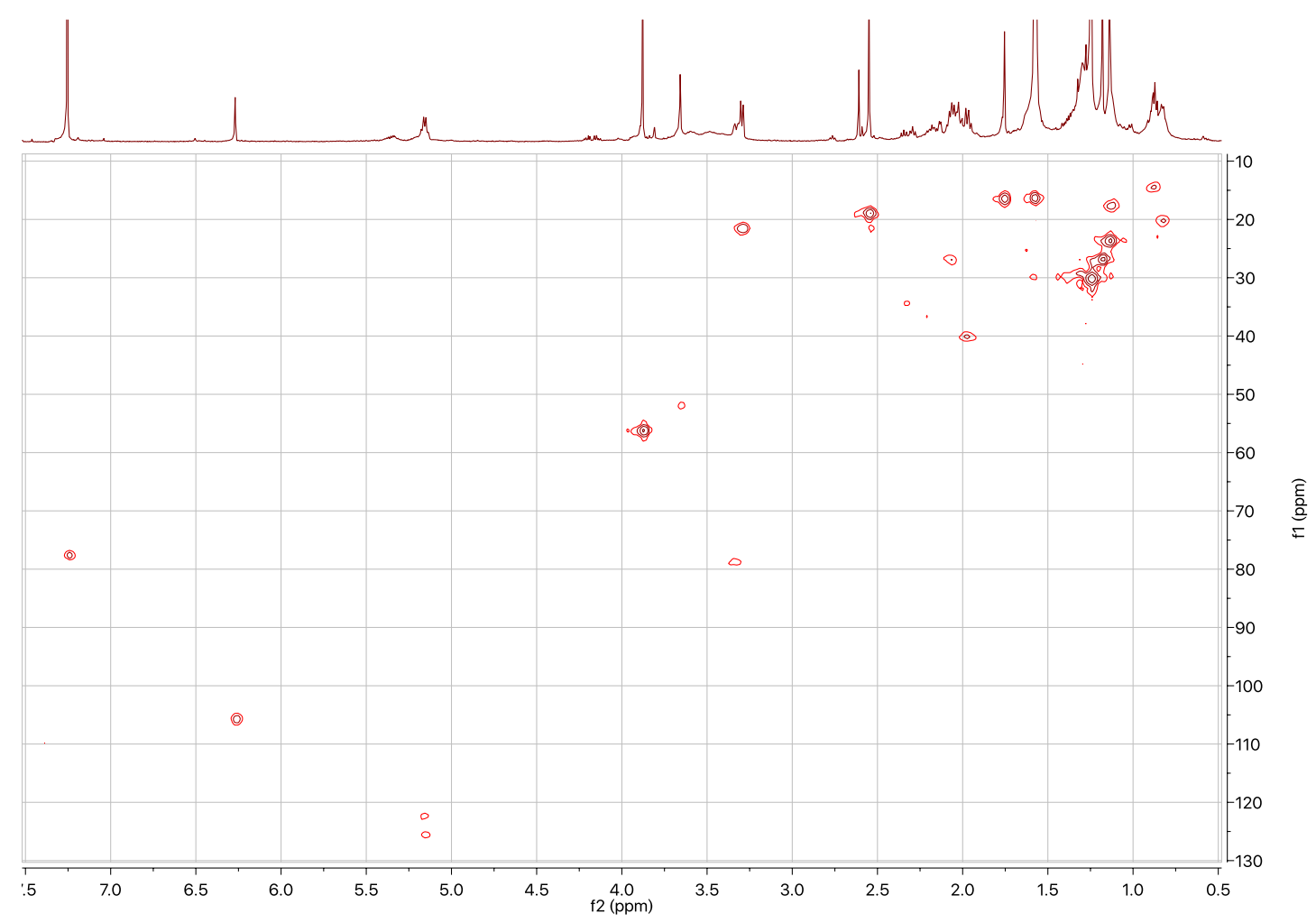

Figure S36. HMQC spectrum of 4- $O$-methylated-4'

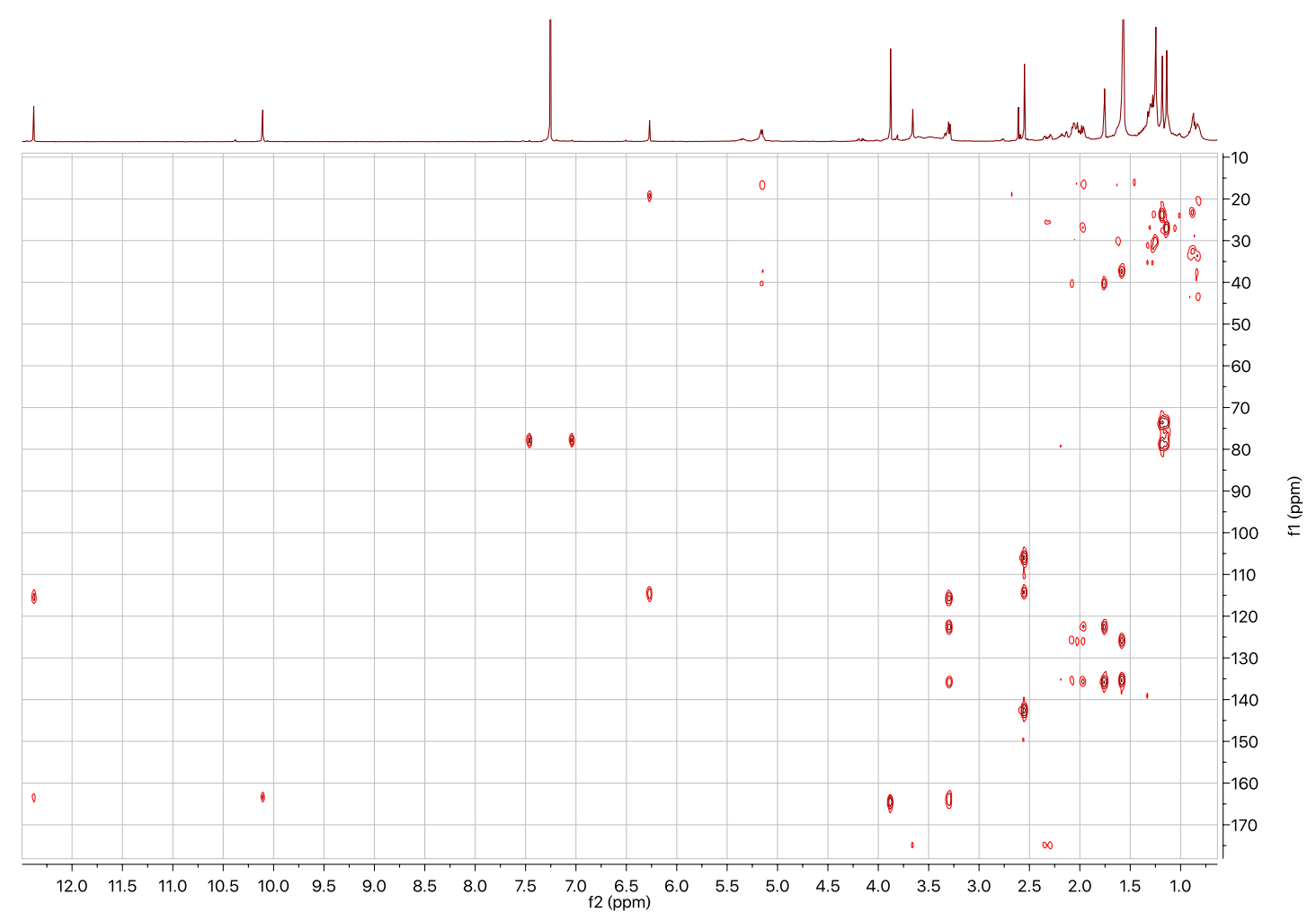

Figure S37. HMBC spectrum of 4- $O$-methylated-4' 


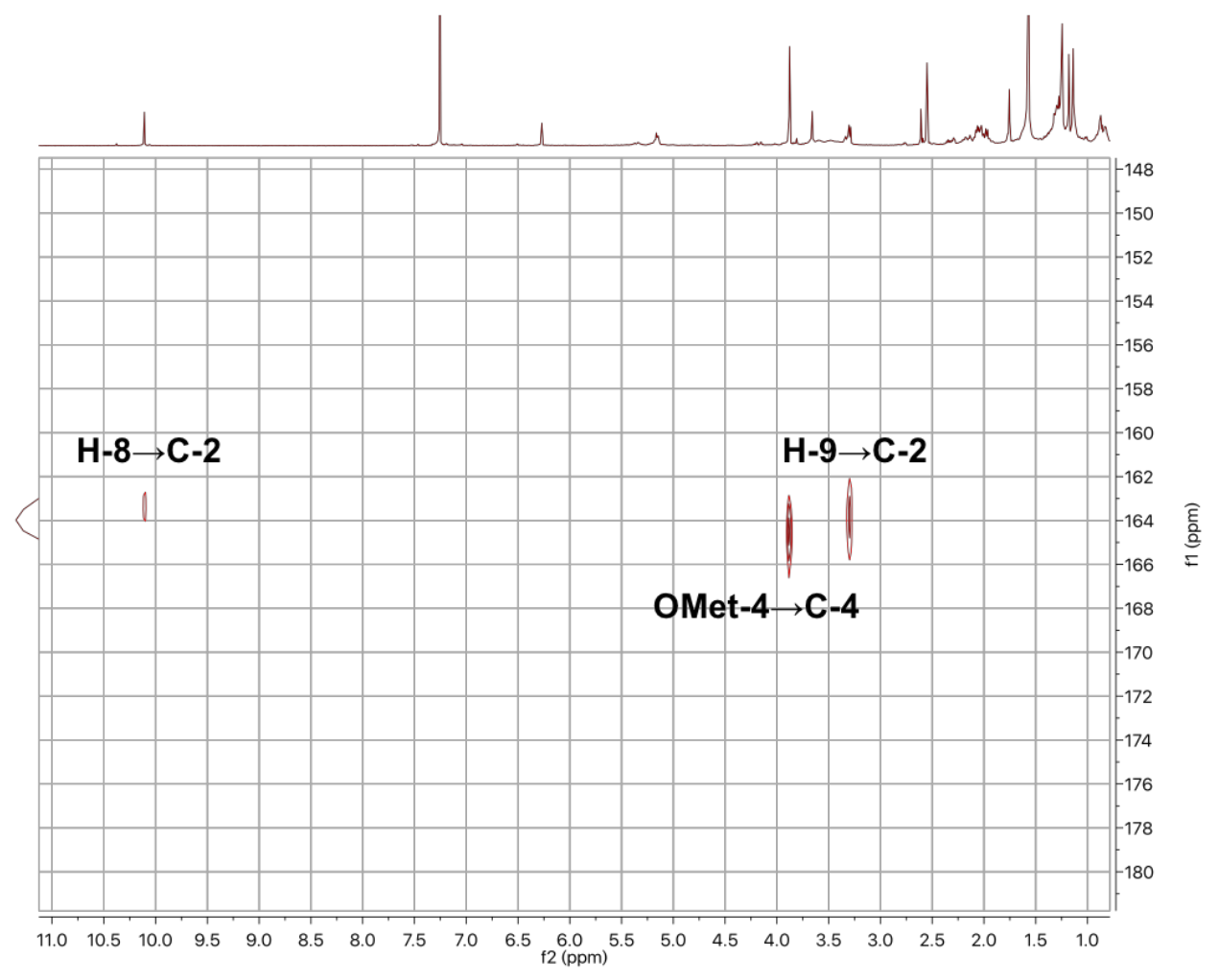

Figure S38. Key HMBC correlation of 4- $O$-methylated-4' 


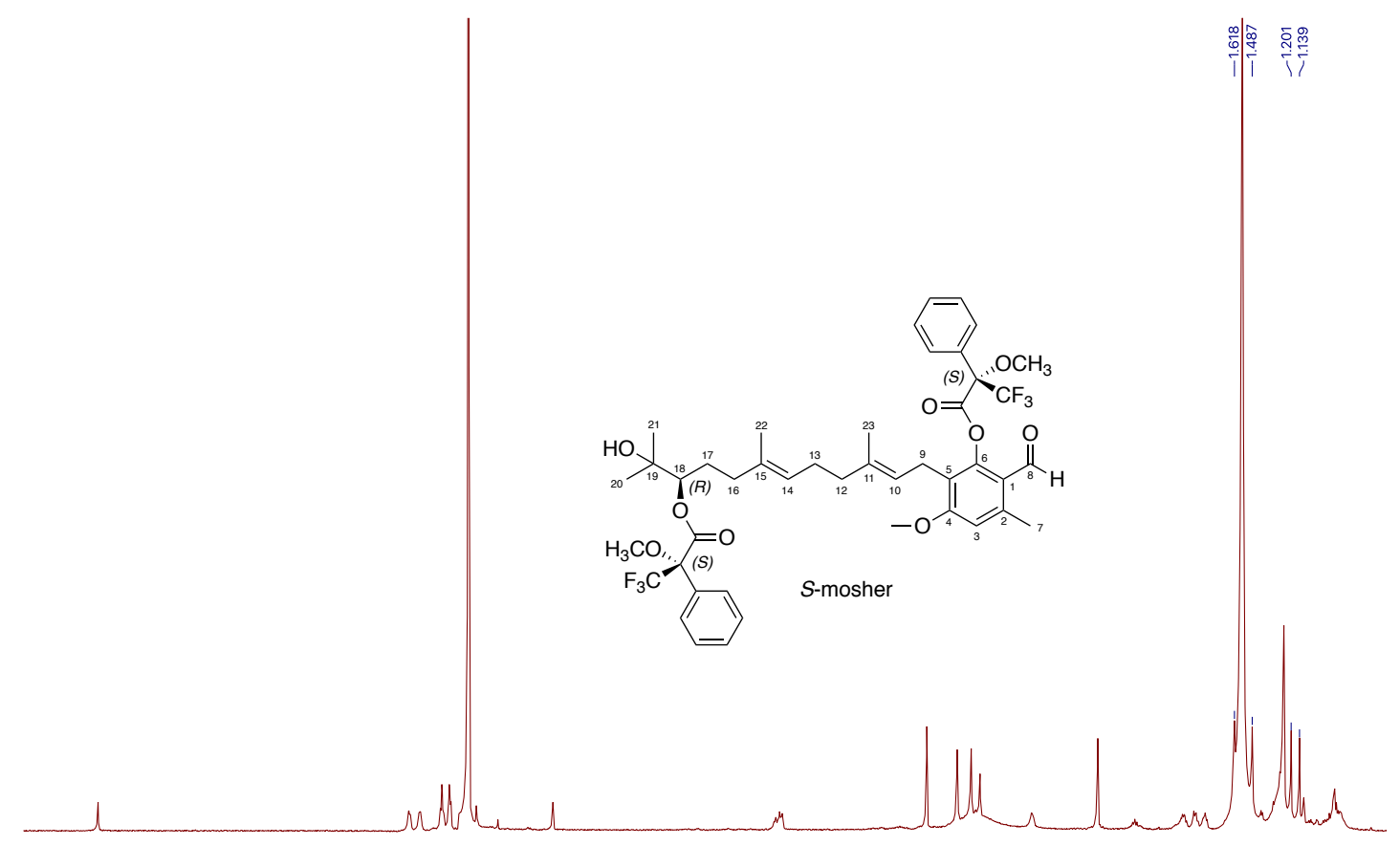

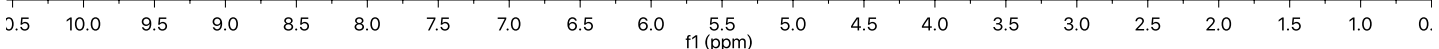

Figure S39. 'H NMR spectra of $S$-mosher diester of 4- $O$-methylated-4'

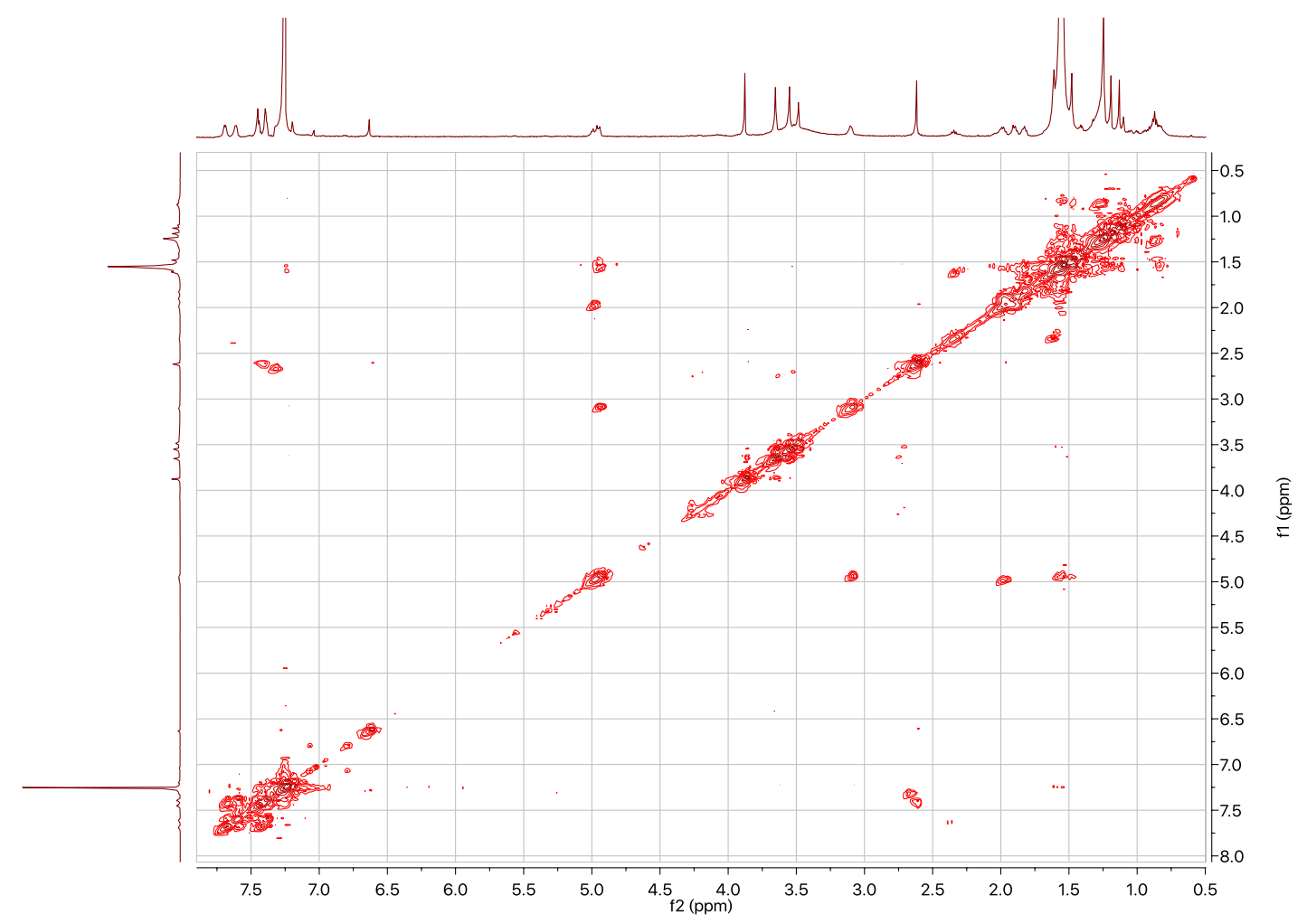

Figure S40. COSY spectrum of $S$-mosher diester of 4-O-methylated-4' 


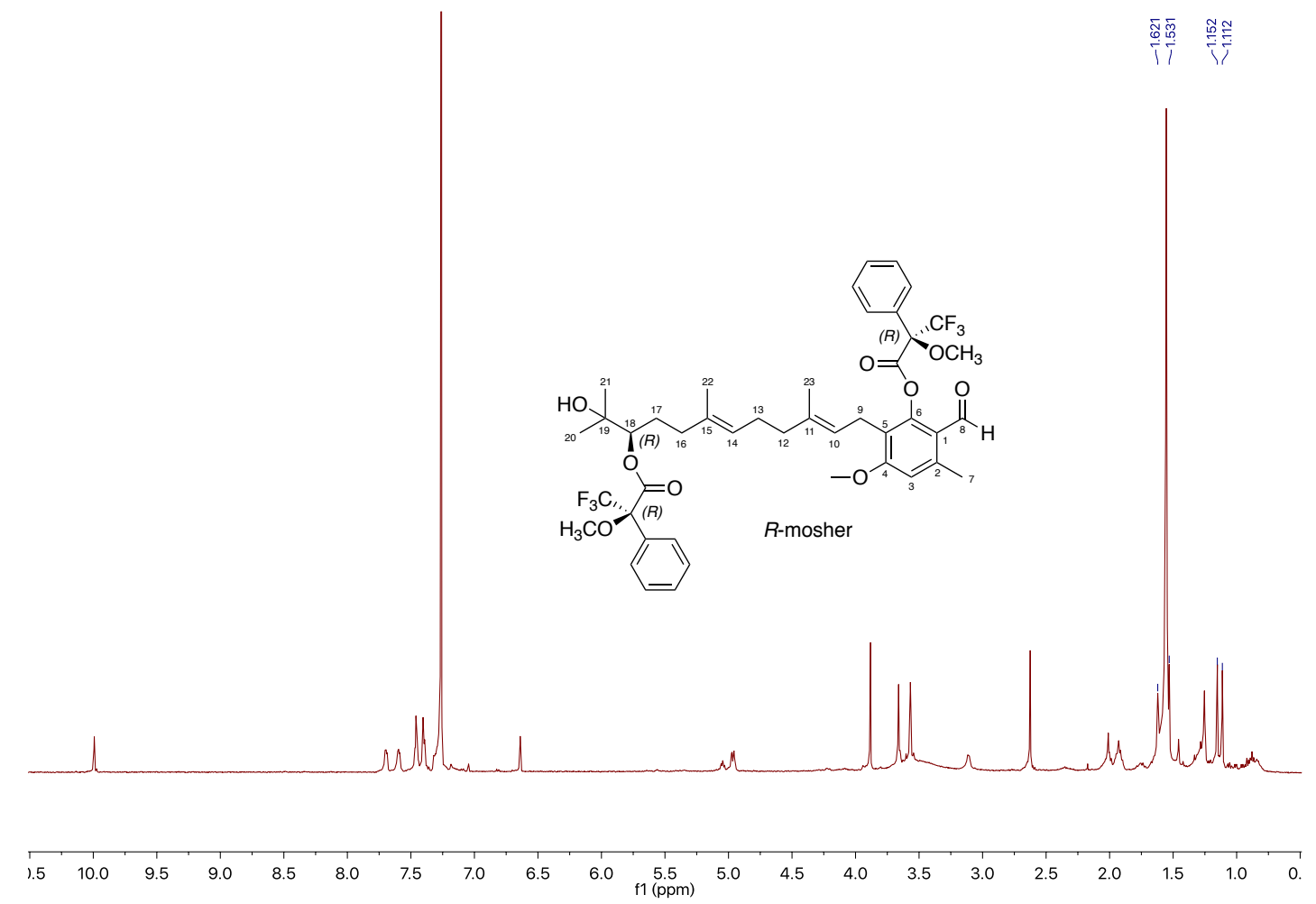

Figure S41. 'H NMR spectrum of $R$-mosher diester of 4- $O$-methylated-4'

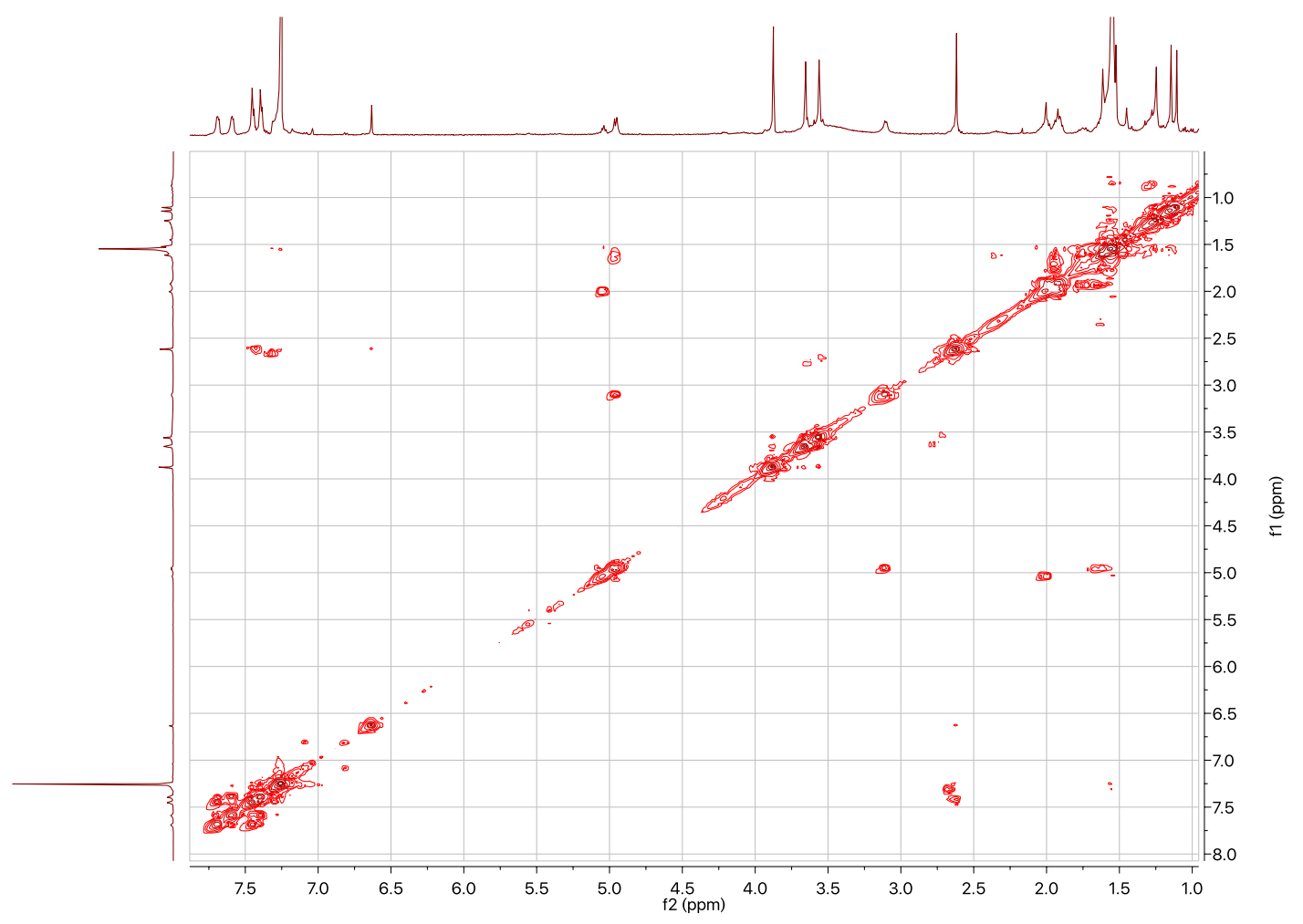

Figure S42. COSY spectrum of $R$-mosher diester of 4- $O$-methylated-4' 


\section{Supplementary References}

1. Chooi, Y.-H.; Cacho, R.; Tang, Y., Identification of the viridicatumtoxin and griseofulvin gene clusters from Penicillium aethiopicum. Chemistry \& biology 2010, 17, 483-494.

2. Jin, F. J.; Maruyama, J.-i.; Juvvadi, P. R.; Arioka, M.; Kitamoto, K., Development of a novel quadruple auxotrophic host transformation system by $\operatorname{argB}$ gene disruption using adeA gene and exploiting adenine auxotrophy in Aspergillus oryzae. FEMS microbiology letters 2004, 239, 79-85.

3. Kubodera, T.; Yamashita, N.; Nishimura, A., Transformation of Aspergillus sp. and Trichoderma reesei using the pyrithiamine resistance gene (ptrA) of Aspergillus oryzae. Bioscience, biotechnology, and biochemistry 2002, 66, 404-406. 4. Matsuda, Y.; Wakimoto, T.; Mori, T.; Awakawa, T.; Abe, I., Complete biosynthetic pathway of anditomin: nature's sophisticated synthetic route to a complex fungal meroterpenoid. Journal of the American Chemical Society 2014, 136, 15326-15336.

5. Gomi, K.; Iimura, Y.; Hara, S., Integrative transformation of Aspergillus oryzae with a plasmid containing the Aspergillus nidulans argB gene. Agricultural and biological chemistry 1987, 51, 2549-2555.

6. Arkoudis, E.; Stratakis, M., Synthesis of cordiaquinones B, C, J, and K on the basis of a bioinspired approach and the revision of the relative stereochemistry of cordiaquinone C. The Journal of organic chemistry 2008, 73, 4484-4490.

7.Zhang, X.; Archelas, A.; Furstoss, R., Microbial transformationsd. 19. Asymmetric dihydroxylation of the remote double bond of geraniol: a unique stereochemical control allowing easy access to both enantiomers of geraniol-6, 7-diol. The Journal of Organic Chemistry 1991, 56, 3814-3817.

8. Oulos, T. H. L. P. Structure of a Cytochrome P450 - Redox Partner Electron-Transfer Complex. Proc. Natl. Acad. Sci. U.S.A. 1999, 96, 1863-1868.

9. Joyce, M. G.; Ekanem, I. S.; Roitel, O.; Dunford, A. J.; Neeli, R.; Girvan, H. M.; Baker, G. J.; Curtis, R. A.; Munro, A. W.; Leys, D. The Crystal Structure of the FAD/NADPH-Binding Domain of Flavocytochrome P450 BM3. FEBS J. 2012, 279, 1694-1706. 